\author{
Sergio Date Fugita
}

\title{
Smart Meter Integrado a Analisador de Qualidade de Energia Para Propósitos de Identificação de Cargas Residenciais
}

Tese apresentada à Escola de Engenharia de São Carlos da Universidade de São Paulo, sendo parte dos requisitos para obtenção do título de Doutor em Ciências, Programa de Engenharia Elétrica.

Área de Concentração: Sistemas Elétricos de Potência Orientador: Prof. Dr. Ivan Nunes da Silva 
AUTORIZO A REPRODUÇAO TOTAL OU PARCIAL DESTE TRABALHO, POR QUALQUER MEIO CONVENCIONAL OU ELETRÔNICO, PARA FINS DE ESTUDO E PESQUISA, DESDE QUE CITADA A FONTE.

Fugita, Sergio Date

F958s Smart Meter integrado a analisador de qualidade de energia para propósitos de identificação de cargas residenciais/ Sergio Date Fugita; orientador Prof. Ivan Nunes da Silva. São Carlos, 2014.

Tese (Doutorado) - Programa de Pós-Graduação em Engenharia Elétrica e Área de Concentração em Sistemas Elétricos de Potência -- Escola de Engenharia de São Carlos da Universidade de São Paulo, 2014.

1. Smart grid. 2. Smart meter. 3. Identificação de cargas. 4. Distorções harmônicas. 5. Redes neurais artificiais. 6. Transformada discreta de Fourier. I. Título. 


\section{FOLHA DE IULGAMENTO}

Candidato: Engenheiro SERGIO DATE FUGITA.

Título da tese: "Smart Meter integrado a analisador de qualidade de energia para propósito de identificação de cargas residenciais".

Data da defesa: $20 / 11 / 2014$

\section{Comissão Julgadora:}

Prof. Associado Ivan Nunes da Silva (Orientador) (Escola de Engenharia de São Carlos/EESC)

Prof. Dr. Rogério Andrade Flauzino

(Escola de Engenharia de São Carlos/EESC)

Prof. Dr. Darizon Alves de Andrade

(Universidade Federal de Uberlândia/UFU)

\section{Prof. Dr. José Alfredo Covolan Ulson}

(Universidade Estadual Paulista "Júlio de Mesquita Filho"/UNESP-Bauru)

Prof. Dr. Jorge Luiz e Silva

(Instituto de Ciências Matemáticas e Computação/ICMC)

Coordenador do Programa de Pós-Graduação em Engenharia Elétrica:

Prof. Dr. Luís Fernando Costa Alberto

Presidente da Comissão de Pós-Graduação:

Prof. Associado Paulo César Lima Segantine

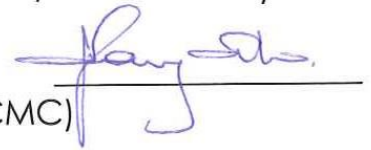

\section{Resultado:}
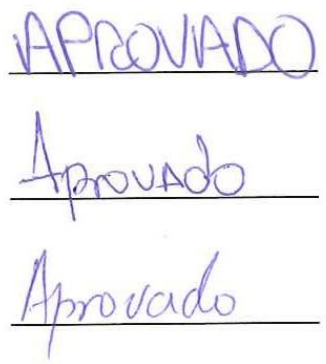
"Porque Dele e por meio Dele, e para Ele, são todas as coisas. Glória, pois a Ele eternamente.

Amém.”

Romanos 11, 36 


\section{Agradecimentos}

A princípio, agradeço a Deus por me dar forças para a realização deste trabalho.

Agradeço a toda minha família por ter me dado todo o apoio necessário para que eu alcançasse meus objetivos. Agradeço a minha prima, Profa. Roberta Date, pelas correções de todos os meus trabalhos.

Agradeço a minha mãe, que sempre me incentivou e me deu forças para continuar até o final do doutorado. Ao meu pai que contribuiu na minha formação. Ao meu irmão Marcelo Date que esteve presente em todas as etapas da minha vida. Aos meus avós, que contribuíram na minha formação desde a infância.

Aos amigos MSc. Daniel Rodrigo Falconi, MSc. Fabbio Borges, Rene Takao Meguro, MSc. Yuri Olivato e Alexandre Defelicibus.

Aos amigos João Ortiz, Beatriz Toledo, Ivan Duarte, Adriana Leonardi, Fabrício Herrera, Gustavo Sanches e Débora Leonardi.

Aos funcionários da EESC - USP.

Ao Prof. Dr. Rogério Andrade Flauzino pelas sugestões que foram dadas com o intuito de contribuir com o projeto de doutorado.

Ao Prof. Dr. Ivan Nunes da Silva, que me aceitou no curso de pósgraduação, pela contribuição na minha formação e pela atenção que foi dado durante todo o curso.

Aos amigos de laboratório (LAIPS): Prof. Dr. Danilo Hernane Spatti e Prof. Dr. Marcelo Suetake.

Aos professores da área de automação do Instituto de Ciências e Tecnologias de São Paulo - IFSP. 
Aos demais amigos que não foram mencionados, mas que também são importantes na minha vida, meu muito obrigado.

Agradecimentos também ao CNPq (Conselho Nacional de Desenvolvimento Científico e Tecnológico) pela concessão de bolsa de doutorado (Processo $\mathrm{n}^{\circ}$ 141481/2009-9). 


\section{SUMÁRIO}

Resumo

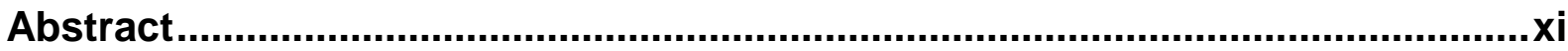

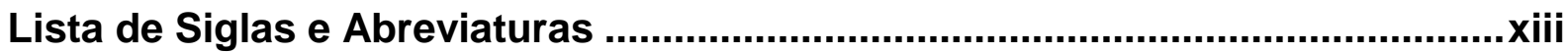

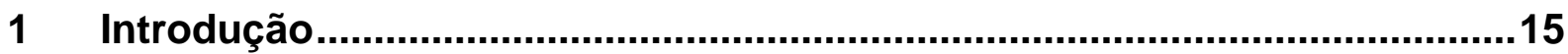

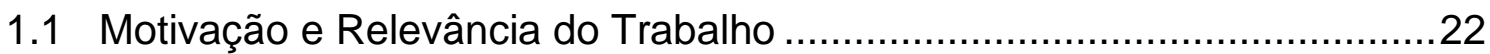

1.2 Justificativas e Objetivos da Tese .....................................................25

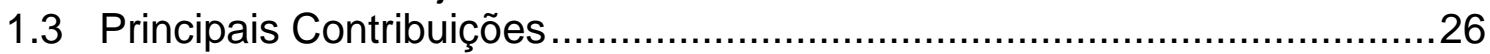

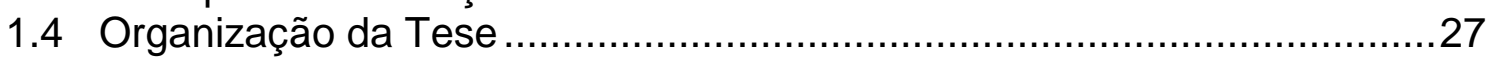

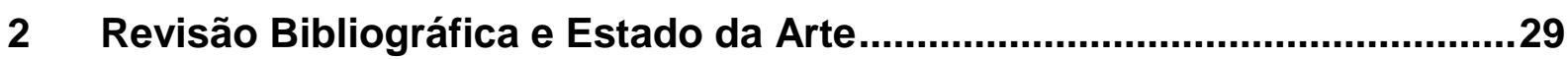

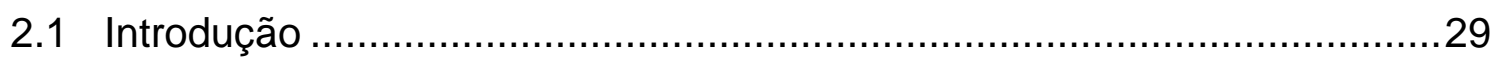

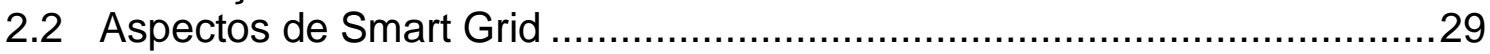

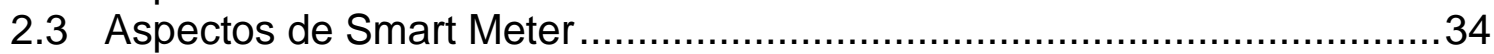

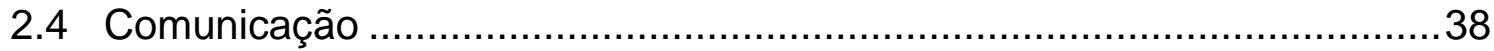

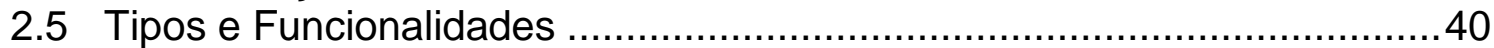

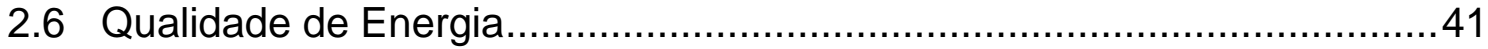

3 Arquitetura do Smart Meter Integrado ao Analisador de Qualidade de

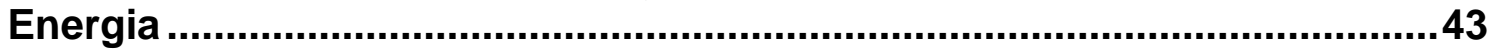

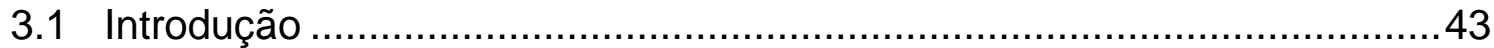

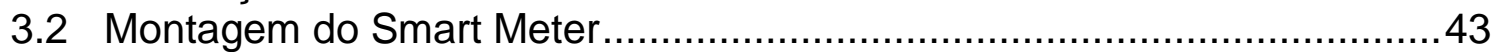

3.2.1 Sensores de Efeito Hall ............................................................. 43

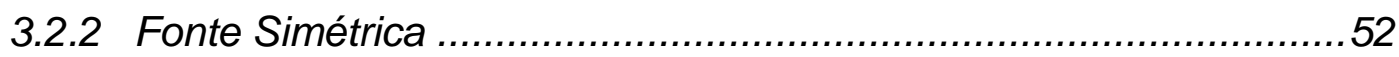

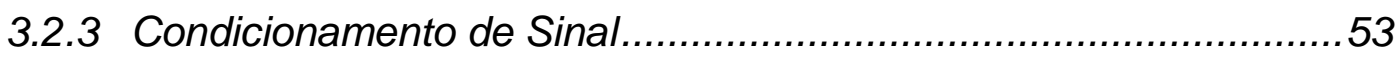

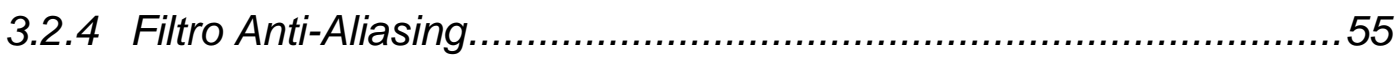

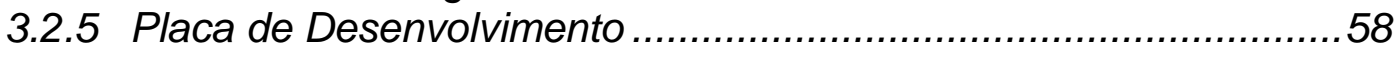

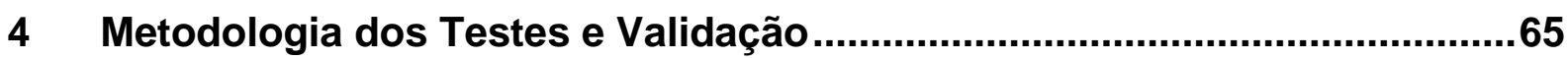

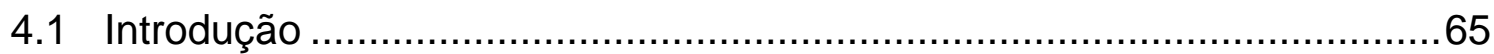

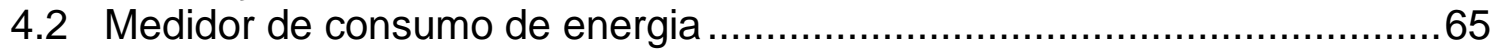

4.3 Detecção dos distúrbios de VTCD .....................................................67

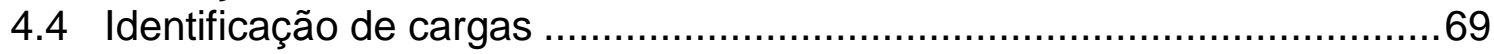

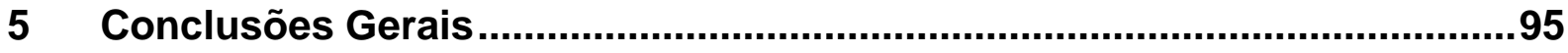

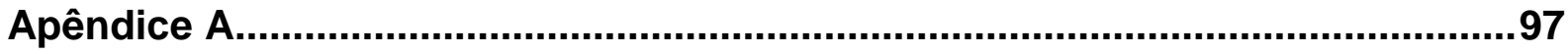

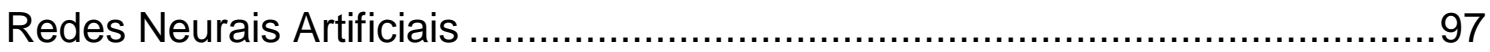

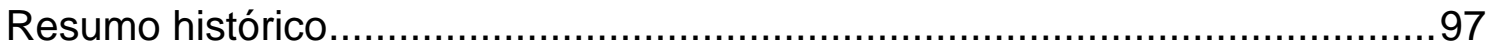

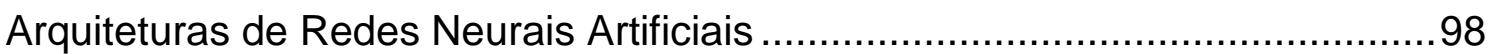

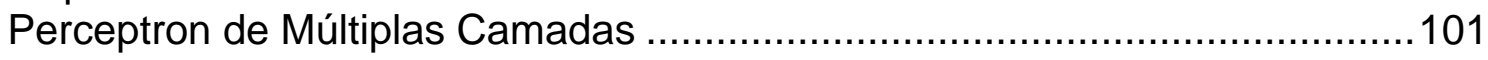

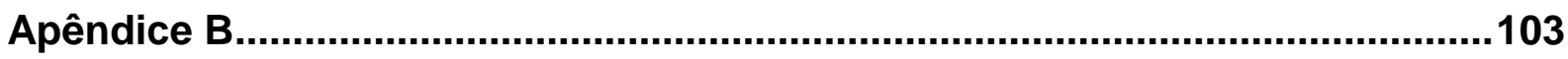

Código fonte da rede neural embarcada .................................................103

Anexo 1 
Fonte de Alimentação (Webench) 109

Referências Bibliográficas................................................................................. 121 


\section{Resumo}

FUGITA, S. D. Smart Meter Integrado a Analisador de Qualidade de Energia para Propósitos de Identificação de Cargas Residenciais. Tese de Doutorado - Escola de Engenharia de São Carlos, Universidade de São Paulo, São Carlos, 2014.

Este trabalho consiste em apresentar o desenvolvimento de um Smart Meter, integrado a um analisador de qualidade de energia, para análise de distorções harmônicas, utilizando método de redes neurais artificiais embarcado em hardware. Tal Smart Meter está incluído dentro dos conceitos de Smart Grid, que serão apresentados também neste trabalho. $O$ intuito do desenvolvimento do Smart Meter para análise de distorções harmônicas é auxiliar concessionárias de energia elétrica a identificar que tipo de carga o consumidor utiliza em sua residência, a fim de contribuir para a tomada de decisões apropriadas, tais como a diminuição da emissão de correntes harmônicas, demanda de energia, detecção de falhas no fornecimento de energia elétrica e faturas diferenciadas de acordo com a quantidade de harmônicas injetadas na rede elétrica. Adicionalmente, observou-se que o Smart Meter desenvolvido pode ser ainda utilizado para detectar fenômenos de VTCD, como elevação, afundamento e interrupção de energia. Todo o processo de desenvolvimento do Smart Meter é apresentado no decorrer desta tese de doutorado.

Palavras Chave: smart grid, smart meter, identificação de cargas, distorções harmônicas, redes neurais artificiais, transformada discreta de Fourier. 


\section{Abstract}

FUGITA, S. D. Smart Meter Integrated to Power Quality Analyzer for Identification Purposes of Residential Loads. Doctorate Thesis- São Carlos Engineering School, University of São Paulo, São Carlos, 2014.

This thesis consists to present the development of a Smart Meter integrated to power quality analyzer for the analysis of harmonic distortion, using methods based on artificial neural networks in embedded hardware. This Smart Meter is included within the concepts of Smart Grid, which will be also presented in this work. The intention of the development of the Smart Meter for analysis of harmonic distortion is to assist utilities companies to identify what loads type the consumer uses at your residence in order to contribute for supporting decisions, such as reducing the emission of the harmonic currents, power demand and fault's detection in electric energy supply and distinct bills according to the amount of harmonics injected into the power grid. In addition, it was observed that this developed Smart Meter can be even used to detect the VTCD phenomena, such as swell, sag and interruption of the energy supply. All development steps of this Smart Meter is presented in this doctoral thesis.

Keywords: smart grid, smart meter, load identification, harmonic distortion, artificial neural network, discrete Fourier transform. 


\section{Lista de Siglas e Abreviaturas}

$\begin{array}{ll}\text { A/D } & \text { Analog to Digital } \\ \text { AFE } & \text { Analog Front End } \\ \text { AMI } & \text { Advanced Meter Infrastructure } \\ \text { ANEEL } & \text { Agência Nacional de Energia Elétrica } \\ \text { CI } & \text { Circuit Integrated } \\ \text { CNE } & \text { Comisión Nacional de Energía } \\ \text { DFT } & \text { Discrete Fourier Transform } \\ \text { GSM } & \text { Global System for Mobile Communication } \\ \text { IHD } & \text { In-Home-Display } \\ \text { Kw } & \text { Kilowatt } \\ \text { LCD } & \text { Liquid Crystal Display } \\ \text { MLP } & \text { Multi-Layer Perceptron } \\ \text { PDA } & \text { Personal Digital Assistant } \\ \text { PLC } & \text { Power Line Communication } \\ \text { RNA } & \text { Redes Neurais Artificiais } \\ \text { SPI } & \text { Serial Peripheral Interface } \\ \text { TCP } & \text { Transmission Control Protocol }\end{array}$




\section{Introdução}

Devido a problemas com interrupções de energia, impactos ambientais, preocupação dos consumidores com a diminuição do valor das tarifas de energia, necessidade de melhor monitoramento da rede elétrica, furtos de energia, entre outros fatores, um novo conceito de sistema de distribuição e medição têm sido estudado e testado em vários países, com destaque para Itália, Estados Unidos, Japão e alguns outros países europeus (MME, 2010; YAN et al., 2013). Este novo conceito, chamado de Smart Grid, é o tema mais estudado nos últimos anos na área de engenharia elétrica, como poderá ser visto no decorrer desta tese.

A definição para Smart Grid é muito ampla e envolve várias áreas do sistema elétrico como é relatado por vários autores.

Para YAN et al. (2013) e XI et al. (2012), Smart Grid é um termo que se refere à rede de energia da próxima geração, em que a transmissão, distribuição e medição de energia elétrica são incorporados a avançados sistemas computacionais e sistemas de comunicações bidirecionais entre concessionárias e consumidores, a fim de se obter um melhor controle, monitoramento, eficiência, confiabilidade e segurança.

Dentro deste contexto de Smart Grid encontra-se a medição eletrônica, a telecomunicações, a automação, a tecnologia da informação e outras ferramentas de sensoriamento e capacidade computacional, a geração e o armazenamento distribuídos, além de estrutura de fornecimento de energia elétrica a veículos 
elétricos. Entretanto, um dos desafios da implantação do Smart Grid é fazer com que essas novas tecnologias operem de forma coordenada.

A implantação das tecnologias do Smart Grid implica em uma melhoria no sistema de fornecimento de energia elétrica e, assim, uma melhor eficiência energética. Um exemplo é a implantação da geração distribuída de energia. Trata-se de um gerador de energia próximo aos grandes centros de carga ou até mesmo próximo aos consumidores que utilizam fontes renováveis de energia. Estes geradores contribuem no fornecimento de energia elétrica, pois a ideia não seria substituir as grandes geradoras, mas sim contribuir na geração da energia (MME, 2010).

Outro exemplo de tecnologia que contribui para uma melhoria do sistema elétrico é a implantação dos sistemas de comunicação entre concessionárias de energia e consumidores, pois acredita-se que em uma comunicação direta com as concessionárias de energia, o consumidor compreenderá melhor seu consumo de energia. Em contrapartida, as concessionárias poderão monitorar a qualidade de energia e também a forma com que o consumidor utiliza a energia fornecida (MME, 2010).

Para Huang et al. (2013), o Smart Grid é um sistema de fornecimento de energia inteligente que utiliza uma plataforma de comunicação para a troca de informações para melhorar a eficiência, confiabilidade e sustentabilidade dos serviços de energia elétrica. Neste sistema, é necessário uma infraestrutura de comunicação de duas vias para trocar as informações em tempo real entre os serviços públicos e os consumidores.

Sendo assim, para que haja essa comunicação de consumidores e fornecedores de energia, foi desenvolvido um sistema de transmissão e leitura dos 
dados de energia com o nome de $A M I$ (Advanced Meter Insfrastructure) e AMR (Advanced Meter Reading), respectivamente.

Segundo Yan et al. (2013), o AMI é um fator chave para o Smart Grid, sendo que este consiste em uma arquitetura automatizada para comunicações bidirecionais entre um Smart Meter e uma empresa de serviços públicos.

Para Hart (2008), AMl é a implantação de uma solução de medição com comunicações bidirecionais entre as concessionárias de energia e os Smart Meters.

O $A M l$ inclui novas redes de comunicações e sistemas de banco de dados que irá modernizar a rede elétrica, além de proporcionar benefícios importantes para empresas de energia elétrica e para consumidores. O AMI envolve duas vias de comunicação entre os medidores inteligentes e os dispositivos de gerenciamento de energia. Isto permite que as empresas respondam mais rapidamente aos problemas potenciais, assim como comunicar os preços da eletricidade em tempo real (LIU et al., 2009).

O termo AMR (Advanced Meter Reading) consiste na tecnologia cujo objetivo é ajudar a recolher os dados do medidor de forma automática e, possivelmente, enviar comandos para o cliente consumidor (KHALIFA et al., 2011).

Segundo Khalifa et al. (2011), a implantação da AMR gera benefícios como:

- Amostragem de preços em tempo real, em que a cada hora é mostrado aos clientes o valor a ser pago, fazendo-se com que eles tenham maior controle dos seus gastos;

- Medição da qualidade de energia por meio de leituras mais detalhadas a fim de melhorar o seu fornecimento; 
- Gerenciar cargas com o intuito de economizar energia. O cliente pode enviar sinais de controle para fazer o desligamento de equipamentos eletrônicos presentes na residência;

- Ligar e desligar o fornecimento de energia dos consumidores à distância, no caso, por exemplo, de inadimplência dos mesmos;

- Fornecer notificações de interrupção para as concessionárias com o intuito de solucionar mais rapidamente tal problema;

- Integrar todos os tipos de medidores (água, gás e eletricidade) em uma única tecnologia de comunicação e um protocolo padrão.

Entretanto, devido a inclusão da troca de informações bidirecional entre as concessionárias e os medidores, o sistema passou a ser chamado de AMI.

Muitos outros autores, no entanto, acreditam que o ponto de partida para a implantação do Smart Grid seria a troca dos medidores eletromecânicos pelos Smart Meters ou medidores inteligentes, que possuem sistemas de comunicação e informática integrados, fazendo com que possam trocar várias informações sobre o comportamento do consumidor em relação à utilização da energia e o consumo da mesma.

Um Smart Meter pode ser definido como um dispositivo de medição, baseado em diferentes princípios de funcionamento, como elétrico, eletrônico e mecânico, porém, cada vez mais enriquecido com sistemas eletrônicos e recursos digitais que o tornam uma ferramenta interativa (ANGLANI et al., 2011).

Embora os autores acreditem na melhoria da rede elétrica com a implantação das tecnologias de Smart Grid, cada país possui os seus principais motivadores com diferentes avanços na implantação das mesmas. 
A modernização da rede elétrica nos EUA tem sido em grande parte restrita aos sistemas de transmissão e não tanto ao sistema de distribuição. Esta modernização pode ser atribuída a várias inovações, tais como a ampliação da área de medição e controles mais rápidos, a instalação de estabilizadores de sistemas de potência e transformadores de mudança de fase. (SIMOES et al. 2012).

A empresa Duke Energy construirá em Indiana, nos Estados Unidos, um sistema de distribuição de energia com tecnologia Smart Grid, que deverá estar pronto dentro de cinco a seis anos. De acordo com a empresa, o sistema permitirá que os consumidores controlem o consumo de energia diariamente. No estado da Califórnia, já existem cerca de 5,5 milhões de medidores inteligentes em uso (LEW, 2009).

Na União Europeia, a estratégia de rede inteligente é motivada por conceitos de inovação no domínio das reformas sociais e ambientais para uma economia interativa. Os primeiros projetos relacionados às redes inteligentes foram agrupados dentro de integração de fontes renováveis de energia, medição e geração distribuída no cluster Europeia rede elétrica (SIMOES et al. 2012).

Em agosto de 2010, na França, o governo publicou um decreto que torna obrigatória a instalação de Smart Meters. O decreto visa a instalação de Smart Meters em 95\% do território francês de janeiro de 2012 até o final de 2016 (JIXUAN et al., 2013).

O governo do Reino Unido tem como objetivo substituir cerca de 27 milhões de Smart Meters em residências até o final de 2020. Já para consumidores maiores, como indústrias, o objetivo é implantar 168 mil Smart Meters até o final de 2014. 
No Brasil, os três principais motivadores para implantação de Smart Grid são os seguintes: redução de perdas não técnicas, melhoria da continuidade e eficiência energética (LAMIM, 2013).

Diante da importância do reconhecimento do trabalho realizado em outros países, em setembro de 2008, a ANEEL realizou o Seminário Internacional Sobre Medição Eletrônica, trazendo experiências do órgão regulador espanhol (Comisión Nacional de Energía - CNE) e de empresas de distribuição da Itália (ENEL S.p.A.) e do Canadá/Ontário (Hydro One Networks).

No Brasil, existem poucos estudos e implementações das tecnologias de Smart Grid. Algumas concessionárias de energia estão realizando projetos em algumas cidades dando nome de cidades inteligentes para testar as tecnologias e os custos envolvidos.

O Ministério de Minas e Energia, por meio da Portaria MME nº 440/2010, criou um grupo de trabalho com o objetivo de analisar e identificar ações necessárias para subsidiar o estabelecimento de políticas públicas para a implantação de um Programa Brasileiro de Rede Elétrica Inteligente (MME, 2010).

Já a ANEEL expediu nos últimos anos diferentes regulamentos relacionados às redes inteligentes, como a utilização das instalações de distribuição de energia elétrica como meio de transporte para a comunicação digital ou analógica de sinais (Power Line Communications - PLC) (REN no 375/2009), as condições para o acesso de microgeração e minigeração distribuída aos sistemas de distribuição, com a criação do sistema de compensação de energia elétrica (REN no 482/2012), e os sistemas de medição eletrônica (REN no 502/2012).

Para o caso de medição inteligente, a ANEEL deixou para as distribuidoras a função de planejar e instalar os sistemas, de forma que sejam priorizadas as decisões 
das empresas. O regulador delegou às distribuidoras a decisão de seleção dos planos mais adequados, por terem conhecimento profundo de sua área de atuação.

A CEMIG iniciou a implantação de Smart Meters na cidade de Sete Lagoas e realiza a troca dos medidores eletromecânicos para os eletrônicos, conscientizando o consumidor sobre os benefícios da troca (CEMIG, 2013).

Já a Eletropaulo anunciou que mais de $R \$ 70$ milhões serão investidos para o novo modelo de distribuição de energia na cidade de Barueri. O projeto inicia com a regularização e instalação de medidores inteligentes para 2.100 famílias (ELETROPAULO, 2014).

Em suma, os estudos e investimentos para a implantação de Smart Meters são inúmeros, pois, a mudança para um melhor sistema de distribuição e medição de energia é necessário, devido a fatores como elevação excessiva do consumo de energia, interrupções de energia, furtos de energia e controle da qualidade de energia fornecida.

Os conceitos de Smart Grid e Smart Meters serão mais bem detalhados no decorrer desta tese, em que serão apresentados os fatores que motivaram esta pesquisa (Seção 1.1), as justificativas para as motivações comentadas e os objetivos a serem alcançados ao final da pesquisa (Seção 1.2), as principais contribuições advindas desta pesquisa (Seção 1.3) e, por fim, a organização do texto (Seção 1.4). 


\subsection{Motivação e Relevância do Trabalho}

Após esta breve introdução, verifica-se que o Smart Meter é um equipamento de grande importância no conceito de Smart Grid, pois, por meio destes medidores, as concessionárias de energia podem obter uma comunicação com os consumidores finais e, dessa forma, obter informações sobre a utilização da energia fornecida.

Tais informações podem estar relacionadas ao consumo de energia (como o valor em kW e também o valor a ser pago até o momento da solicitação dessas informações), ao fator de potência, ao fator de crista, entre outros.

Segundo Gungor et al. (2012), uma das características do Smart Grid é ser um sistema de coleta e monitoramento de informações utilizando Smart Meters, mas as informações que são recolhidas e aproveitadas para criar uma rede elétrica mais eficiente podem ser utilizadas para outros fins, como análises do comportamento da rede elétrica, identificação de furtos de energia, controle de demanda de carga e faturas de energia em tempo real.

Os Smart Meters possuem uma conexão direta com a concessionária de energia por vários meios de comunicação; por exemplo, por meio do sistema PLC (Power Line Communication), que utiliza as linhas de energia existentes para a transmissão de dados via GSM (Global System for Mobile Communication), Zigbee, entre outros (YAN et al., 2013).

Por meio dos Smart Meters, é então possível obter alguns benefícios como medição mais precisa de energia e uma cobrança mais rápida, suspender contratos ou realizar medições sem a necessidade de deslocamento de pessoal e evitar fraudes (YAN et al., 2013). Os benefícios podem, ainda, ser estendidos para os consumidores finais, pois, a troca de informações do consumo de energia é de 
grande importância para a sua economia, devido ao consumidor entender melhor o que é cobrado em sua fatura.

Os Smart Meters existentes no mercado são utilizados por alguns autores para coletar os dados da rede elétrica e posteriormente analisá-los.

Em Weiss et al. (2012), os autores aproveitam os dados retirados de um Smart Meter, do fabricante Landys + Gyr (modelo E750), para fazer análises de reconhecimento de carga. $\mathrm{O}$ autor propõe um algoritmo baseado em cálculos de potência ativa e aparente, em que se consegue detectar se a carga foi ligada ou desligada. Esses cálculos são feitos em um computador e enviados para um smartphone.

Já em Tomosada e Shinohara (2011), os autores desenvolveram um método de geração de dados virtuais de demanda de energia, sendo estes dados relatados no estudo como sendo próximos aos reais, coletados por Smart Meters.

Ning et al. (2012) utilizam os dados do consumo de energia mensal e diário para realizar estudos de furto de energia, da maneira como os consumidores utilizam a energia, dos diagnósticos de falha e dos comportamentos anormais de cargas residenciais. O autor compara os dados dos medidores de várias residências e realiza cálculos estatísticos para avaliar a forma de utilização da energia de cada consumidor.

Em De Capua e Romeo (2007), os autores apresentam um medidor capaz de calcular a distorção harmônica total do sinal por meio da Transformada Rápida de Fourier (responsável por determinar o espectro de harmônicas presentes no sinal). Neste mesmo trabalho os autores utilizam sensores de efeito Hall (modelo LV-25400 do fabricante LEM) para captura de sinais de tensão. Estes transdutores foram escolhidos por apresentarem uma ótima linearidade com relação à entrada e saída 
de tensão e frequência. Assim como relatado, os estudos são feitos com dados retirados de Smart Meters e, posteriormente, analisados em algoritmos e sistemas computacionais.

Cabe comentar que as características e funcionalidades dos Smart Meters existentes, assim como aquele proposto por esta tese, serão tratados com mais detalhes no decorrer do texto.

De acordo com o texto supracitado, pode-se observar que há uma preocupação com a forma de se utilizar a energia elétrica, para que as concessionárias possam melhorar o seu fornecimento.

Outra maneira de analisar o sistema de fornecimento de energia é a utilização de equipamentos chamados de analisadores de qualidade de energia. Este aparelho tem como função detectar distorções harmônicas, fenômenos de VTCD e VTLD, registrar o horário da ocorrência dos fenômenos e armazenar os dados em uma memória. Entretanto, este equipamento tem um custo de aquisição muito alto. Assim, alguns autores propõem a construção de analisadores de qualidade de energia com custo mais baixo, porém, com uma quantidade menor de funções de análise.

Em Lira et al. (2005), o autor propõe a construção de um analisador espectral utilizando um microcontrolador. O analisador proposto faz o uso da Transformada Discreta de Fourier e tem capacidade de calcular até a $16^{\text {a }}$ componente harmônica, sendo sua frequência de amostragem igual a $1920 \mathrm{~Hz}$, o que equivale a uma taxa de amostragem igual a 32 pontos por ciclo. $O$ resultado calculado é mostrado em um display LCD. Neste caso, o autor propõe apenas um meio de se obter as componentes harmônicas para, posteriormente, realizar algumas análises. 
Sendo assim, este trabalho propõe o projeto e construção de um Smart Meter de baixo custo, composto de todas as características dos medidores construídos até hoje, além de integrar ao Smart Meter um analisador de qualidade de energia para o propósito de identificação de cargas. O Smart Meter proposto permite que os dados sejam processados e analisados no próprio medidor, a fim de diminuir a quantidade de equipamentos que são utilizados para este propósito.

\subsection{Justificativas e Objetivos da Tese}

As justificativas desta tese se dão devido ao fato de o Smart Grid ser a solução atual para o controle do aumento excessivo do consumo de energia, diminuição de impactos ambientais causados pela construção de usinas geradoras de energia, perdas não técnicas de energia, entre outros problemas relacionados ao fornecimento de energia.

Entretanto, como dito anteriormente, muitos dos estudos apontam o Smart Meter como sendo um dos pontos mais importantes para a implantação do Smart Grid e, também, sendo muito utilizado para realizar algumas análises da rede elétrica.

Um dos problemas encontrados e também estudados nesta tese são as distorções harmônicas. Essas distorções são geradas por cargas não lineares, sendo que suas grandes emissões acarretam a degradação da qualidade de energia elétrica. Um dos problemas relacionados à má qualidade de energia é o mau funcionamento dos equipamentos do próprio consumidor. Sendo assim, faz-se necessária a análise destas correntes harmônicas, a fim de preservar a qualidade de energia fornecida. 
Outros problemas encontrados na rede elétrica são os fenômenos de VTCD, sendo eles: afundamento, interrupção e elevação de energia. Dessa forma, a detecção desses fenômenos são também de grande importância para que as fornecedoras de energia atuem de forma a controlar e corrigir tais fenômenos.

Depois de realizados os estudos, notou-se a possibilidade de integração dos dois equipamentos, pois, segundo os trabalhos realizados por outros autores, as análises de comportamento da rede elétrica são feitas por computadores ou equipamentos analisadores de qualidade de energia, com dados coletados dos medidores. Sendo assim, há uma necessidade de se fazer uso de muitos equipamentos para a realização destas análises. Além disso, os equipamentos utilizados para realizar análises de comportamento da rede elétrica possuem custos elevados para a compra e manutenção.

Com o equipamento proposto nesta tese pode-se utilizar apenas um único dispositivo para realizar as análises. No caso do equipamento proposto, o grande foco é a identificação por meio de redes neurais artificiais de cargas conectadas na residência dos consumidores. Além disso, podem ser feitas também análises de VTCD, ou seja, afundamento, elevação e interrupção de energia. Vale lembrar também que a proposta da pesquisa é a construção do equipamento com baixo custo. Assim sendo, as etapas de construção e testes são relatadas no decorrer da tese.

\subsection{Principais Contribuições}

De acordo com as informações supracitadas, as principais contribuições desta tese são os seguintes: 
- Confecção de um hardware contendo todas as características comuns de um Smart Meter;

- Aquisição de sinais de tensão e corrente, por parte do Smart Meter desenvolvido, para análises de VTCD;

- Implantação a este Smart Meter de um sistema de processamento de sinais para aquisição de componentes harmônicas mediante cálculos de DFT (Discrete Fourier Transform), incorporado diretamente ao hardware;

- Implementação de uma rede neural embarcada em hardware para análise de distorções harmônicas.

\subsection{Organização da Tese}

Este trabalho é organizado em cinco capítulos principais, seguindo a sequência descrita a seguir.

O Capítulo 1 trata da motivação e relevância do presente trabalho, bem como sua proposta e justificativa.

O Capítulo 2 destina-se ao estado da arte, em que são tratados os aspectos relacionados aos Smart Grid, em especial o desenvolvimento e os aspectos dos Smart Meters, mostrando todos os tipos de infraestrutura de medição, tipos de comunicação e funcionalidades dos Smart Meters.

Todos os aspectos relacionados à arquitetura do Smart Meter desenvolvido para o propósito de identificação de cargas, bem como o software para recepção e análise dos dados coletados, são descritos no Capítulo 3.

O Capitulo 4 trata de toda a metodologia de testes e validação do Smart Meter proposto. 
Finalmente, as conclusões e temas de continuidade do trabalho são fornecidas no Capítulo 5. 


\section{Revisão Bibliográfica e Estado da Arte}

\subsection{Introdução}

Conforme apresentado anteriormente, este trabalho tem o objetivo de desenvolver um Smart Meter que tem sido considerado um dos pontos mais importantes para a implantação do Smart Grid.

Sendo assim, no Tópico 2.2, serão apresentados os conceitos de Smart Grid, bem como suas características e benefícios gerados por este novo conceito de fornecimento de energia elétrica. Já no Tópico 2.3, são apresentados os aspectos de Smart Meter, e suas características e contribuição para o Smart Grid. O Tópico 2.4 mostra os tipos de comunicação existentes dentro dos conceitos de Smart Grid, mostrando alguns trabalhos realizados e, por fim, no Tópico 2.5 apresentam-se os tipos de funcionalidades dos Smart Meters.

\subsection{Aspectos de Smart Grid}

Desde o surgimento do Smart Grid, vários estudos e projetos têm sido realizados em vários países, em maior concentração nos países europeus.

O termo Smart Grid é bastante amplo, envolvendo vários tipos de tecnologias, como Power Line Communication (PLC), Smart Meter, processamento de informação, geração distribuída, entre outros. Basicamente, Smart Grid trata-se de uma rede elétrica inteligente que combina estas tecnologias a fim de proporcionar 
uma rede elétrica mais segura e confiável, atendendo às exigências econômicas e à demanda de energia do futuro (LI e ZHOU, 2011).

Para Fan et al. (2013) e Khattak et al.(2012), um Smart Grid é uma rede inteligente de energia elétrica que integra as ações de todos os usuários conectados a ela por meio de tecnologias avançadas de comunicação e faz uso das informações para economizar energia, reduzir custos e aumentar a confiabilidade e transparência. $O$ desenvolvimento desta nova rede exigirá esforços significativos no desenvolvimento de tecnologia, normas, políticas e atividades regulatórias, devido à sua complexidade inerente.

Segundo o Departamento de Energia dos Estados Unidos (DOE), um Smart Grid se caracteriza como sendo uma rede que utiliza tecnologia digital para melhorar a segurança, confiabilidade e eficiência do sistema elétrico, tendo como principais características as seguintes:

- Transmissão mais eficiente de energia elétrica;

- Restabelecimento mais rápido de energia após distúrbios na alimentação;

- Custo de energia mais baixo para os consumidores;

- Maior integração das fontes de energia renovável;

- Maior segurança.

Segundo Potter, Archanmbault e Westrick (2009), um dos pontos mais importante do Smart Grid é tornar a rede elétrica autônoma, ou seja, caso aconteça uma interrupção, os sensores instalados no sistema elétrico identificarão as áreas, aumentando a rapidez de operações e podendo até mesmo reconfigurar o sistema com o intuito de mitigar tal fenômeno.

O Smart Grid visa também à integração de fontes de energia renováveis utilizadas nas residências e na rede elétrica, o que possibilita ao consumidor, além 
de produzir energia para si, devolver a sobra de energia para a rede. Com isso, o consumidor poderá obter uma economia na fatura de energia, já que estará contribuindo no seu fornecimento.

Essa integração de fontes de energia ou descentralização da produção de energia contribui para que se diminua a necessidade de construção de novas usinas geradoras de energia, necessárias para suprir o aumento da demanda de consumo de energia elétrica (GROB, 2009).

A geração distribuída normalmente refere-se à pequena unidade modular, distribuída e confiável, de alto desempenho e de poucas centenas de megawatts, estando localizada nas proximidades dos usuários. A mesma se configura como qualquer tipo de fontes de energia descentralizadas (incluindo fontes de energia renováveis), sendo que sua finalidade é aumentar a eficiência da utilização de fontes convencionais de energia.

As tecnologias de Smart Grid estão presentes desde a transmissão de energia até o consumidor final. Em Morgan et al. (2009), estes estão divididos e melhor explicados em níveis como:

- Nível de cliente: são encontrados os medidores inteligentes, que por meio deles podem ser feitas medições de consumo a distância por intermédio de sistemas de comunicação como ethernet, Zigbee, wi-fi, entre outros. Além disso, podem-se obter outras informações sobre a forma de utilização da energia fornecida por meio desses medidores.

- Nível de distribuição: são implantados sistemas de automação, no qual há uma mudança no sistema de distribuição. Na maioria dos sistemas de distribuição toda a potência proveniente de um alimentador entra em um ponto (raiz) e flui para fora para as cargas ao longo dos ramos do alimentador 
de distribuição para os clientes. Se houver um problema, disjuntores podem desligar automaticamente o alimentador inteiro, porém, se forem feitas mudanças como criar outros alimentadores, o trecho afetado seria redirecionado a outro alimentador.

Outra tecnologia presente neste nível é a implantação de gerações distribuídas, em que são utilizadas geralmente fontes de energia alternativa. Esses pequenos geradores de energia são conectados à rede elétrica e podem fornecer energia por um determinado tempo caso haja uma falha no seu fornecimento.

- Nível de transmissão: são encontradas melhorias com relação a medições e adição de dispositivos eletrônicos, de modo a obter dados mais precisos para melhor estabilidade do funcionamento do sistema.

Para Wei, Yu-hui e Jie-lin (2009), o termo "Smart Grid" representa uma visão para uma atualização digital da distribuição e redes de transmissão de longa distância, usando comunicações bidirecionais, sensores avançados e computadores, para melhorar a eficiência, confiabilidade e segurança do fornecimento e utilização da energia. O conceito básico de Smart Grid é adicionar monitoramento, análise, controle e capacidade de comunicação ao sistema de fornecimento elétrico, a fim de maximizar o rendimento do sistema.

O Smart Grid se baseia em muitas das tecnologias já utilizadas por companhias de eletricidade, mas adiciona capacidades de comunicação e controle que vão otimizar o funcionamento de toda a rede elétrica.

Porém, essa tese se concentrará nos níveis de cliente e distribuição, mais precisamente com relação à medição do consumo de energia. 
Para Kapetanovic e Botting (2008), este novo sistema de distribuição e medição de energia elétrica leva o nome de Smart Grid que, segundo a comissão europeia (European Smart Grids Technology Platform), responsável por formular e promover esta estratégia para o desenvolvimento das redes elétricas daquele continente, é definido como uma rede de distribuição de energia elétrica que consegue, de forma inteligente, integrar as ações de todos os consumidores conectados ao sistema e, assim, disponibilizar bens e serviços de eletricidade.

Todo o sistema elétrico apresentado contendo Smart Grid está ligado pela $A M I$, que facilita a comunicação bidirecional para enviar dados de consumo de energia para os clientes, a implementação do controle de potência ativa, e o envio de respostas a partir dos clientes (CHO, YAMAZAKI e HAHN, 2009).

Em uma consulta pública realizada em 03 de setembro de 2009, a ANEEL propôs uma nova forma de tarifação de energia. Assim como é feito nos serviços de telefonia, faixas de valores diferenciados serão criadas para fomentar o consumo de eletricidade fora dos horários de picos. Com essas faixas, as empresas de energia podem cobrar mais pela eletricidade usada no horário comercial e menos durante a madrugada, por exemplo. Assim, busca-se a criação do hábito do consumo consciente no consumidor, contribuindo-se para evitar panes ou blecautes. Entretanto, para esse sistema funcionar, os medidores digitais precisam estar em operação para que seja possível fazer a diferenciação de valores e horários.

Outra forma de cobrança para o fornecimento de energia é o emprego de tecnologia pré-paga, que foi a solução encontrada pelo Grupo Rede para garantir a adimplência dos consumidores. O pré-pago seria uma maneira mais flexível de comprar energia, adequando o consumo à renda dos respectivos clientes, além de impedir os furtos de energia. 
Em contrapartida, embora o Smart Grid seja uma tecnologia em grande ascensão, este apresenta ainda custo um tanto elevado para sua instalação, devido a toda adaptação no setor elétrico. Porém, a longo prazo, este tipo de investimento resultará em economias e benefícios tanto para as concessionárias quanto aos consumidores finais. Isto se deve ao fato de que, com esta tecnologia, pode-se utilizar a energia elétrica de forma mais racional, ou seja, pode-se fornecer energia elétrica de acordo com o que cada cliente necessitar.

\subsection{Aspectos de Smart Meter}

Como mencionado anteriormente, um dos instrumentos inovadores do Smart Grid é o medidor inteligente. Muito mais do que uma medição mais precisa, a medição eletrônica é a porta de entrada para a criação de um canal de comunicação em tempo real com o consumidor. A partir da tecnologia, as redes inteligentes poderão ser criadas e permitirão uma elevada interatividade entre o operador da rede e as cargas de cada unidade consumidora.

Especificamente no ramo de medição de energia elétrica, as novas tecnologias têm ganhado amplo espaço, pois, os sistemas de medição eletrônica já são empregados no mercado atacadista, nas fronteiras e nos pontos de intercâmbio de energia. Tal tecnologia está presente também em sistemas de medição de subestações e de unidades consumidoras, com instalações conectadas aos sistemas de média e alta tensão. Sendo comum na medição de grandes blocos de energia, a inserção da tecnologia para pequenos consumidores certamente causará grandes mudanças nas relações de consumo. 
Um Smart Meter pode ser usado para identificar e medir o consumo de energia elétrica e pode também se comunicar com outro dispositivo (Owen e Ward, 2006).

Para Depuru et al. (2011), Smart Meter é um medidor de energia avançado que mede o consumo de energia de um consumidor e fornece informações adicionais à companhia de energia elétrica, e pode fornecer em tempo real, além do consumo, ângulo de fase, valores de tensão, frequência, entre outros. Além disso, o medidor inteligente pode ser usado para monitorar e controlar todos os eletrodomésticos e dispositivos nas instalações elétricas de um consumidor.

Um medidor inteligente, além de medir o consumo de energia, pode também ser usado como uma espécie de roteador de Internet, por meio do qual a concessionária pode controlar remotamente o uso da energia e, também, do mesmo modo, acessar as informações, sem a necessidade de ir ao local. Os consumidores serão capazes de saber exatamente o valor de suas tarifas de energia a qualquer momento e podem ajustar os seus hábitos de consumo. Os medidores inteligentes são equipados com um display para o envio de dados sobre a quantidade de energia consumida, ou do seu custo correspondente, para os clientes. A Figura 2.1 exemplifica um medidor eletrônico. 


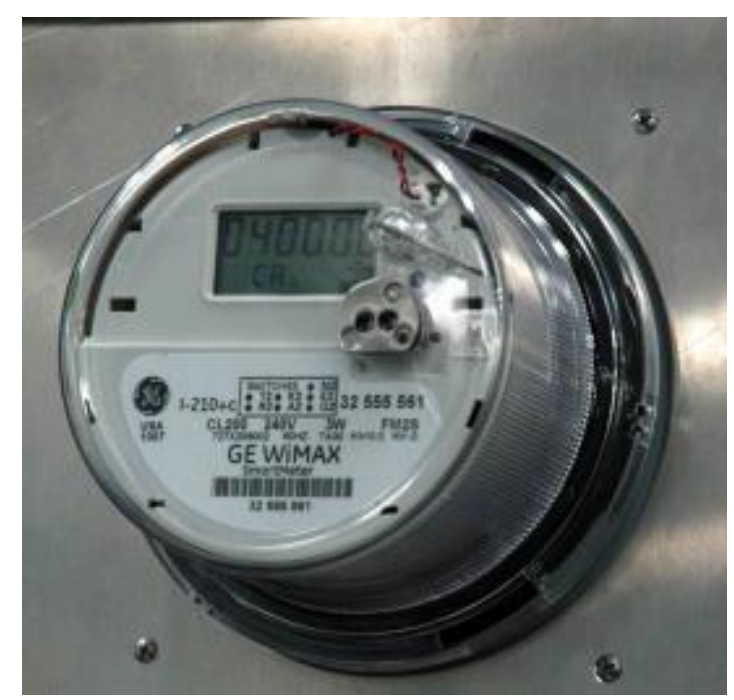

Fonte: (GE)

Figura 2.1 - Exemplo de medidor eletrônico (Smart Meter).

Os medidores eletrônicos de medição de energia elétrica oferecem um conjunto de funcionalidades e vantagens que tornam atrativa a implantação da tecnologia. Entre essas novas funcionalidades e vantagens, destacam-se, além da mensuração da energia ativa consumida, o faturamento de energia reativa; o monitoramento de aspectos como: qualidade da energia elétrica (controle de interrupções e de nível de tensão); novas modalidades de tarifação (tarifas diferenciadas ao longo do dia, venda de energia na modalidade de pré-pagamento, etc.); telemetria; atuação remota e informações mais claras e abundantes aos consumidores e também às distribuidoras, o que facilita as atividades de operação e manutenção das redes.

Deve-se destacar também que o aproveitamento de determinadas funcionalidades e a maior disponibilidade de informações fornecidas pelos medidores eletrônicos permitem aumentar o nível de conhecimento sobre o consumo e sobre os valores das tarifas aplicadas, o que pode promover alteração dos comportamentos dos consumidores e gerar eficiência energética e redução do risco 
de crises de energia. Para os consumidores, essa alteração no comportamento pode gerar faturas menores, o que implica na redução das despesas.

Assim sendo, os benefícios desta tecnologia são inúmeros, porém, qualquer troca em grande escala acarreta em elevados custos operacionais, isto é, o investimento inicial para realizar a substituição, o esforço de se reeducar os consumidores e os riscos de insucessos não são desprezíveis.

Para a ANEEL, a implantação de sistemas com medidores eletrônicos em baixa tensão representa a possibilidade de aprimoramento do processo de fiscalização, já que tais sistemas facilitam a auditagem dos dados, principalmente na apuração dos indicadores de qualidade e informações sobre faturamento.

Adicionalmente, os instrumentos eletrônicos de medição também se apresentam como meios eficientes ao combate a alguns dos principais problemas do setor elétrico do país, isto é, fraude, furto e inadimplência.

A simples mudança de tecnologia do medidor eletromecânico para o eletrônico já traz algumas vantagens contra perdas não técnicas (ou perdas comerciais). Em todo o mundo, empresas de energia perdem cerca de 20 bilhões de dólares devido a essas perdas não técnicas (DEPURU et al., 2011).

A tecnologia de medição eletromecânica já possui mais de uma centena de anos e, portanto, é muito difundida, o que facilita a efetivação de intervenções e fraudes. Comparando-se com o medidor eletromecânico, os eletrônicos permitem maior facilidade na detecção de fraudes, seja por meio de alarmes ou por intermédio de indicadores.

Ainda com relação à inadimplência, a modalidade de pré-pagamento é uma opção que pode gerar benefícios para distribuidoras e consumidores. Esses últimos podem preferir esta modalidade de pagamento por diversos motivos, por exemplo, 
se eles possuem experiências com dificuldades de pagamento de faturas, se moram em residência alugadas ou se preferem implantar hábitos de controle de planejamento familiar.

Os Smart Meters são considerados elementos principais para troca de informações com as concessionárias de energia, estando intimamente ligado à infraestrutura avançada de medição ou AMI (Advanced Meter Infrastructure). O AMI é encarado como uma ponte para construção do Smart Grid (LUAN et al., 2009).

\subsection{Comunicação}

O método de comunicação mais difundido para Smart Grid utilizado para conectar os Smart Meters com a concessionária de energia é o sistema PLC (Power Line Communication), que usa a rede elétrica para transferência de dados de forma rápida e confiável. O PLC utiliza sinais de baixa e média frequência atrelados que se propagam ao longo dos condutores da linha de alimentação. Um sistema PLC é composto por conjuntos terminais (transmissores, receptores e relés), equipamentos de acoplamento e condutores de linhas de alimentação entre terminais. Entre os aplicativos de PLC estão telemetria, comunicação de voz, internet, etc. Em sistemas $A M I$, também são utilizadas técnicas de $P L C$ na transmissão de dados entre medidores e concessionárias de energia (SILVA e WHITNEY, 2002).

Outra tecnologia que pode ser utilizada em AMI é o sistema GSM usado em telefonia celular.

Em Kim (2006) descreve-se um sistema telefônico para AMR, contendo um módulo de interface para conectar-se ao centro de controle remoto por meio de uma linha telefônica, uma unidade de controle principal para gerenciar sinais de controle 
que incorpora o identificador de chamada, um decodificador para descodificar o sinal de pedido de leitura do medidor e uma memória para armazenar temporariamente as leituras.

Outros tipos de comunicação utilizados em AMR são os sistemas de rádio frequência, como Bluetooth, Wireless Mesh e Zigbee.

Em Koay et al. (2003), descreve-se um Smart Meter utilizando sistemas Bluetooth, em que os dados são transmitidos dos Smart Meters para um PDA ou computador mais próximo.

Entretanto, o Bluetooth não é uma tecnologia muito utilizada para os sistemas AMI de hoje, devido a sua limitação com relação à transferência de dados em longa distância (KHALIFA et al., 2011).

Entre os sistemas de comunicação que utiliza rádio frequência citados anteriormente, aquele que tem ganhado bastante atenção em AMI é o Zigbee.

O Zigbee consiste em uma tecnologia de comunicação sem fio que apresenta, relativamente, baixo consumo de energia, rápida transferência de dados, baixa complexidade e baixo custo de implantação. Esta é considerada uma tecnologia ideal para medição e gerenciamento de energia, pois possui simplicidade, robustez, mobilidade, baixo custo de implantação e fácil implantação de rede utilizando um protocolo padronizado baseado no padrão IEEE 802.15.4. Um Smart Meter contendo Zigbee permite trocar dados com outros dispositivos Zigbee, possibilitando que as concessionárias de energia colham os dados dos medidores e enviem de volta as informações de consumo de energia, e que os usuários as vejam em tempo real (GÜNGÖR et al., 2011).

A rede mesh é uma das topologias utilizadas com o sistema Zigbee, sendo que esta se apresenta flexível quanto à mudança na quantidade de aparelhos 
conectados. Consiste em um grupo de nodos em que novos nós podem se juntar ao grupo, e cada nó pode atuar como sendo um roteador independente. A rede possui vantagens como a boa cobertura em áreas urbanas e suburbanas com capacidade de roteamento multi-hop e a capacidade de transformar cada nó em um repetidor de sinal (GÜNGÖR et al., 2011).

\subsection{Tipos e Funcionalidades}

Devido à troca dos medidores eletromecânicos por medidores inteligentes (Smart Meters), de modo a auxiliar a demanda de energia, vários tipos de medidores, com funcionalidades diferentes, têm surgido no mercado.

Em Ontário, com o intuito de controlar o consumo de energia, medidores convencionais estão sendo trocados por medidores inteligentes, pois, aqueles somente mostram o consumo total dos consumidores e seus dados devem ser lidos manualmente. Sendo assim, foi criado um modelo de medidor inteligente contendo medições em tempo real, podendo ser visualizado pelos usuários por meio de um visor LCD e coleta dos dados de consumo de energia de forma remota, não necessitando o deslocamento de um funcionário para realizar a medição (ANDREY e MORELLI, 2010).

Alguns Smart Meters são capazes de limitar o consumo de energia de uma residência e também realizar o ligamento e o desligamento, remotamente, do fornecimento de energia de qualquer cliente.

Embora existam tipos e funcionalidades diferentes de Smart Meters, o intuito de sua implantação é melhorar a qualidade de fornecimento de energia, gerar 
economias tanto para o consumidor como para as concessionárias, poupar energia, entre outros benefícios, a fim de contribuir na eficiência energética.

Sendo assim, este trabalho apresenta a confecção de um Smart Meter de baixo custo, contendo as funcionalidades comuns como cálculos de consumo de energia, porém integrando um analisador de qualidade de energia, mais especificamente a detecção de cargas conectadas em uma residência.

\subsection{Qualidade de Energia}

A qualidade de energia é um tema muito encontrado na área da engenharia elétrica, devido à preocupação das concessionárias de fornecer uma energia estável e com menos quantidade de distorções harmônicas.

Os distúrbios de qualidade de energia alteram as características da tensão e da corrente, os quais acarretam em um mau funcionamento do fornecimento de energia. Dentre os principais distúrbios de QEE se destacam as distorções harmônicas, interrupções, elevação e afundamento, sendo estes três últimos caracterizados como variações de tensão de curta duração (VTCD).

As VTCDs são caracterizadas como desvios significativos no valor eficaz da tensão em curtos intervalos de tempo, com duração entre 1 ciclo e 1 minuto (IEEE, 2009), podendo ser classificadas como afundamento aquilo que corresponde a uma redução da amplitude da tensão, entre 0,9 e 0,1 p.u.; elevação é aquilo que caracteriza uma variação de tensão acima de 1,1 p.u., e interrupção que é definida por uma redução da variação de tensão abaixo de 0,1 p.u. do valor eficaz da tensão nominal. 
Outro distúrbio muito importante a ser estudado são as distorções harmônicas. A preocupação com as distorções harmônicas começou a crescer devido ao aumento de cargas não lineares conectadas à rede elétrica (DUGAN et al., 2004).

Segundo Arrillaga et al. (2000), as distorções harmônicas são variações na frequência da tensão e corrente, ou seja, são frequências múltiplas da fundamental que surgem na rede elétrica devido às cargas não lineares.

Sendo assim, o aumento dessas distorções harmônicas deve ser controlado, e uma das formas de controlar é estudar o comportamento das cargas conectadas ao sistema elétrico. Concessionárias de energia estudam também a possibilidade de cobrar valores diferenciados para consumidores que produzirem quantidades excessivas de distorções harmônicas. 


\section{Arquitetura do Smart Meter Integrado ao Analisador de Qualidade de Energia}

\subsection{Introdução}

Com base no novo conceito de Smart Grid, este trabalho propõe a construção de um Smart Meter para análises de distorções harmônicas e envio de dados referentes ao consumo de energia elétrica via comunicação serial.

\subsection{Montagem do Smart Meter}

A montagem do Smart Meter envolve várias etapas desde a aquisição do sinal de tensão e corrente da rede elétrica. Estas etapas estão mais bem comentadas nos tópicos seguintes.

\subsubsection{Sensores de Efeito Hall}

O surgimento de uma diferença de potencial em um condutor elétrico, transversal ao fluxo de corrente e um campo magnético perpendicular à corrente, é denominada efeito Hall.

Os sensores de efeito Hall são os mais empregados para a utilização em medidores eletrônicos, devido a sua confiabilidade nas medições. Sendo assim, para o projeto apresentado nesta tese foram utilizados sensores de efeito Hall de tensão 
e corrente como elementos transdutores. Os resultados dos ensaios realizados para verificação da eficácia destes sensores no âmbito de medidores inteligentes serão apresentados nos próximos itens do texto.

A metodologia de ensaios, apesar de compacta, forneceu uma base a respeito da forma como os sensores de efeito Hall podem ser empregados por medidores inteligentes. Assim, configurou-se uma bancada de ensaios da mesma forma que em Fugita et al. (2013) e conforme ilustrado na Figura 3.1.

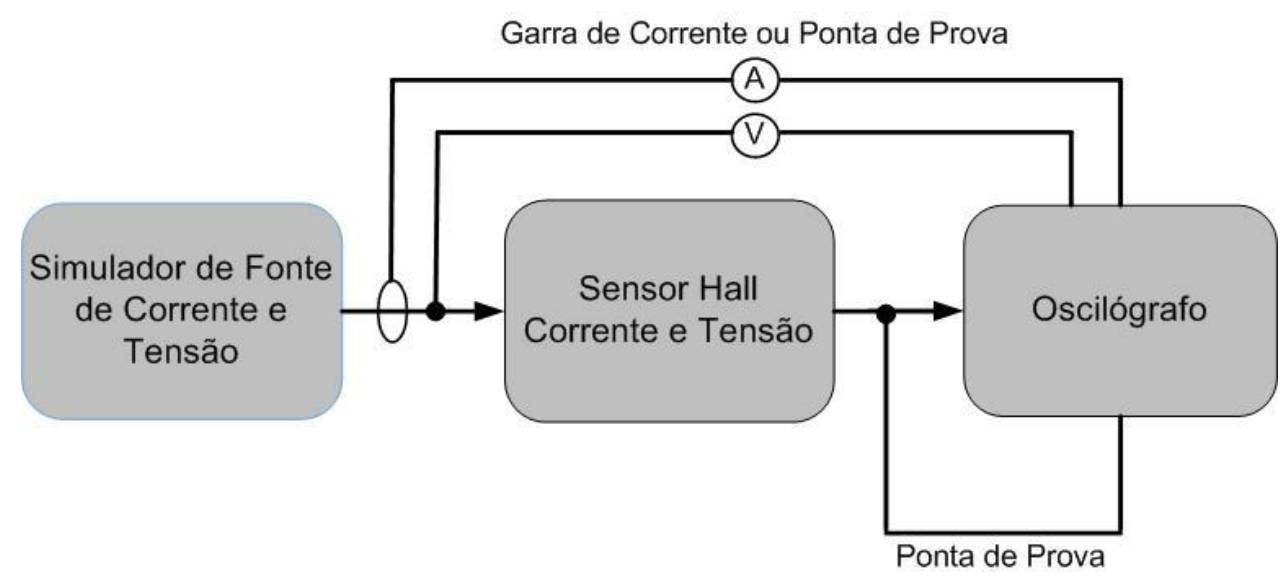

Figura 3.1 - Bancada para os ensaios dos sensores de efeito Hall.

Nota-se que esta bancada é basicamente composta por uma fonte (responsável por gerar as formas de onda com correntes, tensões e frequências necessárias aos ensaios), pelos sensores de efeito Hall modelo LV20-P para tensão e LAH25-NP para corrente e por um oscilógrafo Yokogawa modelo DL750.

Durante os ensaios do sensor de efeito Hall, empregou-se um simulador de fonte de corrente e tensão (modelo F6150 Power System Simulator da fabricante Doble). O simulador utilizado é ilustrado na Figura 3.2. É importante comentar que esta fonte é toda configurada via software e que, por meio deste software, torna-se possível providenciar todos os ensaios de tensão, corrente e frequência. Além disso, também é possível realizar ensaios em que se dá como entrada um arquivo 
COMTRADE com uma forma de onda aleatória (que pode ser proveniente de uma oscilografia real) e, então, tal forma de onda pode ser fornecida como alimentação para o dispositivo sob ensaio (neste caso, o sensor de efeito Hall).

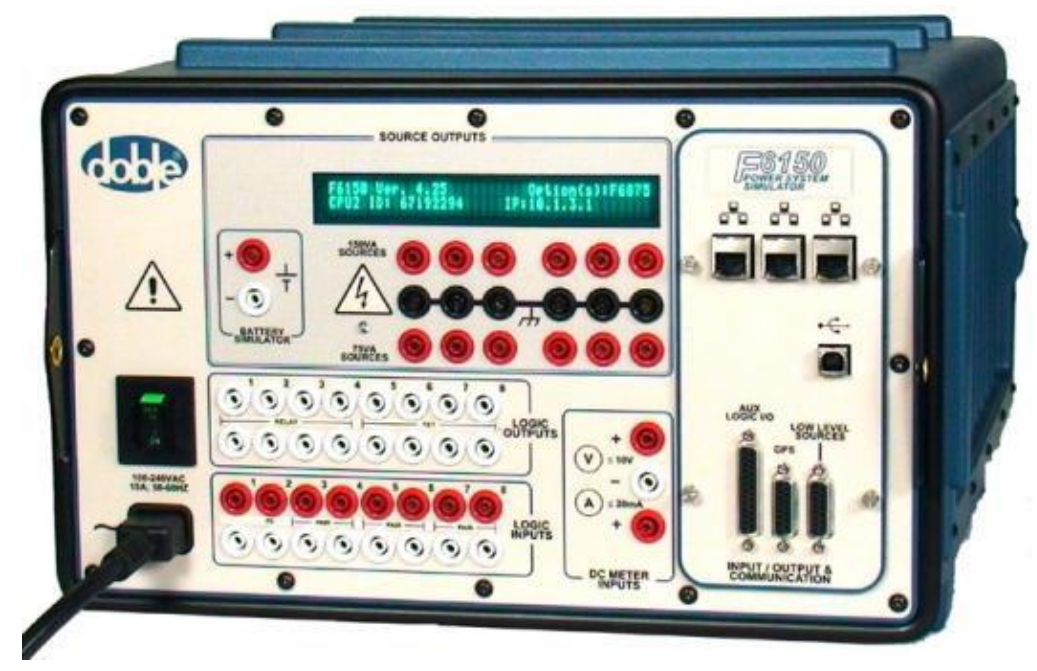

Figura 3.2 - Fonte Doble modelo F6150 Power System Simulator.

Por fim, nota-se que todas as medidas necessárias foram obtidas por meio de um oscilógrafo DL750 da Yokogawa, o qual pode ser visualizado por meio da Figura 3.3.

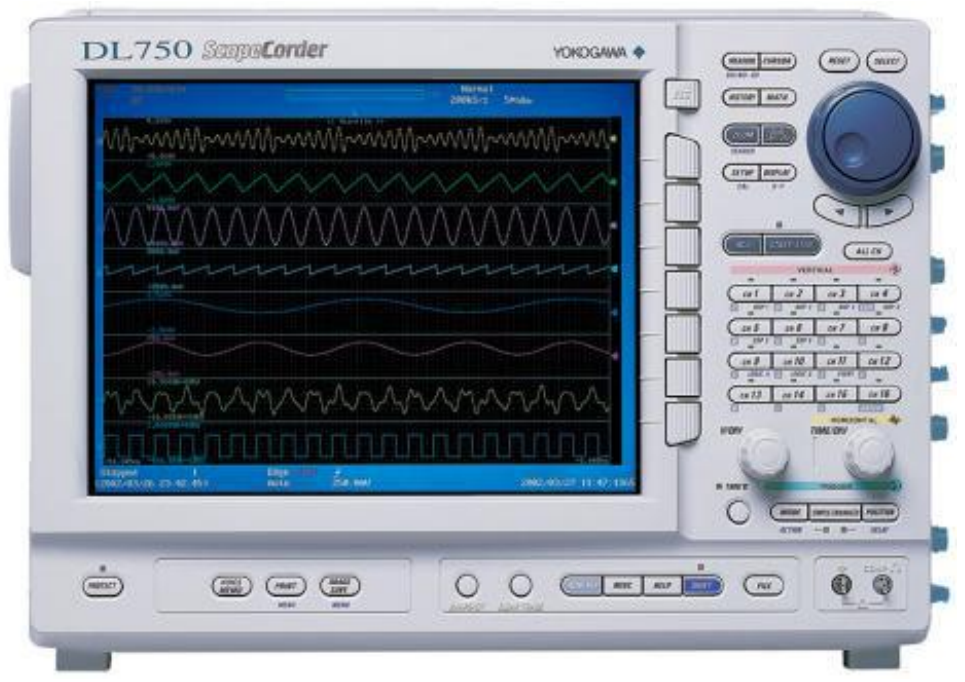

Figura 3.3 - Oscilógrafo empregado durante os ensaios dos sensores de efeito Hall para a obtenção das medidas de tensão e corrente. 
Há de se observar que o oscilógrafo foi utilizado com sua taxa máxima de amostragem, a qual é de $10 \mathrm{MS} / \mathrm{s}$.

\subsubsection{Ensaios do Sensor Hall de Tensão}

É relevante demonstrar que o sensor de efeito Hall de tensão utilizado possui as seguintes características:

- Corrente nominal primária em RMS de 12 mA e secundária de 25 mA;

- Suporta tensões em RMS de até 500 V na entrada;

- Alimentação do sensor é feita de forma simétrica com $\pm 15 \mathrm{~V}$;

- Alta imunidade a interferências externas.

Para este sensor foram feitos ensaios de variação de tensão e frequência. A Figura 3.4 mostra o sensor Hall de tensão utilizado no projeto.

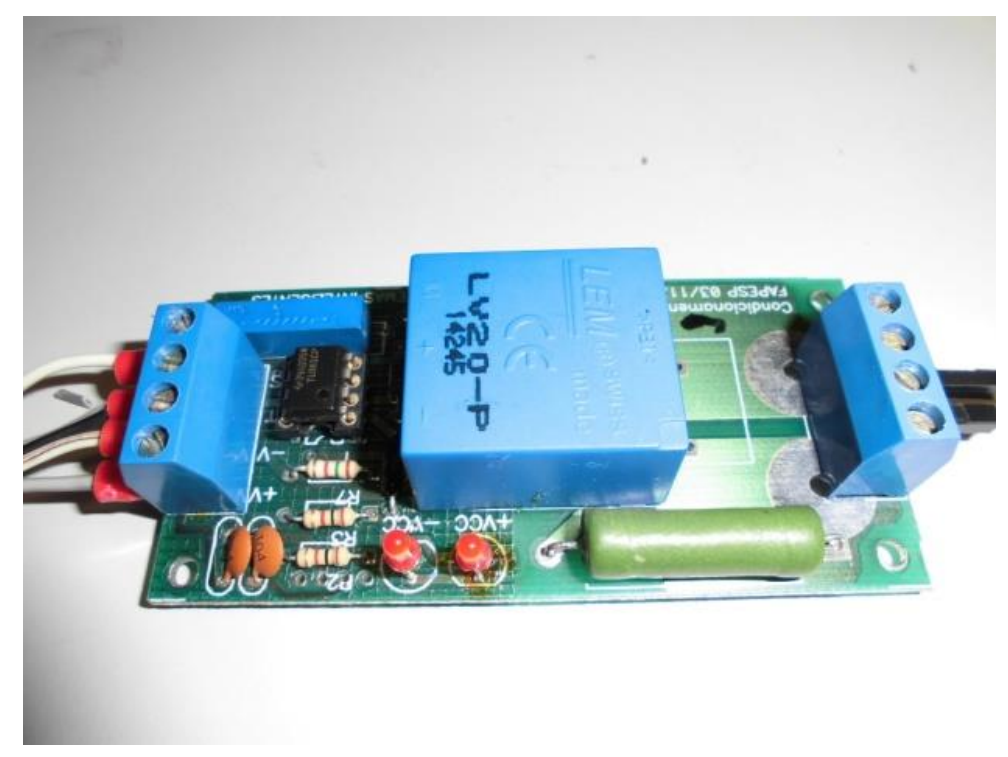

Figura 3.4 - Sensor de efeito Hall de tensão.

Durante os ensaios do sensor de efeito Hall, conforme previamente comentado, injetaram sinais de tensão com amplitudes distintas em sua entrada e 
mediu-se a tensão de saída. Desta forma, tornou-se possível a obtenção de uma resposta de tensão para o sensor, a qual pode ser visualizada por meio da Figura 3.5.

É importante mencionar que o ensaio foi realizado variando-se a tensão num passo de $2 \mathrm{~V}$, em que a faixa de tensão foi iniciada em $2 \mathrm{~V}$ e finalizada em $230 \mathrm{~V}$. Destaca-se que esta faixa de tensão apresentou na saída respectivamente $455 \mathrm{mV}$ e $5,25 \mathrm{~V}$

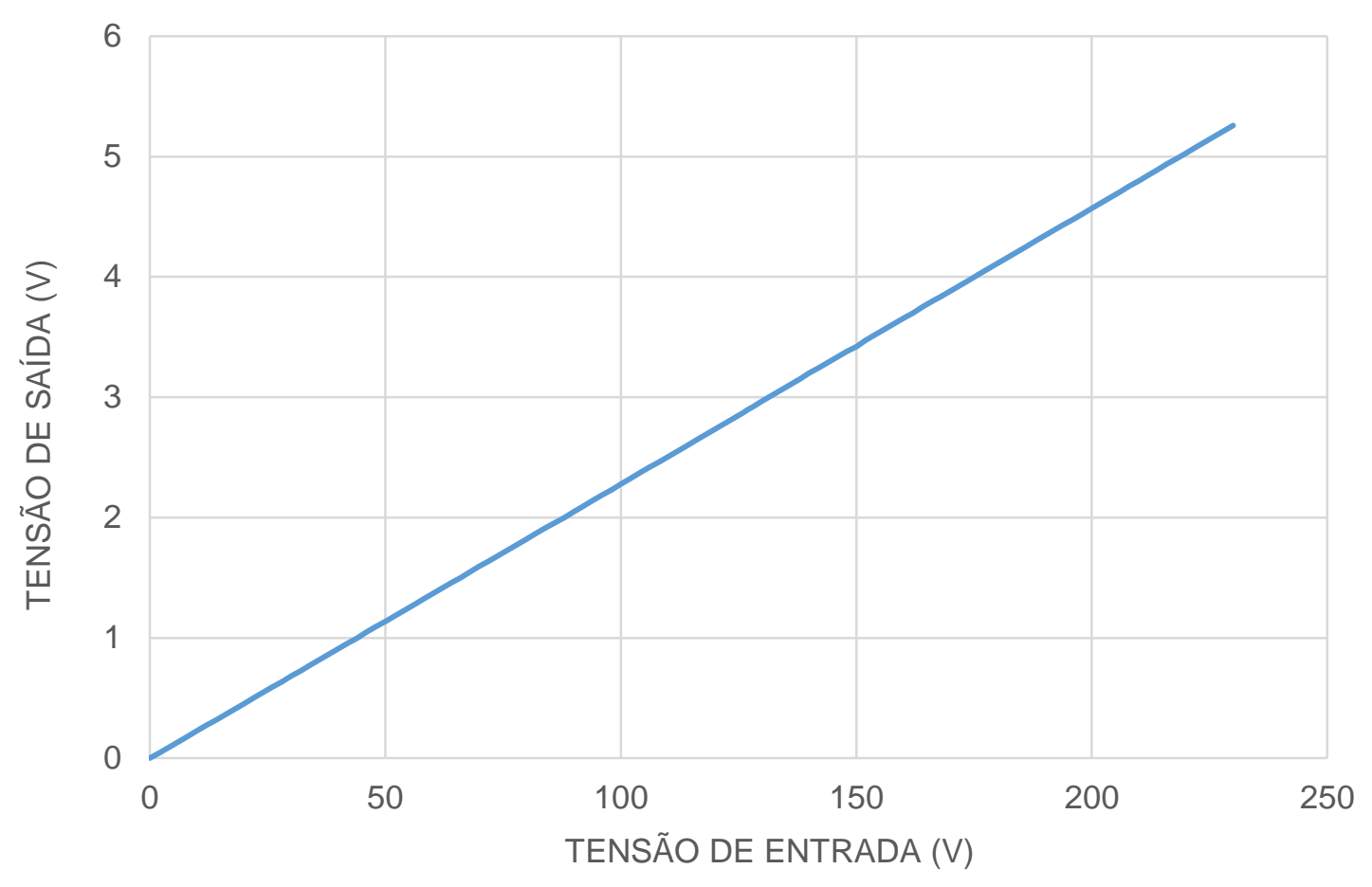

Figura 3.5 - Resposta do sensor Hall mediante a um degrau de tensão.

Conforme pôde ser observado por meio das respostas do sensor de efeito Hall (Figura 3.5) frente aos ensaios propostos, nota-se que esse tipo de sensor apresenta uma resposta bastante linear. Considerando a forma como foram realizados os ensaios, fazendo uso de uma ponta de prova na entrada do sensor e outra ponta de prova na saída, foi possível observar que a tensão adotada na 
entrada é realmente aquela selecionada no equipamento; sendo assim, não há erros na geração dos sinais de tensão e corrente. Portanto, os resultados apresentados com relação ao erro é exclusivamente dos sensores.

Analisando os cálculos realizados, o sensor de tensão apresentou um erro relativo baixo. Somente para a tensão inicial de 2 V, o erro foi um pouco maior, após isto o mesmo diminui gradualmente, como mostra a Figura 3.6.

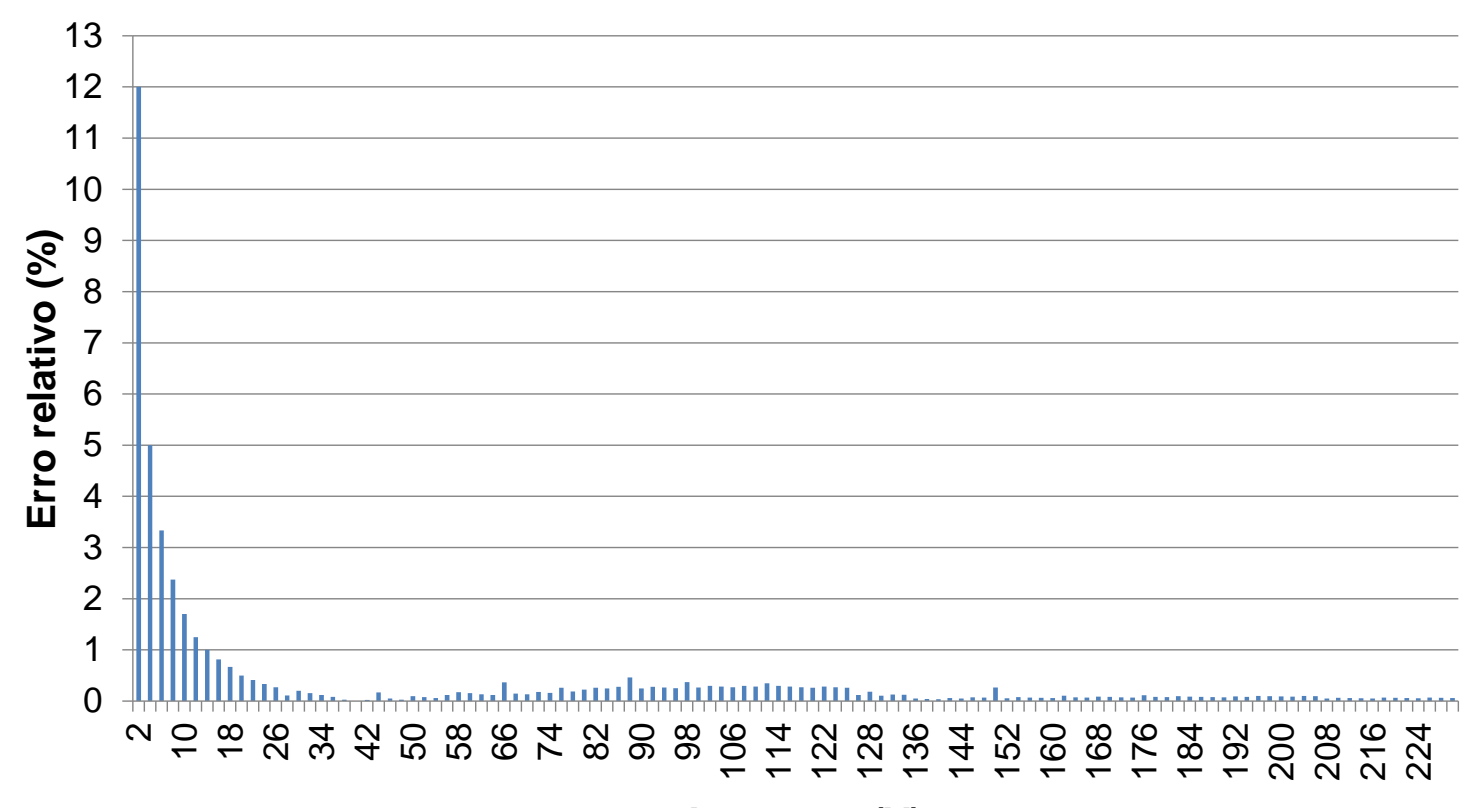

Amostras (V)

Figura 3.6 - Erro percentual do sensor de efeito Hall para o ensaio com degrau de tensão.

\subsubsection{Ensaios do Sensor Hall de Corrente}

O sensor de efeito Hall de corrente utilizado possui as características mencionadas na sequência:

- Corrente nominal em RMS de até $25 \mathrm{~A}$;

- Alimentação do sensor também é feita de forma simétrica com $\pm 15 \mathrm{~V}$; 
- Não há perdas de inserção;

- Capacidade de corrente de sobrecarga.

De forma análoga ao sensor de tensão, foram realizados ensaios de variação de corrente e frequência. A Figura 3.7 mostra o sensor Hall de corrente utilizado no projeto.

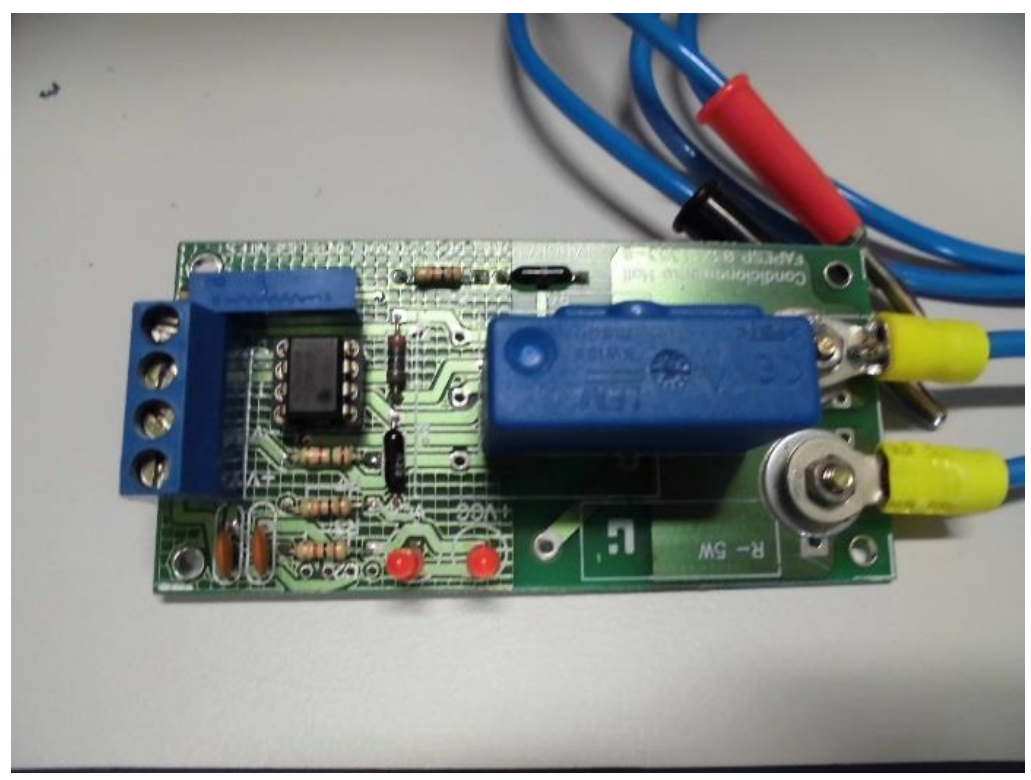

Figura 3.7 - Sensor de efeito Hall de corrente.

Os ensaios referentes ao degrau de corrente foram realizados adotando-se um passo de $0,5 \mathrm{~A}$ até a corrente máxima suportada pelo sensor sob avaliação (25 A). No entanto, a saída do sensor é dada na forma de tensão e, portanto, obteve-se uma resposta que relaciona a corrente de entrada com uma tensão de saída (Figura 3.8). Estas faixas de corrente adotadas para o teste apresentam na saída respectivamente $0,1 \mathrm{~V}$ e 5,02 V. 


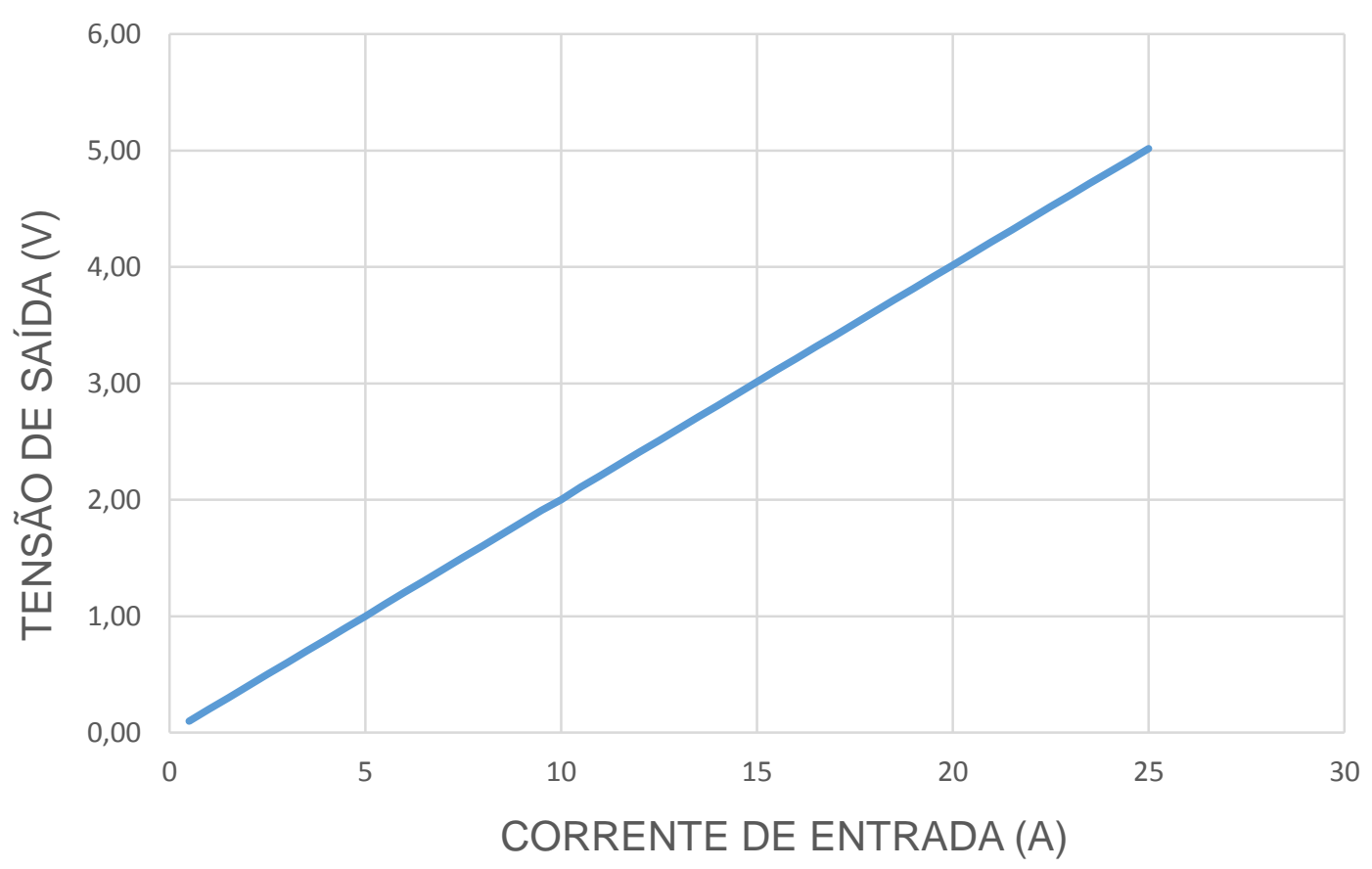

Figura 3.8 - Resposta do sensor de efeito Hall mediante um degrau de corrente.

Como relatado no datasheet dos sensores Hall da LEM, ambos os modelos apresentam ótima linearidade como visto nas Figuras 3.5 e 3.8. Ainda segundo o datasheet do fabricante os sensores possuem boa linearidade em sua resposta em frequência, como demonstrado em Fugita et al. (2013).

Considerando que o PRODIST (Procedimentos de Distribuição de Energia Elétrica no Sistema Elétrico Nacional) normatiza em seu oitavo módulo que os medidores de qualidade de energia elétrica devem ter a capacidade de medir componentes harmônicos até a $25^{\underline{a}}$ ordem, verifica-se então que o sensor de efeito Hall ensaiado garante esta característica, pois, de acordo com o teorema da amostragem de Nyquist, para se garantir a medida de uma determinada frequência de interesse $f_{x}$ deve-se atender à restrição dada pela equação (3.1):

$$
f_{\text {amostrado }} \geq 2 \cdot f_{x}
$$


Assim, para se garantir a medida de uma frequência $f_{x}=1500 \mathrm{~Hz}$ (referente à 25aㅡ ordem harmônica) deve-se garantir uma frequência de amostragem maior ou igual a $3000 \mathrm{~Hz}$. Portanto, o ensaio de degrau de frequência está adequado à norma estabelecida pelo PRODIST caso o medidor inteligente venha a desempenhar funções que dizem respeito à análise da qualidade da energia entregue ao consumidor.

Após a realização dos ensaios, foi verificada também a confiabilidade do sensor utilizado.

Como dito anteriormente, os cálculos do erro relativo foram feitos da mesma maneira que o realizado para o sensor de tensão, sendo que este apresentou um erro relativo baixo, em que a primeira amostra obteve um erro maior do que as outras amostras, como mostrado na Figura 3.9.

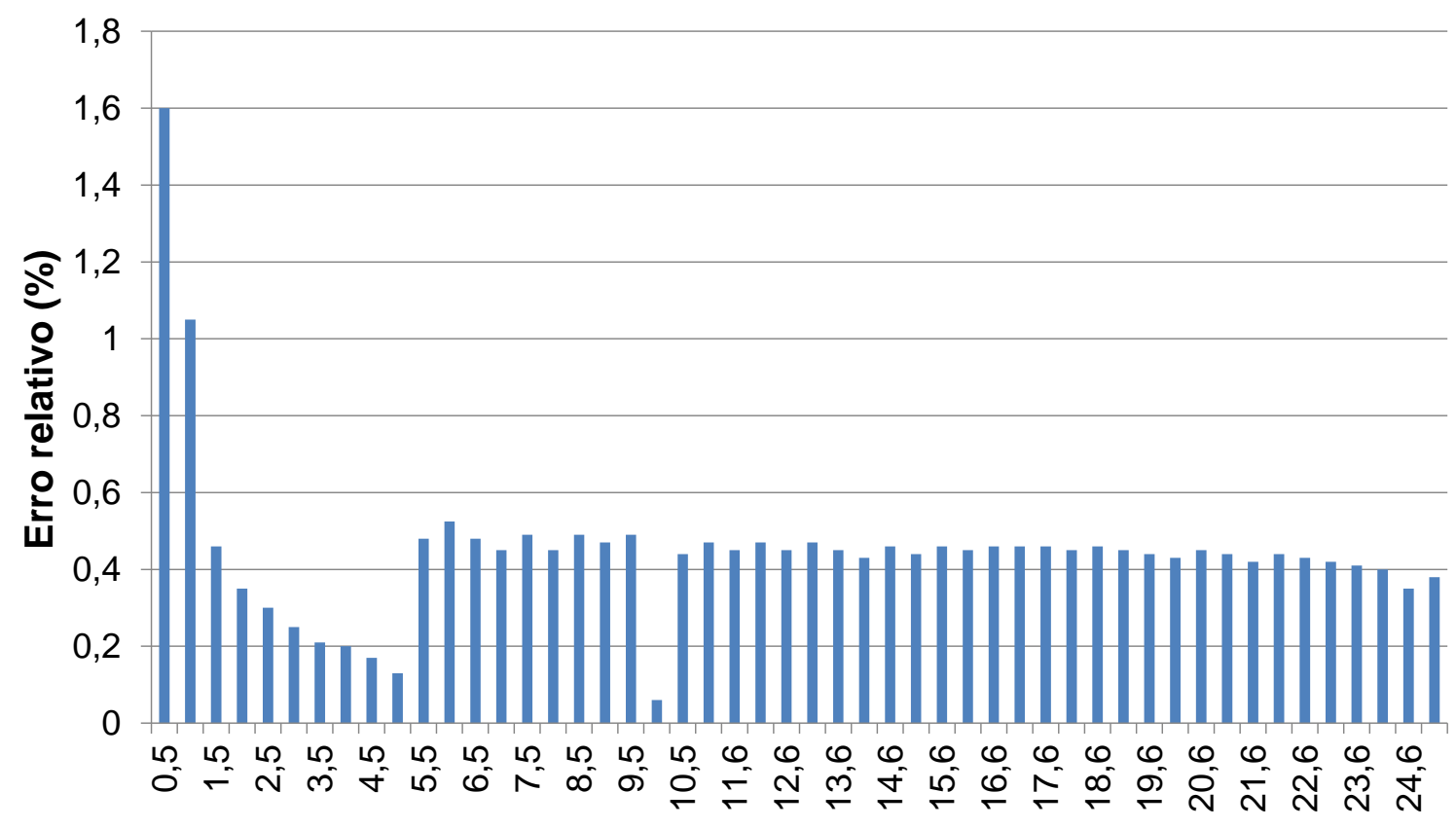

\section{Amostras}

Figura 3.9 - Erro percentual do sensor de efeito Hall para o ensaio com degrau de corrente. 
Além dos sensores de efeito Hall utilizados foi necessário projetar um circuito de condicionamento de sinal para adequação do sinal para a conversão A/D do microcontrolador. Os próximos tópicos relatam melhor todo o projeto desenvolvido para esta tese.

\subsubsection{Fonte Simétrica}

Todo o circuito eletrônico do Smart Meter proposto é alimentado por uma fonte DC, sendo assim, houve a necessidade de projetar uma fonte simétrica de +15 V e -15 V para a alimentação dos sensores de corrente e tensão, bem como a alimentação dos condicionadores de sinal.

Este circuito conta com um transformador de $127 \mathrm{~V}$ para $24 \mathrm{~V}$, e dois reguladores de tensão, o LM7815 e o LM1915. Estes reguladores têm a finalidade de fixar a tensão em $+15 \mathrm{~V} \mathrm{e}-15 \mathrm{~V}$.

A Figura 3.10 ilustra a parte inicial do projeto, em que se encontram a fonte simétrica e os sensores Hall de tensão e corrente. 


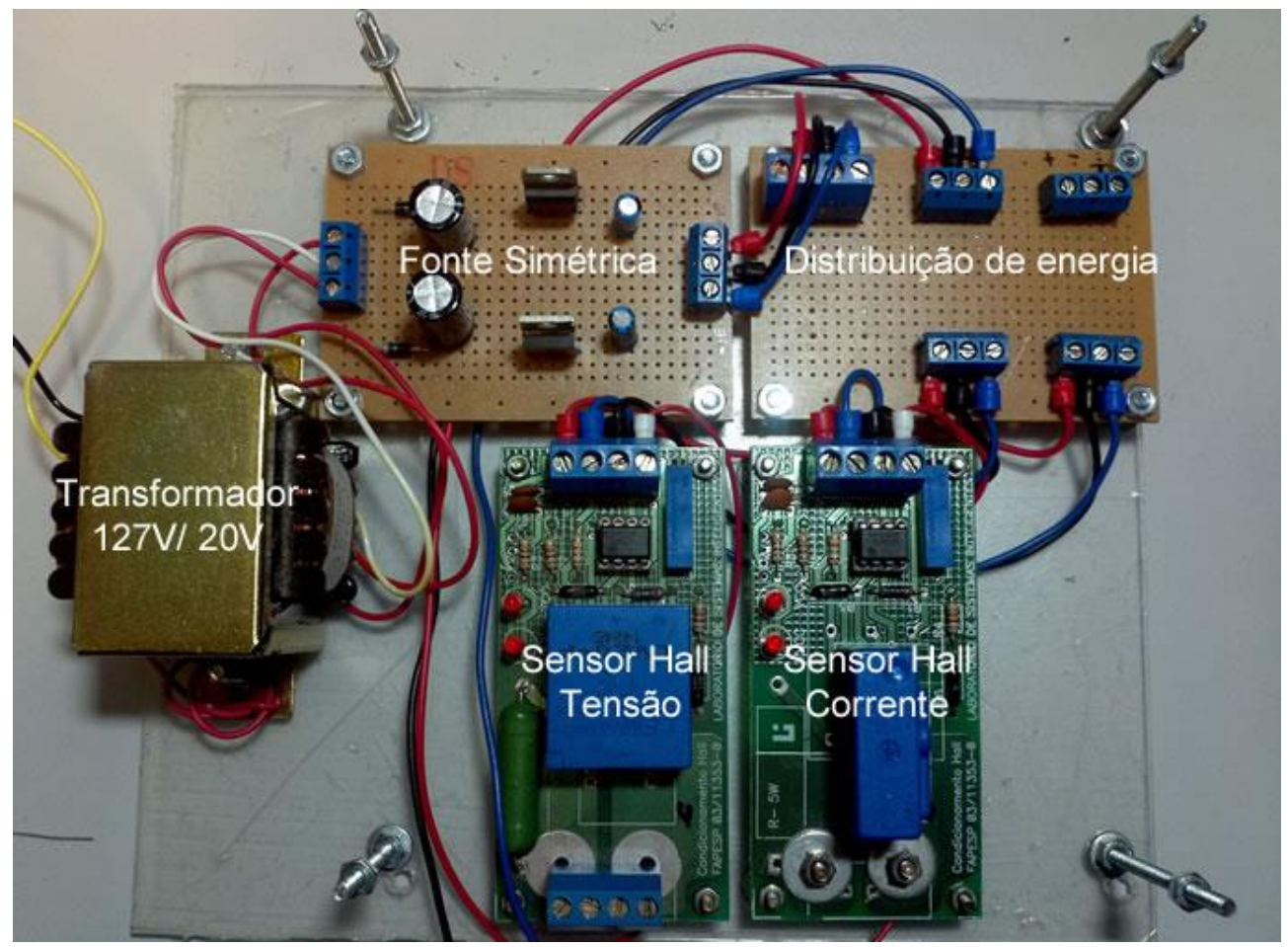

Figura 3.10 - Primeira etapa do projeto do Smart Meter.

Como pode ser visto nas Figuras 3.10 e 3.11 a fonte utilizada foi projetada de maneira compacta e didática, porém, funcional. Pode-se também projetar uma fonte otimizada utilizando o website da Texas Instruments. Um modelo de fonte para este projeto é mostrado no Anexo 1.

\subsubsection{Condicionamento de Sinal}

O sinal proveniente do sensor Hall de tensão possui um intervalo de $-3.3 \mathrm{~V}$ a 3.3 V quando aplicados em sua entrada uma tensão de $-127 \mathrm{~V}$ a $127 \mathrm{~V}$. Como dito anteriormente, o sensor Hall de corrente tem a sua saída dada em forma de tensão e possui um intervalo de $-5 \mathrm{~V}$ a $5 \mathrm{~V}$, quando aplicado em sua entrada a corrente máxima suportada pelo sensor que é de $25 \mathrm{~A}$. Entretanto, o microcontrolador LM4FH5QR trabalha com níveis de tensão entre 0 V e 3 V.

Sendo assim, o circuito de condicionamento de sinal tem como objetivo adequar o sinal da saída dos sensores à entrada A/D do microcontrolador. 
O projeto do circuito consiste em dois amplificadores operacionais, sendo 0 primeiro configurado com um buffer seguidor de sinal, a fim de aumentar a impedância do sinal proveniente dos sensores Hall. O segundo amplificador operacional está configurado como subtrator com controle de offset. Este tem como finalidade retirar a parte negativa do sinal advindo dos sensores Hall. O circuito utilizado é ilustrado na Figura 3.11.

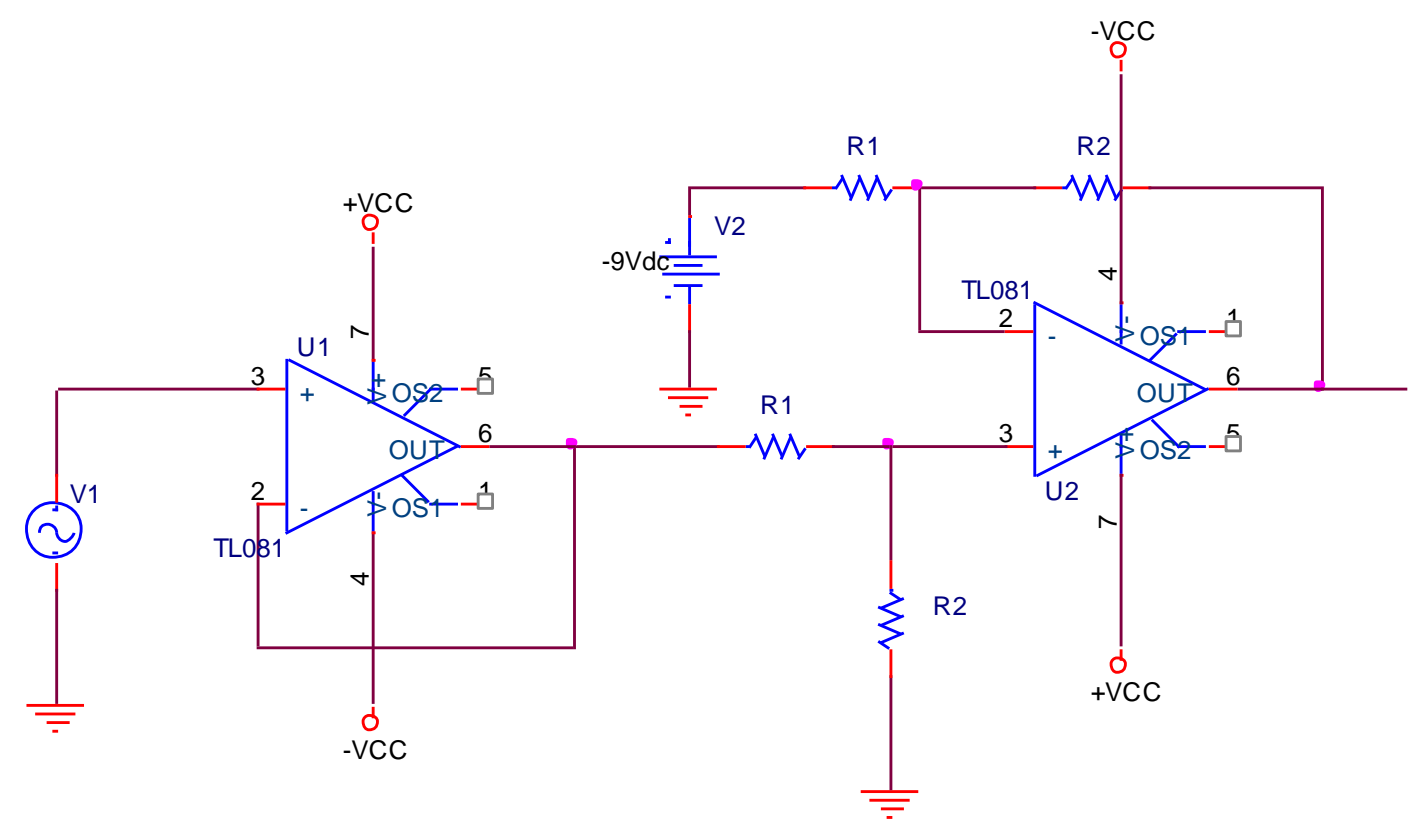

Figura 3.11 - Circuito de condicionamento de sinal.

O circuito de condicionamento para os sinais advindos dos sensores Hall de tensão e corrente possuem as mesmas configurações, exceto os valores dos resistores, que são calculados de acordo com o valor de tensão de cada saída do sensor Hall.

A equação (3.2) mostra o dimensionamento dos resistores em função dos valores de tensão aplicados na entrada do amplificador operacional configurado como subtrator. 


$$
V_{0}=\frac{R_{2}}{R_{1}} \cdot\left(V_{2}-V_{1}\right)
$$

onde: $V_{0}$ é a tensão de saída do amplificador operacional. No caso do condicionamento de sinal do sensor Hall de tensão, o valor é de $3 \mathrm{~V} ; R_{1}$ é o resistor, neste caso o valor optado foi de $1 \mathrm{k} \Omega ; V_{2}$ é a tensão de entrada do pino não inversor, sendo este de $3.3 \mathrm{~V} ; \mathrm{V}_{1}$ é a tensão DC aplicado no pino inversor. Este tem como finalidade retirar o nível negativo do sinal, ajustando para o intervalo de tensão de 0 $V$ a 3 V. Finalmente, $R_{2}$ é o resistor calculado por meio da equação (3.2).

O cálculo para o condicionamento do sinal advindo do sensor Hall de corrente é o mesmo aplicado para a tensão como mostrado anteriormente; entretanto, os valores da tensão de entrada do pino inversor do subtrator é de $5 \mathrm{~V}$, e o valor de $R_{1}$ é de $10 \mathrm{k} \Omega$, sendo assim após utilizar a equação (3.2), obtém-se o valor de $R_{2}$.

\subsubsection{Filtro Anti-Aliasing}

Após o condicionamento de sinal detalhado no tópico anterior, é necessário dimensionar o filtro anti-aliasing passa-baixa. Este filtro tem como finalidade atenuar as componentes de alta frequência do sinal que não são essenciais para a informação contida nele. Logo, o sinal filtrado é amostrado a uma taxa ligeiramente mais elevada do que aquela de Nyquist.

Para este projeto foi calculado um filtro passa baixa com frequência de corte de $3000 \mathrm{~Hz}$. De acordo com Pertence (2007), o filtro aplicado foi implementado seguindo a ordem relatada pelo mesmo. A equação (3.3) mostra o cálculo de $R 1$. 


$$
R_{1}=\frac{1}{b \cdot w_{c} \cdot C}
$$

onde: $b$ é o parâmetro que determina o tipo de função resposta para filtros de ordem ímpar $\geq 3$ (PERTENCE, 2003); o valor $C$ é dado pela relação $10 / F_{C}$, sendo que $F_{C}$ é a frequência de corte estipulada (neste caso é igual a $3000 \mathrm{~Hz}$ ). Para calcular o valor de $R_{3}$, utilizou-se a equação (3.4).

$$
R_{3}=K \cdot R_{1}
$$

onde: Ké o valor do ganho, neste caso o valor é de 0,707.

A Figura 3.12 ilustra o circuito do filtro projetado.

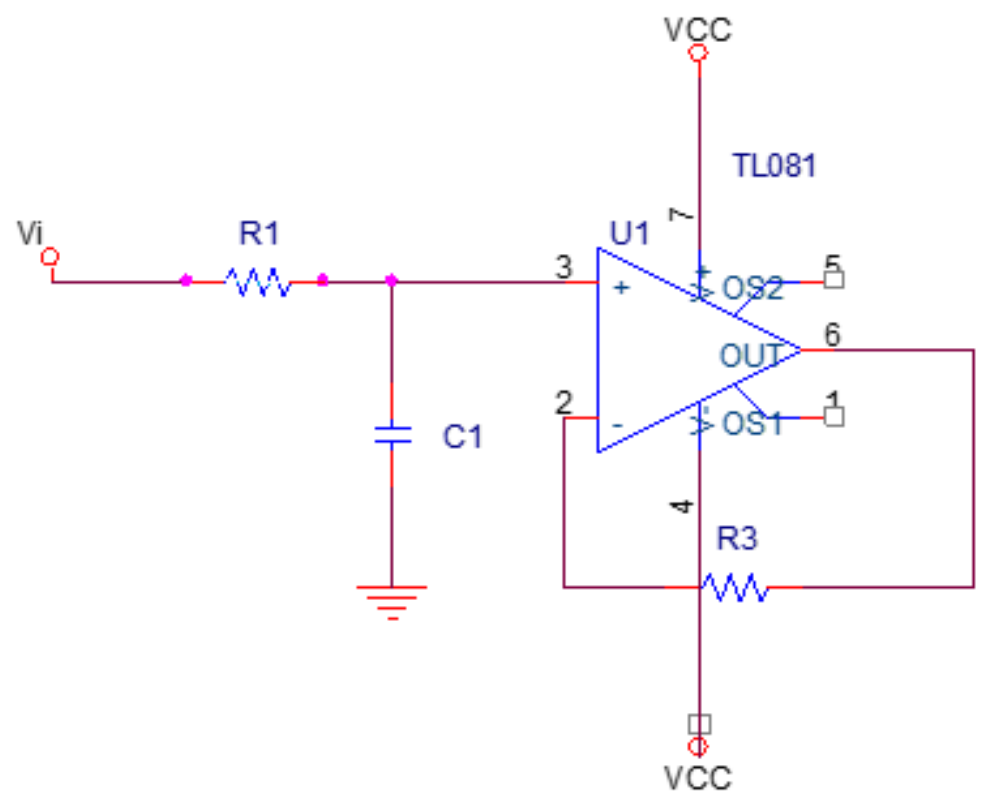

Figura 3.12 - Filtro anti-aliasing.

O circuito de condicionamento de sinal pode ser visto na Figura 3.13. 


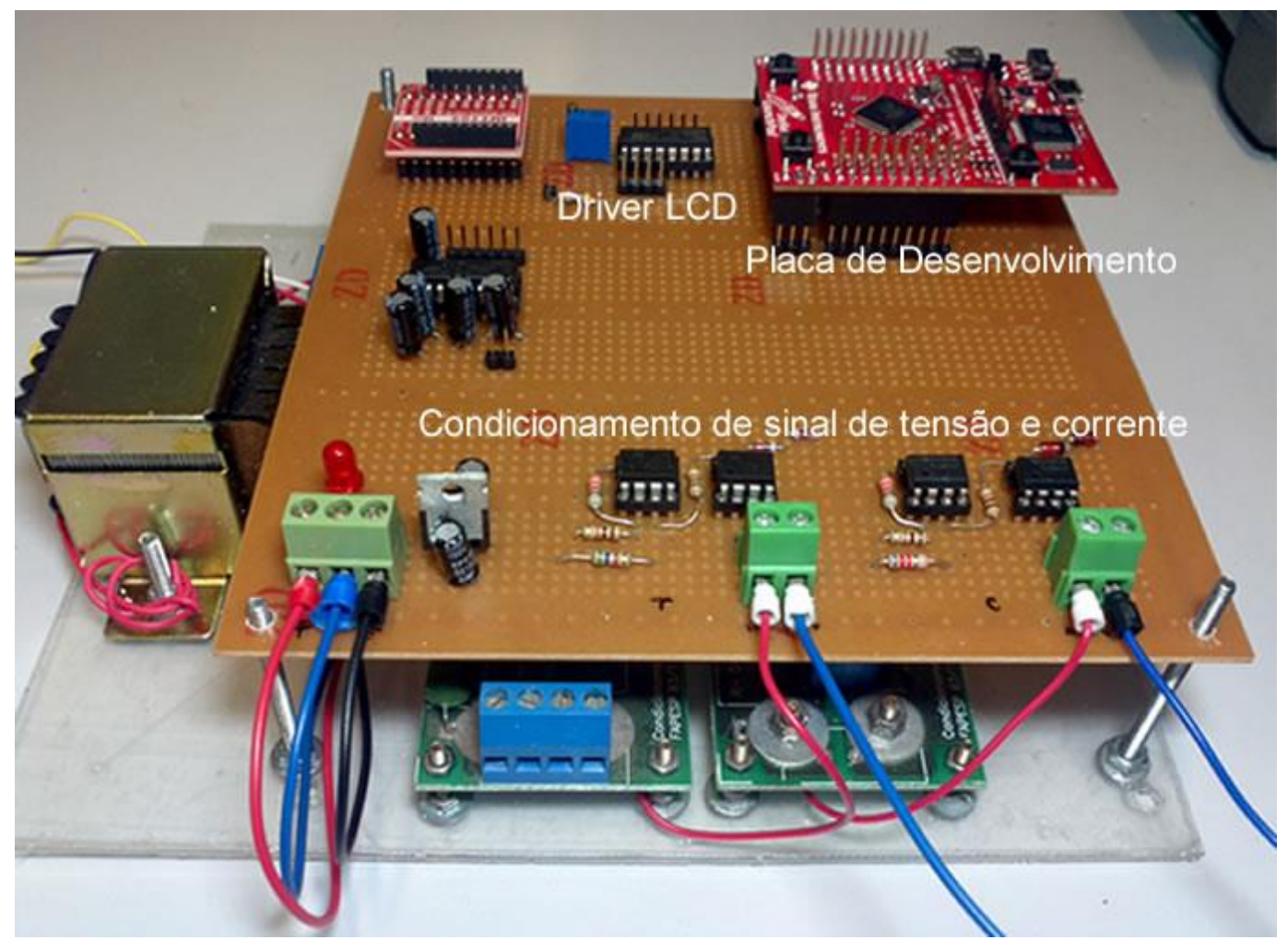

Figura 3.13 - Circuito condicionamento de sinal.

Como visto neste item, foi utilizado um filtro compacto de primeira ordem, devido ao fato de ser somente um protótipo de um Smart Meter; entretanto, pode-se optar por um filtro Chebyshev de $6^{a}$ ordem, com topologia Sallen-key, por possuir uma frequência de corte mais acentuada em relação ao filtro de primeira ordem. $\mathrm{O}$ circuito do filtro Checbychev de $6^{\mathrm{a}}$ ordem e a suas curvas de comportamento são ilustrados nas Figuras 3.14 e 3.15 , respectivamente.

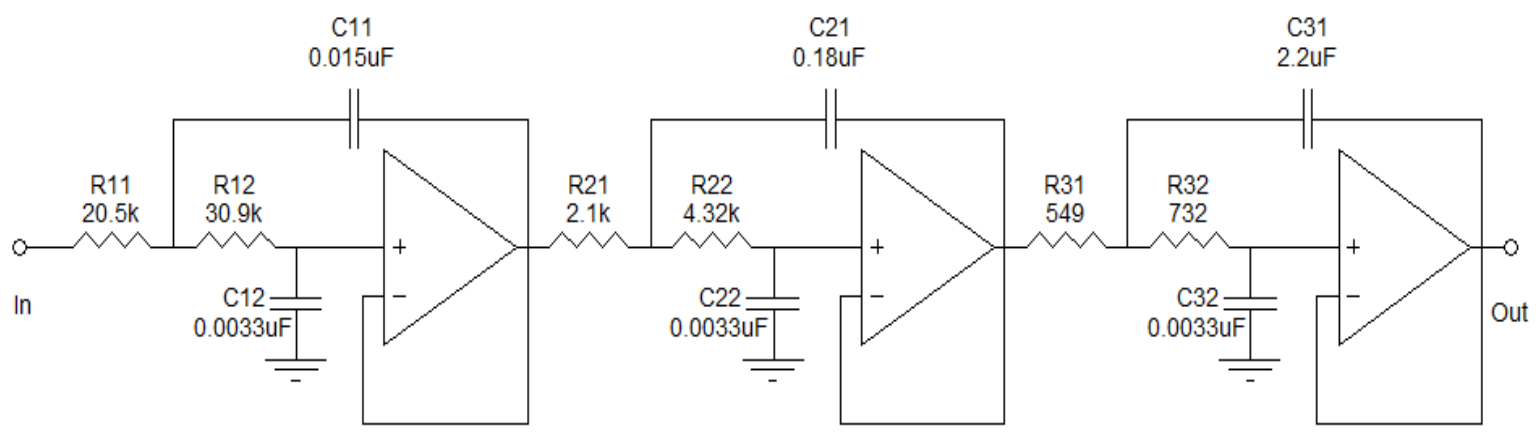

Figura 3.14 - Circuito do filtro Chebychev de $6^{a}$ ordem. 


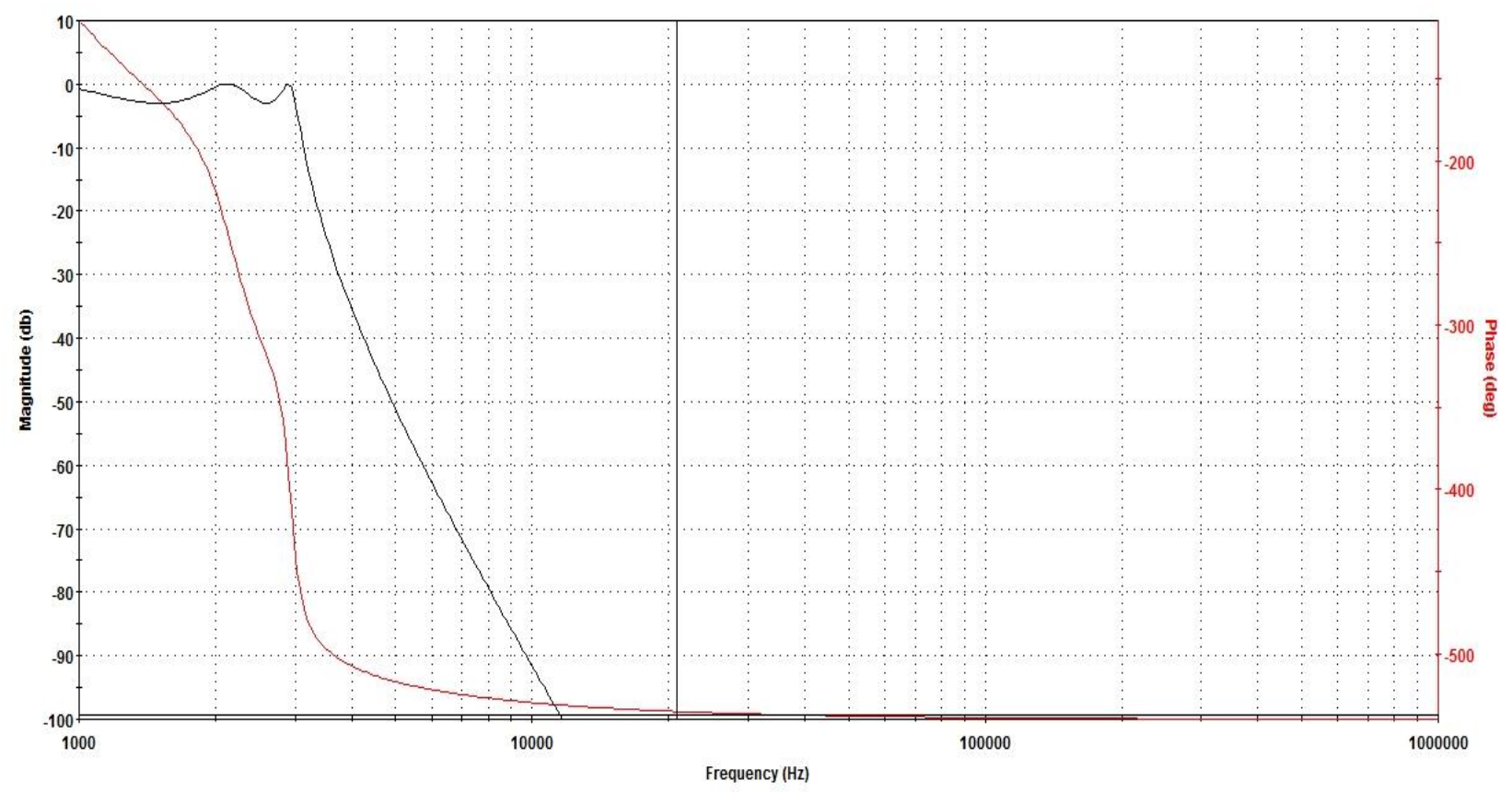

Figura 3.15 - Curva de comportamento do filtro Chebychev de $6^{a}$ ordem.

Vale comentar que o este filtro foi projetado utilizando o software da Microchip denominado FilterLab. As Figuras 3.14 e 3.15 também são retiradas do software FilterLab.

\subsubsection{Placa de Desenvolvimento}

Para a aquisição e processamento de sinais e cálculo de consumo, foram utilizadas duas placas de desenvolvimento da Texas Instruments denominadas Stellaris Launchpad. A Figura 3.16 ilustra a Stellaris Launchpad. 


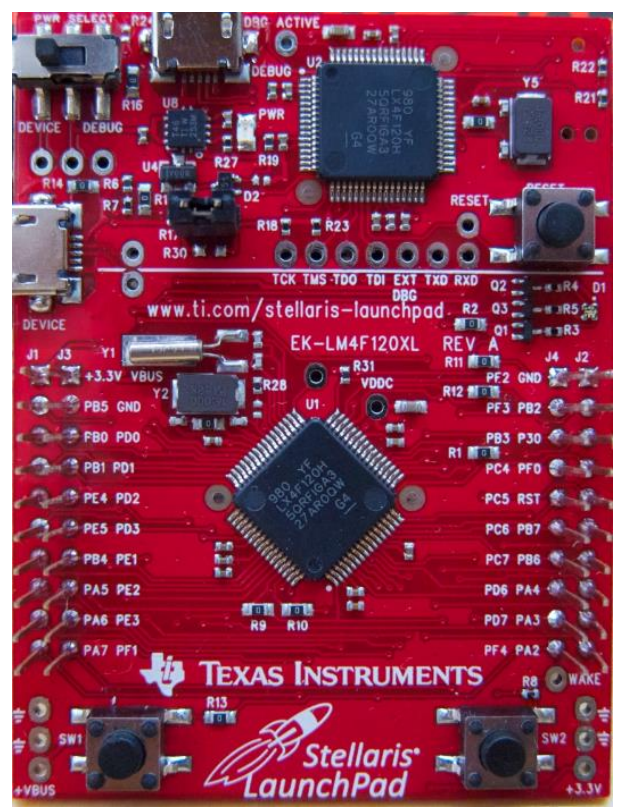

Figura 3.16 - Placa de desenvolvimento Stellaris Launchpad da Texas Instruments.

Estas placas possuem um microcontrolador ARM Cortex-M4, modelo LM4fH5QR, de $80 \mathrm{MHz}$ e 32 bits, com 256 kB de memória flash e 32 kB de SRAM. Possui também 12 canais A/D com 12 bits de resolução e comunicação UART. As portas de entrada e saída deste microcontrolador são de $3.3 \mathrm{~V}$, porém, possui um terminal de saída de $5 \mathrm{~V}$, que foi utilizado para alimentação do LCD de 16X2.

O hardware completo, descrito anteriormente com as placas de desenvolvimento adaptadas, pode ser visto na Figura 3.17. E seu diagrama de blocos é ilustrado na Figura 3.18. 


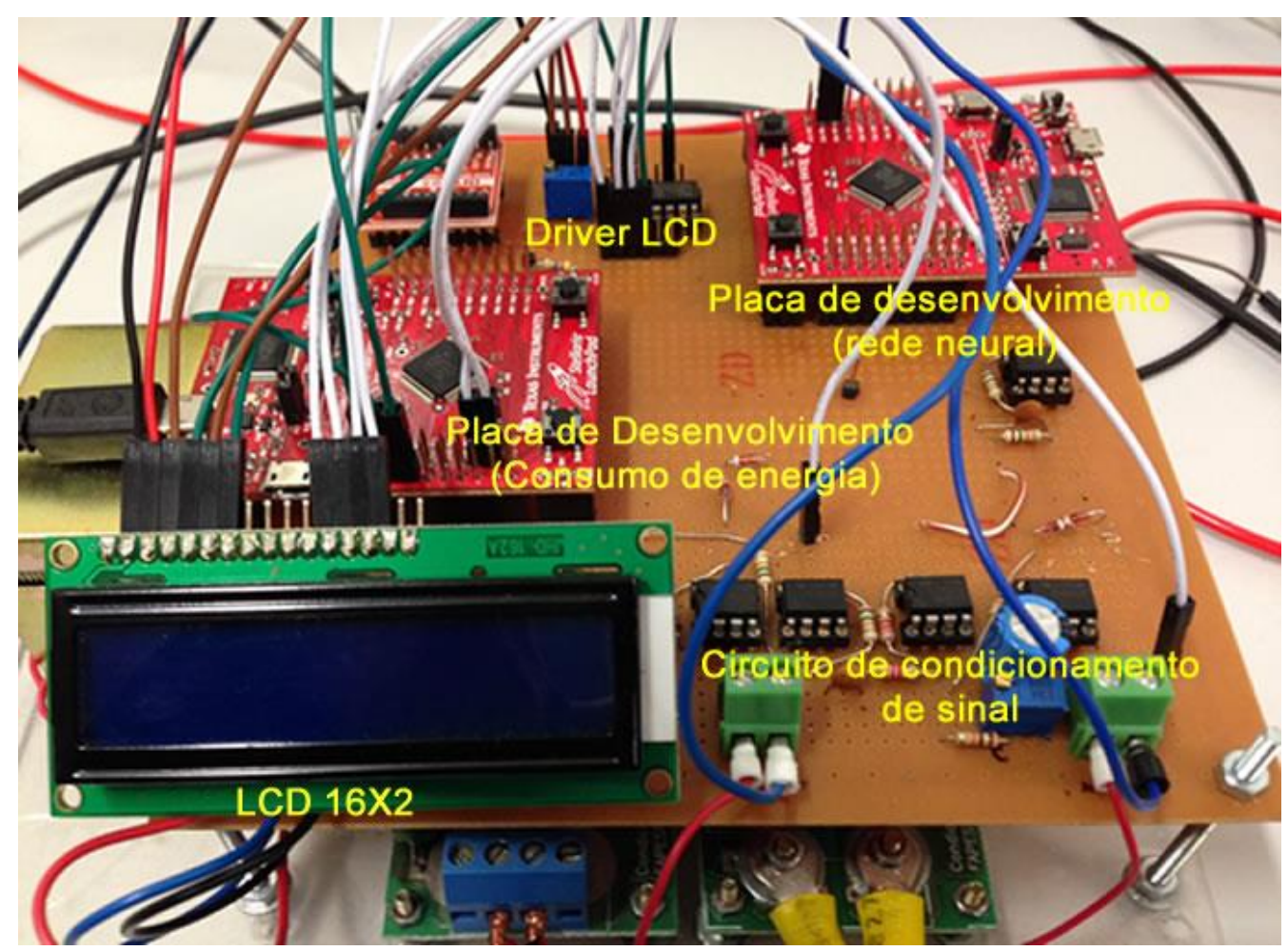

Figura 3.17 - Hardware completo.

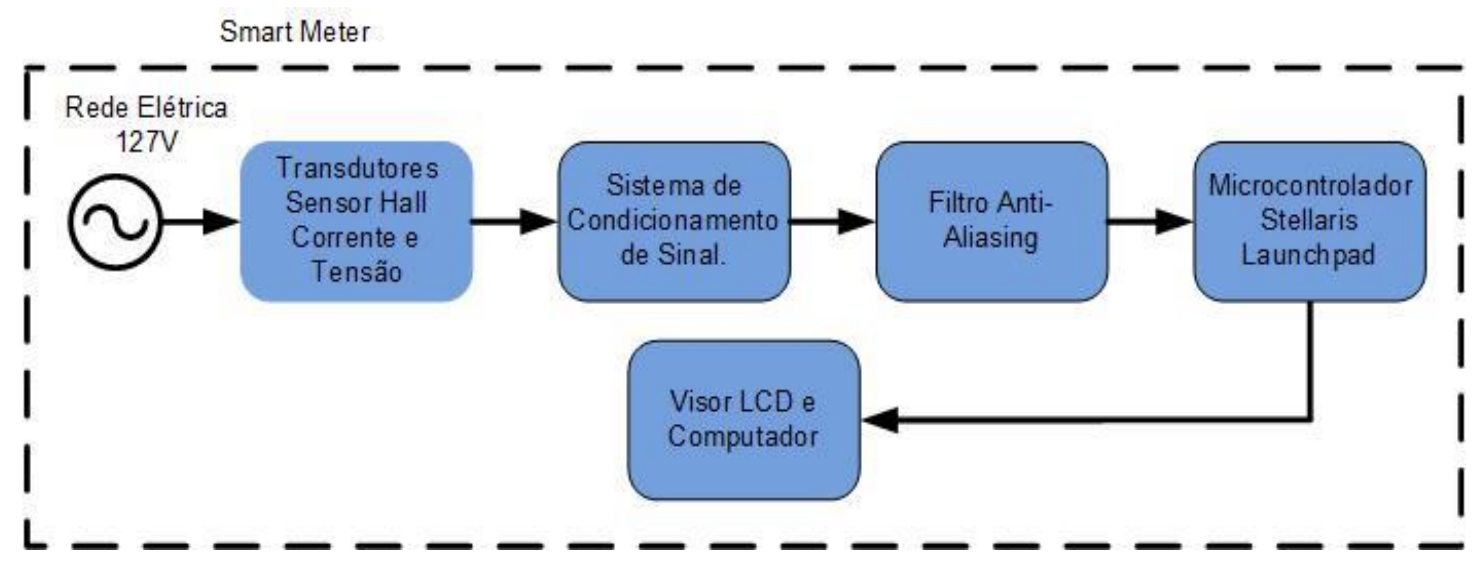

Figura 3.18 - Diagrama de blocos do Smart Meter.

\subsubsection{Aquisição dos Sinais de Corrente e Tensão}

Após todo o processo de condicionamento de sinal, o sinal passa pelo conversor $A / D$ do microcontrolador.

Para a realização dos primeiros testes do conversor $A / D$, o microcontrolador foi configurado para obter uma taxa de aquisição de até $6666 \mathrm{~Hz}$, utilizando um clock 
de $40 \mathrm{MHz}$. Os sinais de tensão e corrente aquisitados podem ser vistos nas Figuras 3.19 e 3.20 , respectivamente.

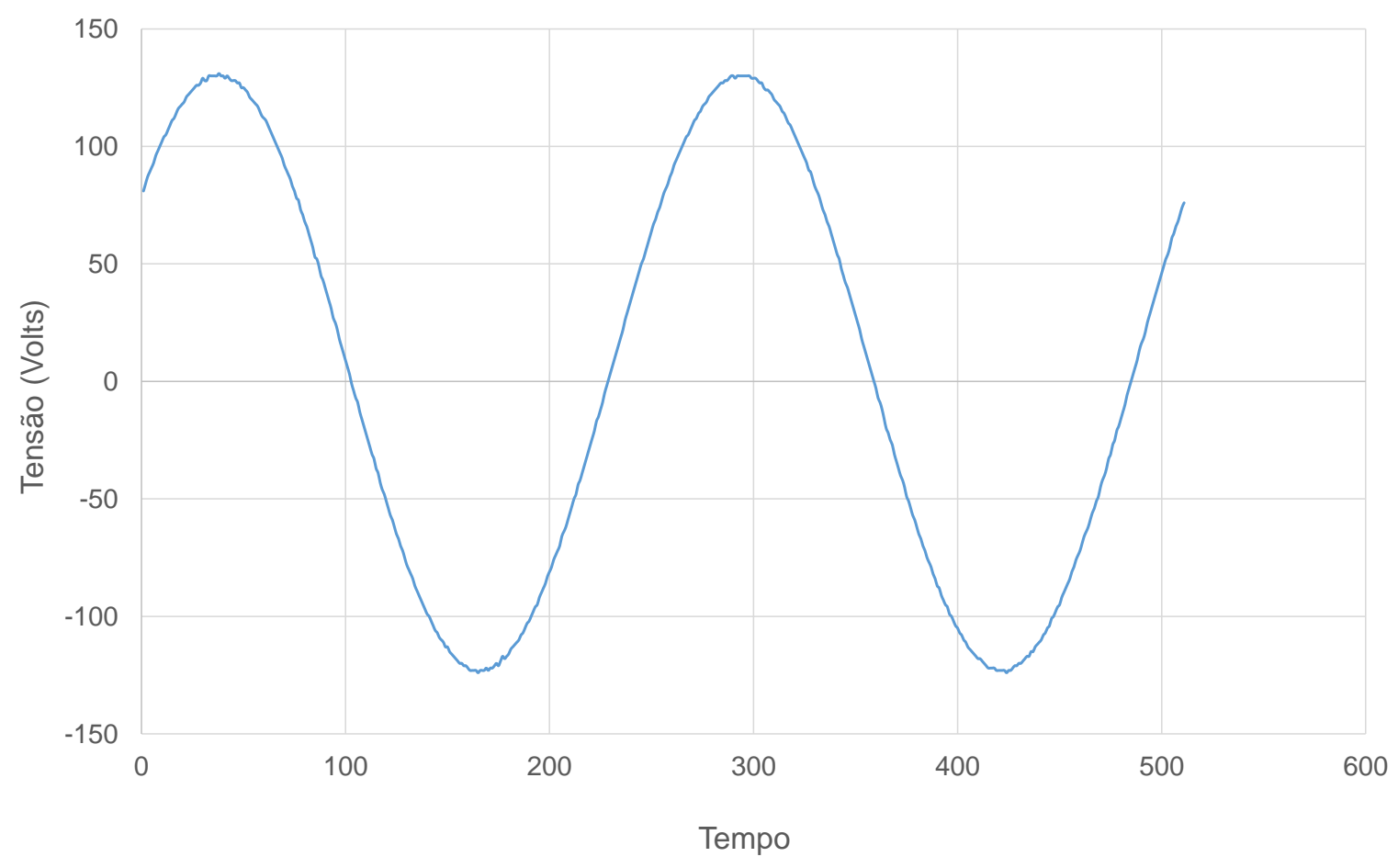

Figura 3.19- Sinal de tensão aquisitado. 


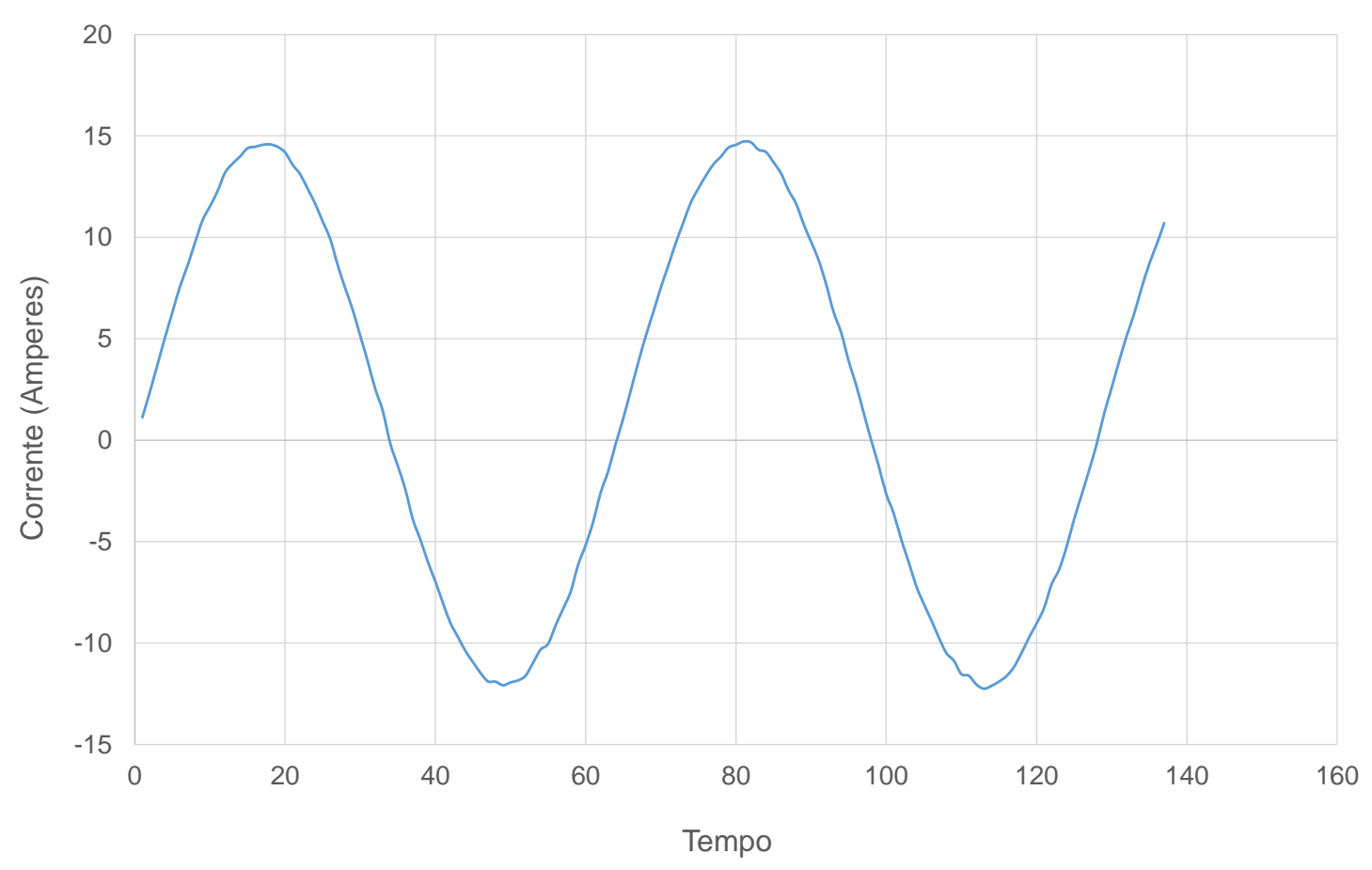

Figura 3.20 - Sinal de corrente aquisitado.

Durante o processo de aquisição do sinal, fez-se necessária a verificação se - mesmo estava com as amplitudes corretas, ou seja, se a saída do condicionamento de sinal estava de acordo com o sinal de entrada dos sensores. Esta verificação comprovou que o sistema de aquisição necessitava de mais um ajuste de offset, para que a amplitude do sinal se corrigisse. Para isto, foi necessário acrescentar um capacitor eletrolítico de $100 \mu \mathrm{F}$ juntamente com um resistor variável de $10 \mathrm{k} \Omega$ na entrada inversora do amplificador operacional. Sendo assim, este ajuste foi realizado para os dois sinais aquisitados.

Vale comentar que os valores das saídas do microcontrolador são em bits. Sendo assim, para amostragem correta dos valores inseridos na entrada do sistema, são então necessários cálculos de conversão de escalas. 


\subsubsection{Transformada Discreta de Fourier Embarcada}

A transformada Discreta de Fourier foi utilizada neste projeto para discretização do sinal aquisitado. Este processo foi feito para utilizar as componentes harmônicas necessárias para o método de detecção de cargas conectadas ao sistema.

A utilização da Transformada Discreta de Fourier para este projeto é devido à facilidade de sua implementação, não necessitando de bibliotecas prontas, como é - caso da Transformada Rápida de Fourier. A equação (3.5) se trata da Transformada Discreta de Fourier.

$$
x[k]=\sum_{n=0}^{N-1} x[n] \cdot W_{N}^{k \cdot n} ; \quad 0 \leq k \leq N-1
$$

onde: $x[n]$ é a sequência discreta no domínio do tempo que descreve os valores amostrados da variável contínua $x(t)$ e $N$ é o número de amostras da sequência da entrada. O código da DFT embarcada no microcontrolador é apresentado no Apêndice B.

Para o primeiro teste realizado com a Transformada Discreta de Fourier embarcada, utilizou-se um sinal de tensão aquisitado com uma frequência de $60 \mathrm{~Hz}$, que corresponde à frequência fundamental. Este se comportou de forma bastante satisfatória, apresentando um resultado correspondente à componente harmônica fundamental, como mostra a Figura 3.21. 


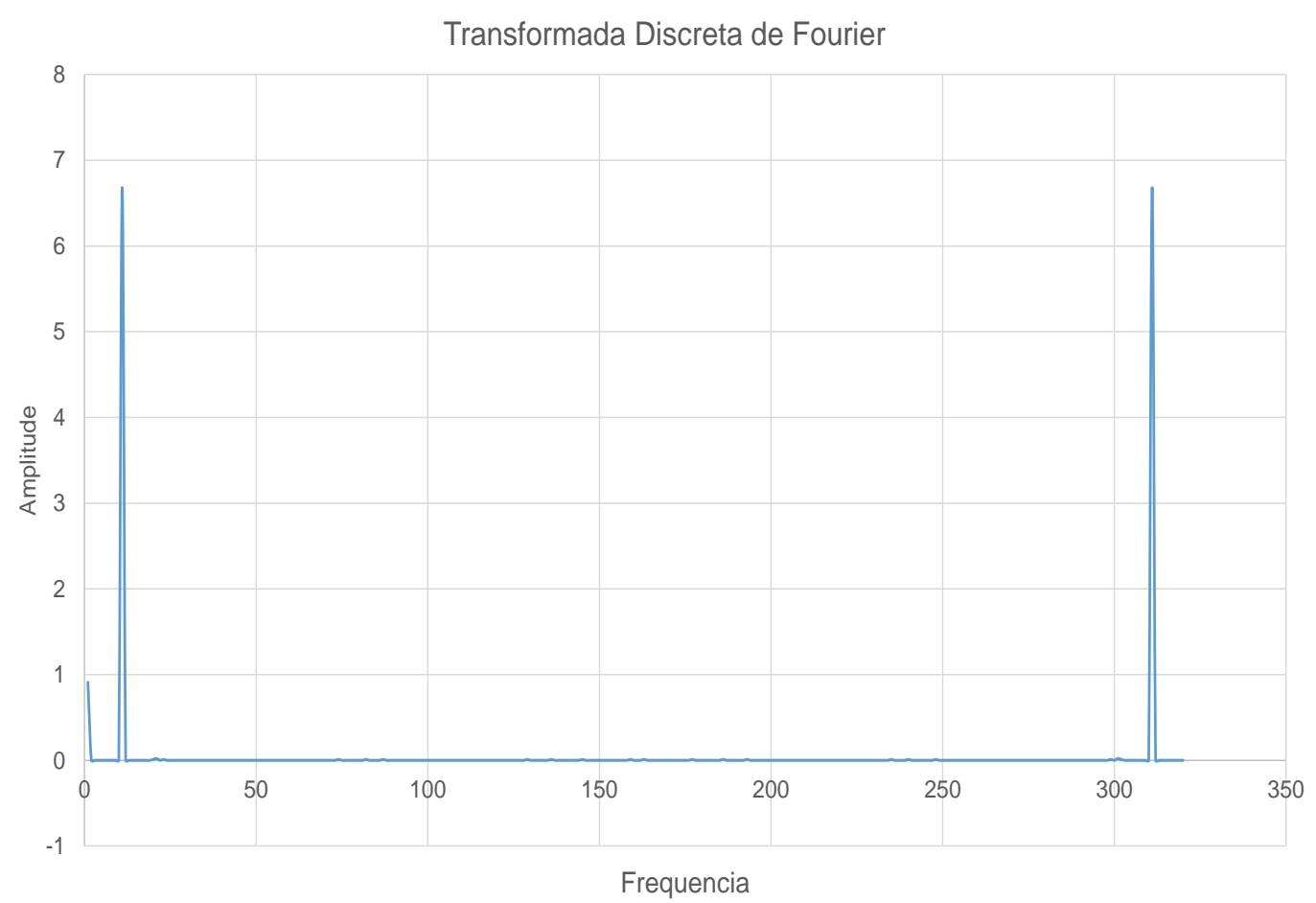

Figura 3.21 - Teste da transformada discreta de Fourier.

Os resultados dos testes com cargas serão apresentados nos próximos tópicos relacionados a testes e validações do sistema. 


\section{Metodologia dos Testes e Validação}

\subsection{Introdução}

Este capítulo é destinado à apresentação da metodologia aplicada no projeto para os testes de consumo de energia e identificação de cargas residenciais, por meio de redes neurais artificiais.

\subsection{Medidor de consumo de energia}

Todo medidor de consumo de energia mede a potência ativa gerada pelas cargas conectadas à rede elétrica. Esta potência ativa é calculada com base na tensão da rede elétrica $v(t)$ aplicada a uma carga, e na corrente $i(t)$ que percorre essa carga. Como ambos os sinais são sinusoidais em função do tempo a potência ativa é dada pela equação (4.1) (Tulcidás, 2010).

$$
P=\frac{1}{T} \int P(t) \cdot d t
$$

onde: $P(t)$ é igual ao produto da tensão $v(t)$ pela corrente $i(t)$; sendo assim a equação pode ser expressa como em (4.2) (Tulcidás, 2010). 


$$
P=\frac{1}{T} \int v(t) \cdot i(t) \cdot d t
$$

ou seja, pode-se dizer que a potência ativa é calculada por meio da integral ao longo do tempo do produto da tensão $v(t)$ pela corrente $i(t)$. A expressão (4.3) mostra a equação utilizada (Tulcidás, 2010).

$$
E=\sum_{i=0}^{t} V_{i} \cdot l_{i} \cdot T s
$$

onde: $V_{i}$ e $l_{i}$ são a tensão e a corrente instantânea, e Ts é o período de amostragem.

Nesta tese utilizou-se uma taxa de amostragem de 256 pontos por ciclo, ou seja, a frequência de amostragem é igual a $2603 \mathrm{~Hz}$. Sendo assim, o valor do período de amostragem é $T s=1 / F s$.

Como dito anteriormente, o cálculo da potência consumida em tempo real (em kW) é dado pelo produto da tensão com a corrente e o período de amostragem. Este produto é multiplicado pelo período de amostragem porque é o intervalo de tempo entre amostras e é dividido por 1000 para a conversão em kW, assim como realizado em Tulcidás, (2010). Portanto, o cálculo utilizado no microcontrolador é mostrado na equação (4.4):

$$
P=\sum_{i=0}^{t} \frac{V_{i} \cdot l_{i} \cdot T s}{1000}
$$

Após serem feitos os cálculos de consumo de energia, foi inserido o cálculo do valor gasto até o momento da leitura. Para isso, faz-se necessário saber o valor referente a $1 \mathrm{Kwh}$ cobrado pela concessionária de energia. Neste caso, utilizou-se o valor cobrado pela Companhia Paulista de Força de Luz (CPFL), que é de 
$R \$ 0,31686$. Para o cálculo de consumo de energia em Reais $\left(C_{R \$)}\right.$, basta então multiplicar o valor do consumo em Kwh por $\mathrm{R} \$$ 0,31686, como mostra a equação (4.5).

$$
C_{R \$}=P \cdot 0,31686
$$

A Figura 4.1 mostra o LCD com os valores de consumo de energia e o valor gasto em reais.

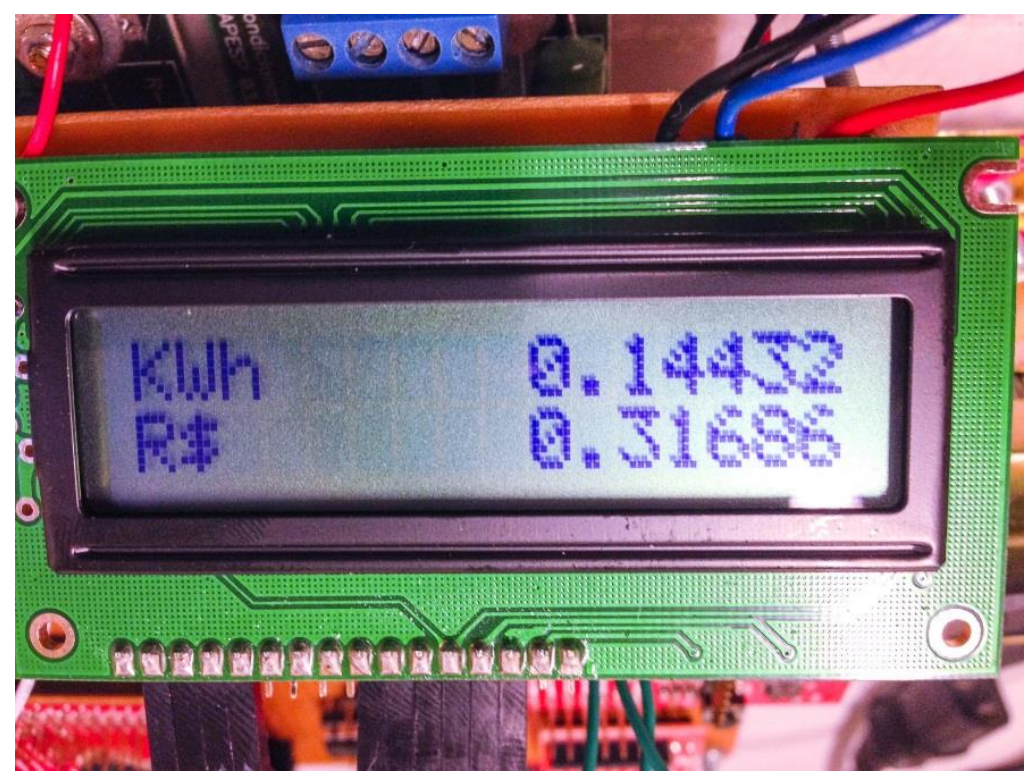

Figura 4.1 - Teste do sistema de medição do consumo.

\subsection{Detecção dos distúrbios de VTCD}

No decorrer do desenvolvimento do Smart Meter proposto, observou-se a possibilidade de realizar a detecção dos distúrbios de VTCD, devido ao fato do medidor realizar leituras da forma de onda de tensão e corrente. Dessa forma, foram realizados testes utilizando o simulador de fonte de tensão e corrente da Doble para gerar as variações nos valores RMS da tensão. Como pode ser visto nas Figuras 4.2 e 4.3 relacionadas ao sinal de saída da fonte e o aquisitado pelo Smart Meter. 


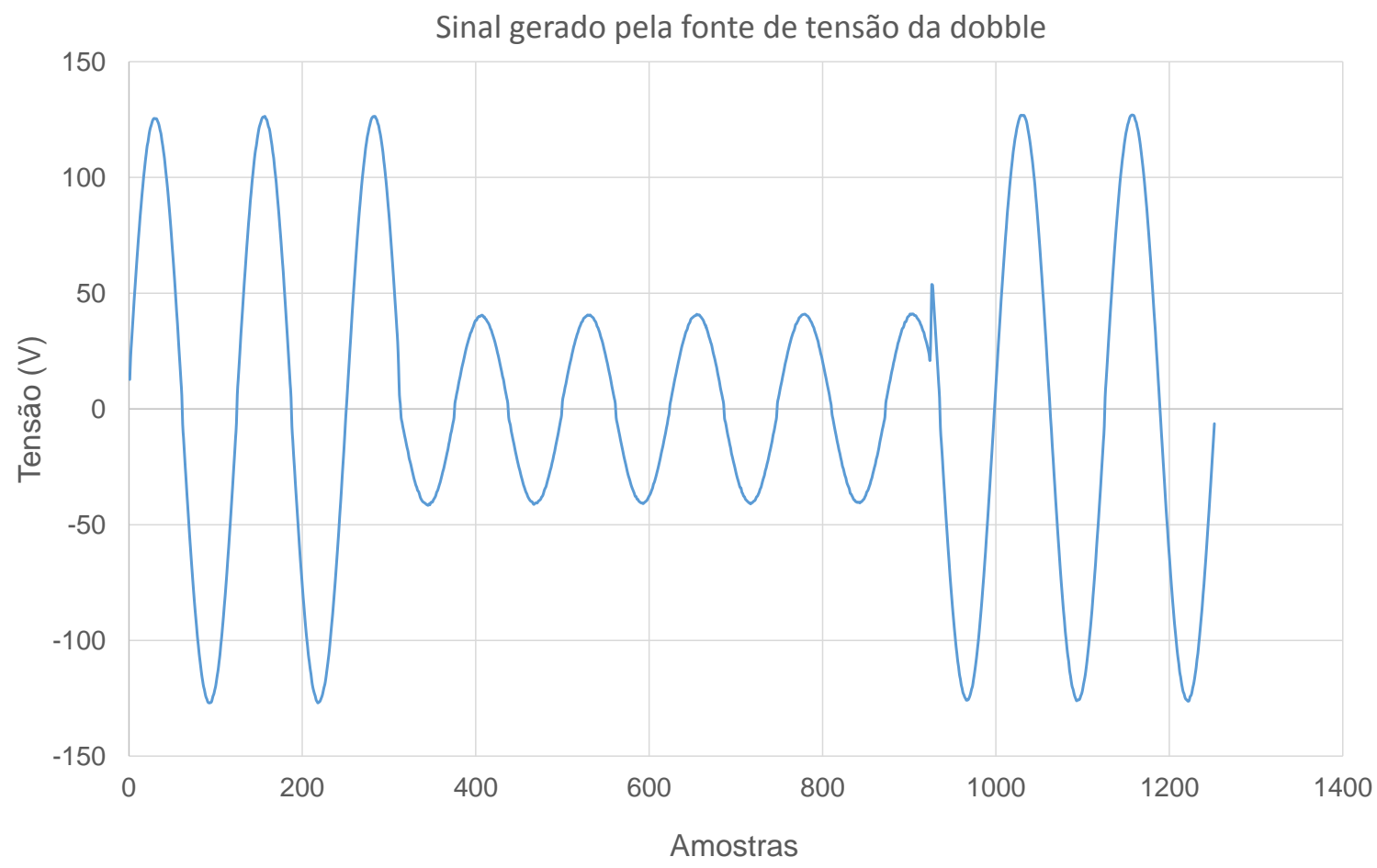

Figura 4.2 - Sinal de saída do equipamento da Doble.

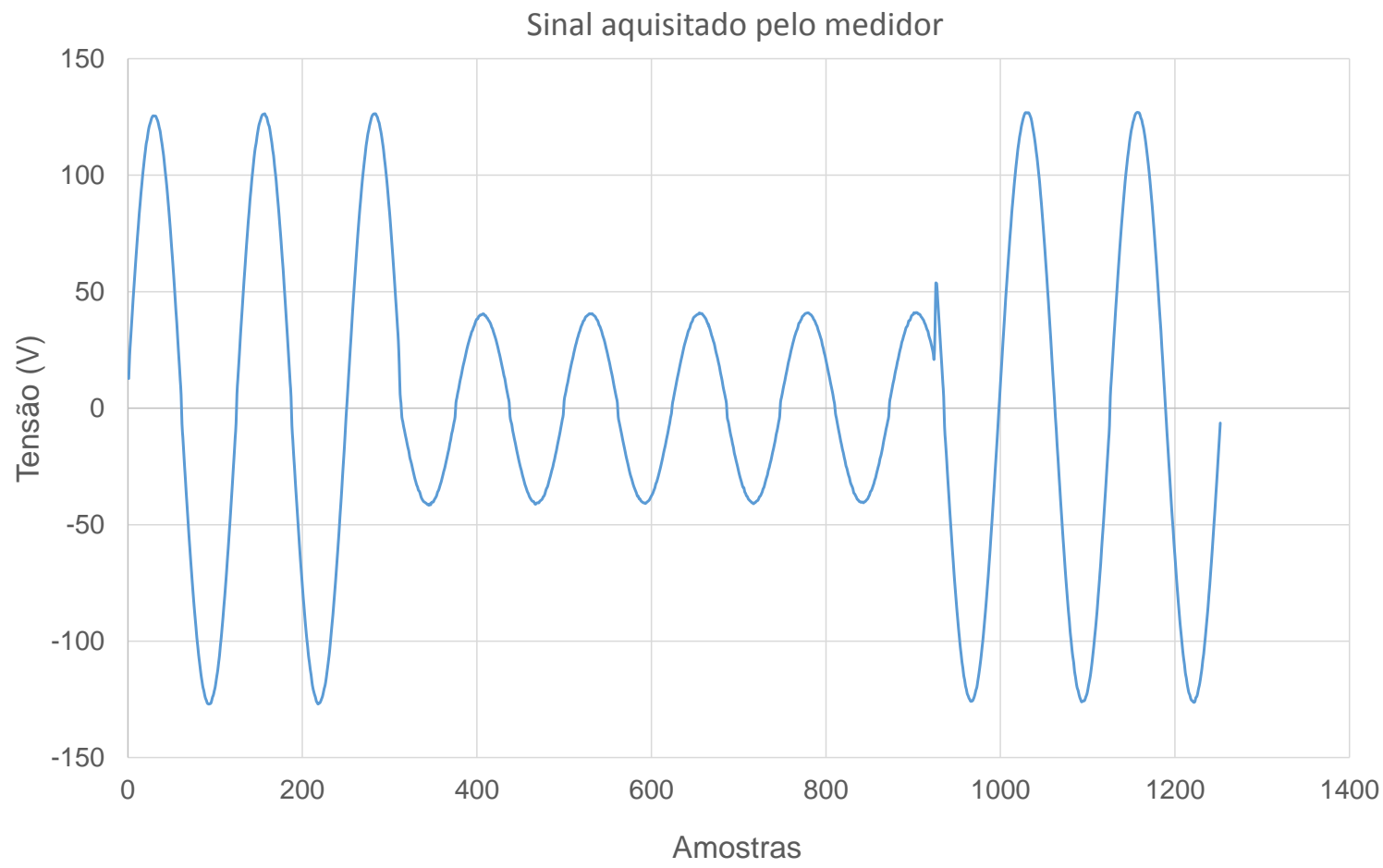

Figura 4.3-Sinal medido pelo Smart Meter. 
Como ilustrado nas Figuras 4.2 e 4.3, o Smart Meter proposto pode ser usado para caracterização de distúrbios de VTCD, entretanto, o foco dessa tese é a análise de distorções harmônicas, sendo relatado no próximo tópico.

\subsection{Identificação de cargas}

De acordo com o sistema proposto, a metodologia utilizada para os testes de identificação de cargas seguiu os seguintes passos: escolha das cargas de acordo com a disponibilidade do laboratório e utilização de um analisador de qualidade de energia da Fluke modelo 435 para comparação com o medidor proposto.

A escolha das cargas utilizadas foi feita de acordo com a disponibilidade do laboratório e também da facilidade de adaptação ao medidor. Sendo assim, foram escolhidas lâmpadas incandescentes e compactas e um motor monofásico (ventilador), sendo esta última carga utilizada apenas nas aquisições com o medidor proposto. Para estas análises, foi utilizada uma bancada de cargas contendo bocais para lâmpadas incandescentes e compactas, como pode ser visto na Figura 4.4. 


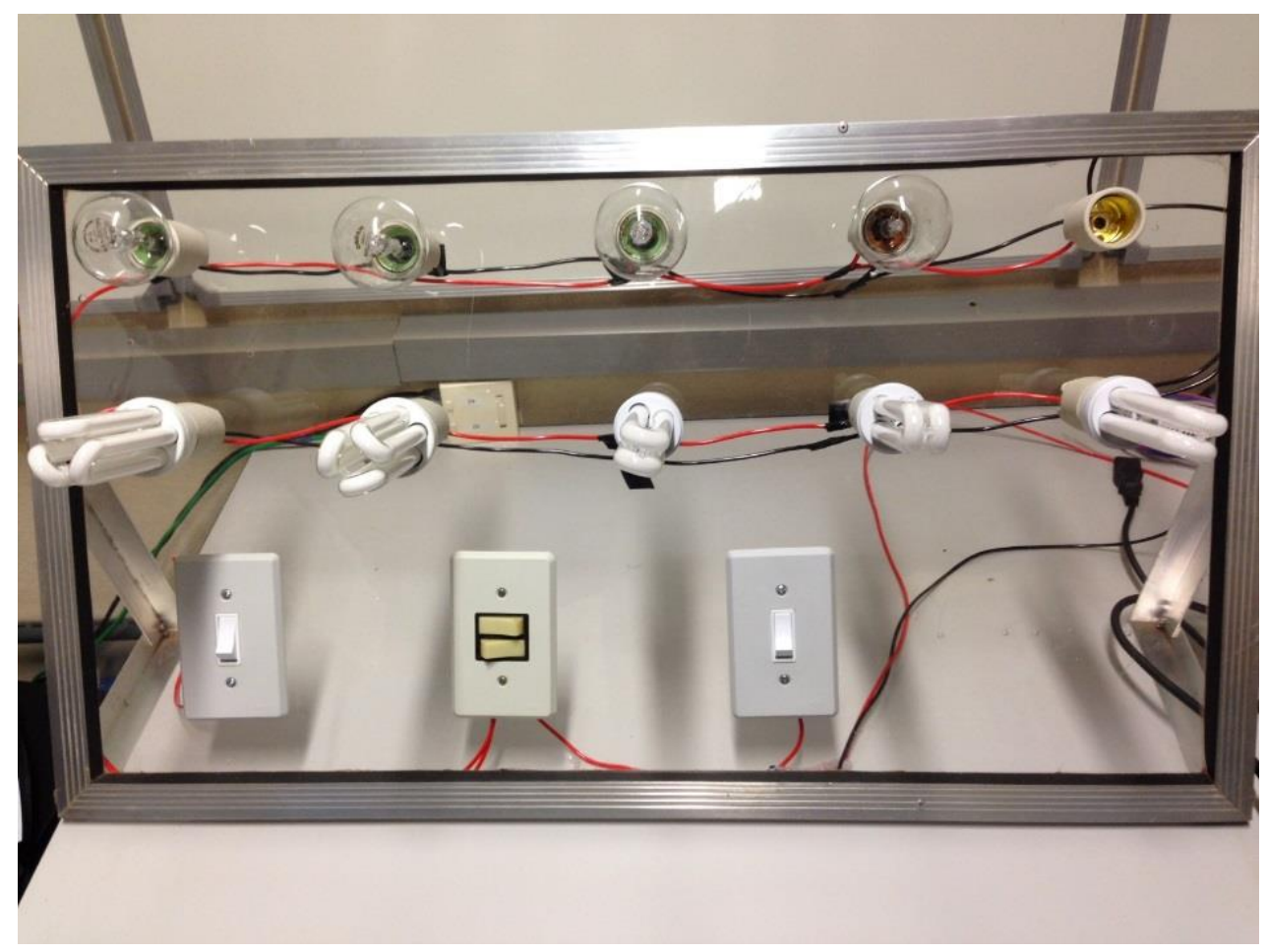

Figura 4.4 - Bancada de cargas para testes.

Seguindo o contexto, foram coletados dados de corrente elétrica com o analisador de qualidade de energia da Fluke. Segundo as especificações deste equipamento, ele realiza aquisições de sinais contendo 1000 pontos por ciclo e também realiza a transformada de Fourier que serão necessárias para os próximos passos.

A aquisição dos sinais de corrente geradas pelas cargas mencionadas foram realizadas por meio de uma garra de corrente, sendo esta colocada no fio fase que vai para a bancada de cargas.

Este procedimento foi realizado a fim de fazer as futuras comparações com o medidor proposto. Sendo assim, foram feitas aquisições dos sinais de correntes harmônicas geradas por lâmpadas incandescentes e compactas.

A forma de onda da corrente gerada pela lâmpada compacta pode ser vista na Figura 4.5, em que se pode observar uma distorção bem elevada da senóide com frequência de $60 \mathrm{~Hz}$. 


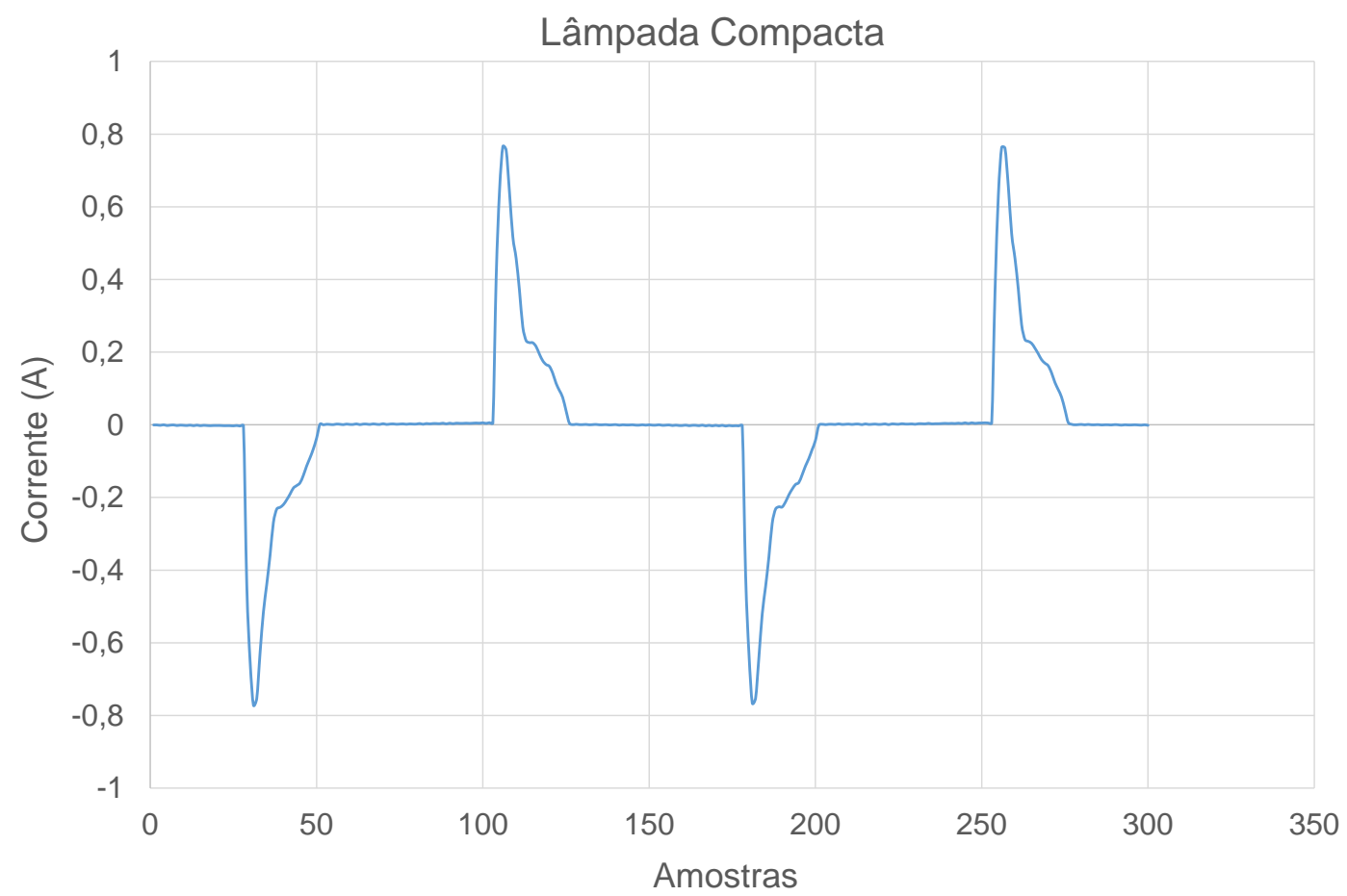

Figura 4.5 - Forma de onda da corrente de lâmpada compacta.

Na Figura 4.6 é mostrada a forma de onda da corrente gerada pela lâmpada incandescente, em que se pode observar que quase não possui distorção na senóide.

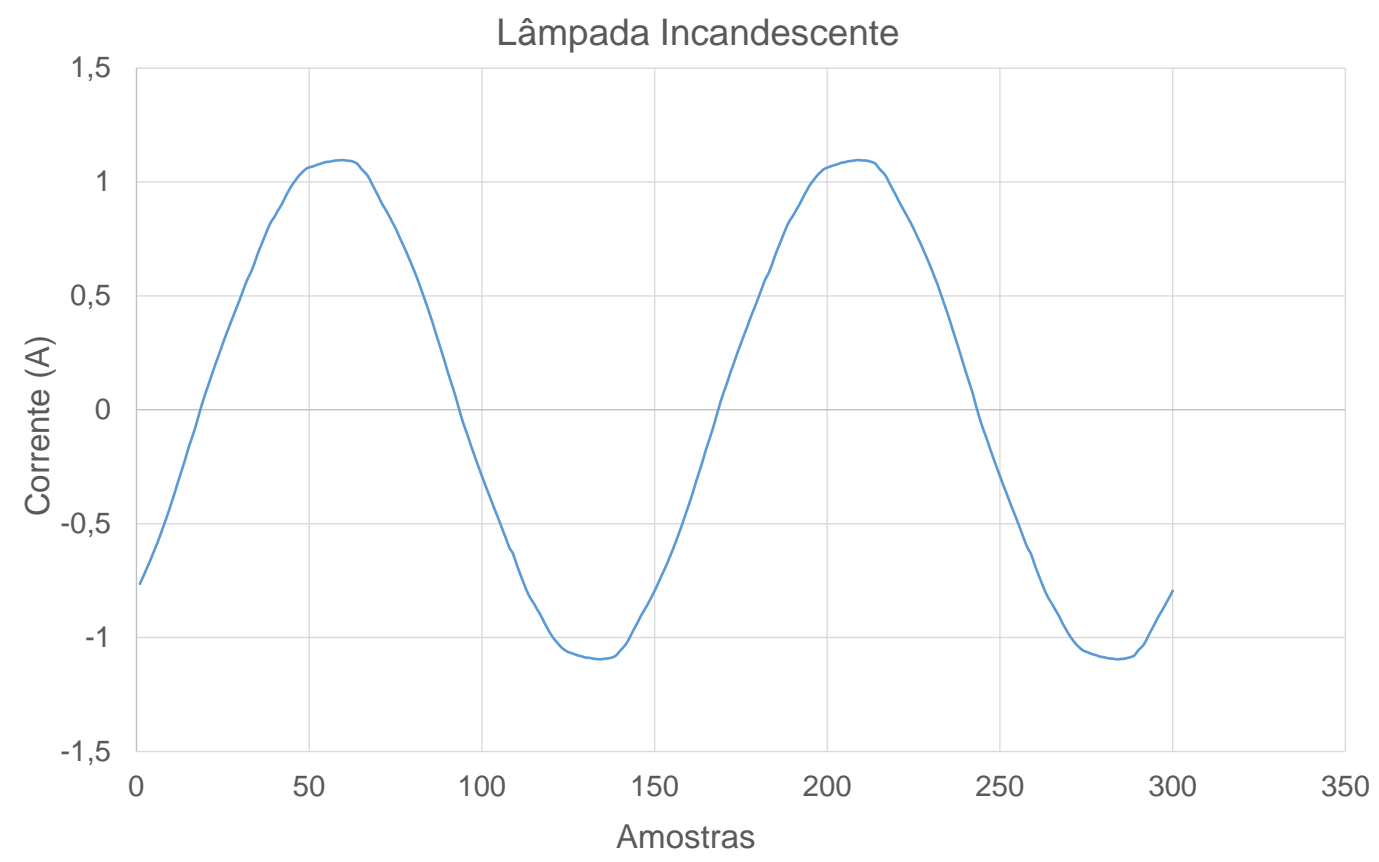

Figura 4.6 - Forma de onda da corrente de lâmpada incandescente. 
Após serem feitas as aquisições com o equipamento analisador de qualidade de energia da Fluke, foi utilizado novamente o oscilógrafo da Yokogawa ilustrado na Figura 3.3, para se obter uma outra comparação com o medidor proposto nesta tese.

A aquisição com o oscilógrafo foi realizada de forma análoga ao equipamento da Fluke, dessa forma, foram aquisitadas as senóides da corrente de lâmpadas incandescentes e compactas.

De acordo com as especificações técnicas do oscilógrafo da Yokogawa, a aquisição dos sinais possui uma taxa de amostragem de 1000 pontos por ciclo. A Figura 4.7 e 4.8 correspondem aos sinais de correntes geradas pelas lâmpadas incandescentes e compactas, respectivamente.

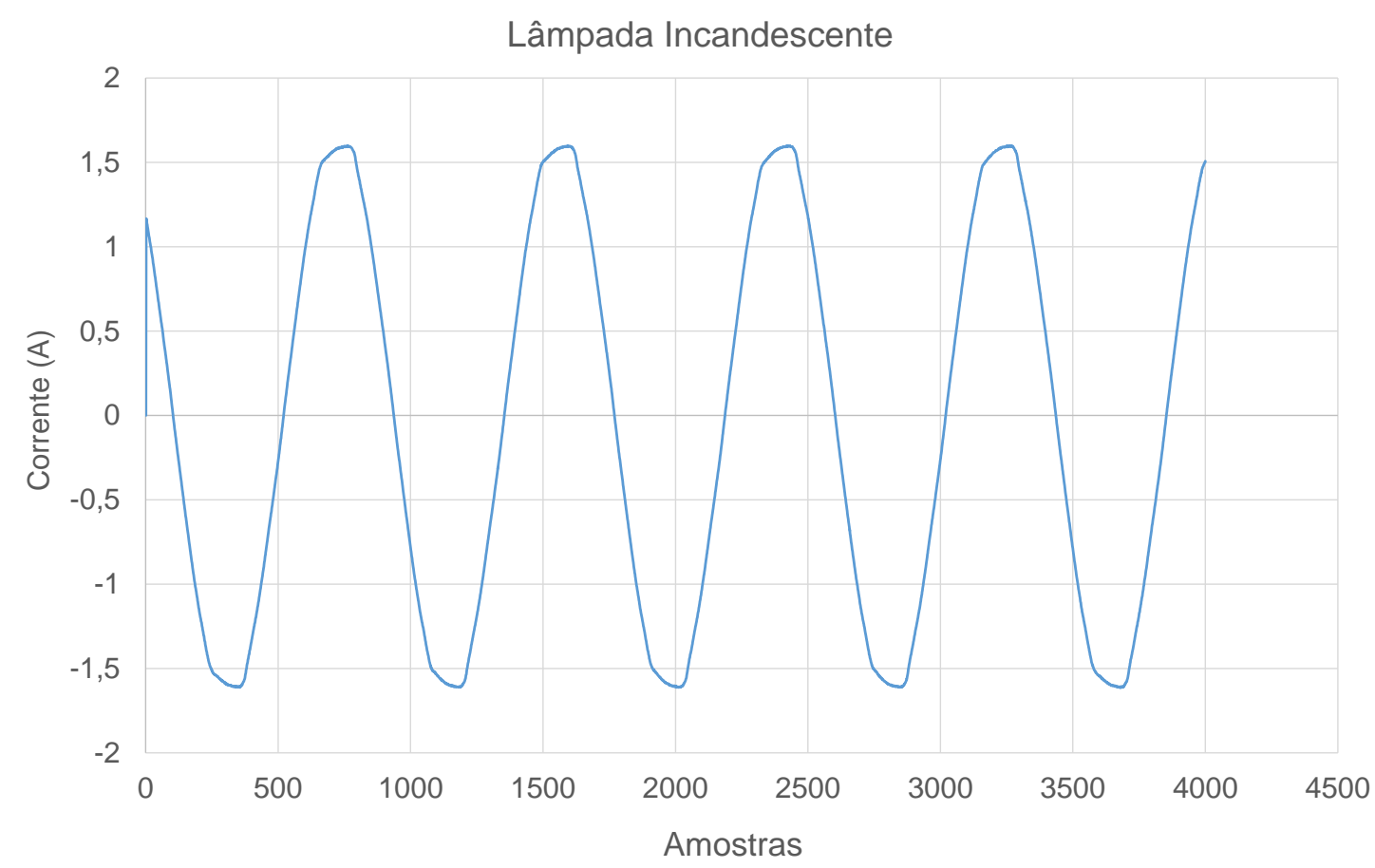

Figura 4.7 - Forma de onda da corrente de lâmpada incandescente aquisitada com oscilógrafo Yokogawa. 


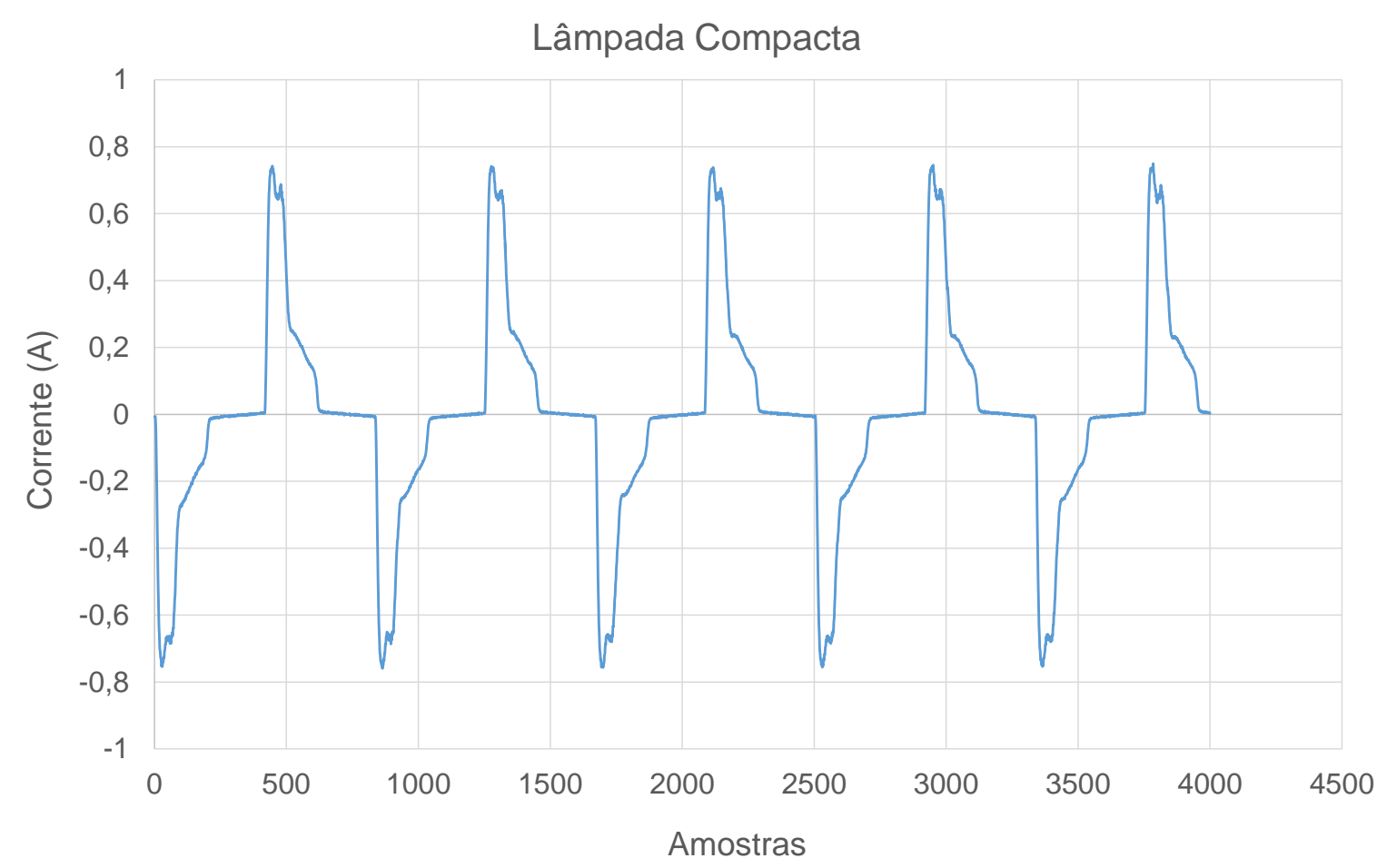

Figura 4.8 - Forma de onda da corrente de lâmpada compacta aquisitada com oscilógrafo Yokogawa.

Após serem feitas as aquisições com o equipamento da Fluke e o oscilógrafo da Yokogawa, foram realizados testes com o medidor proposto, entretanto, foram feitas aquisições dos sinais de corrente das lâmpadas incandescentes e compactas com diversas quantidades de pontos por ciclo, a fim de melhor analisar as correntes harmônicas.

A aquisição do sinal é feita por meio dos canais $A / D$ do microcontrolador que captam primeiramente os valores em bits da senóide, ou seja, ele coleta os valores de 0 a 4096 bits, pois, o conversor A/D do microcontrolador é de 12 bits. Entretanto, faz-se necessária a conversão dos valores em bits para valores reais em RMS para os cálculos propostos.

Sendo assim, primeiramente, foram feitas aquisições da corrente harmônica gerada pelas lâmpadas incandescente e compacta e um motor monofásico com 16 pontos por ciclo. As Figuras 4.9, 4.10 e 4.11 mostram os resultados das aquisições. 


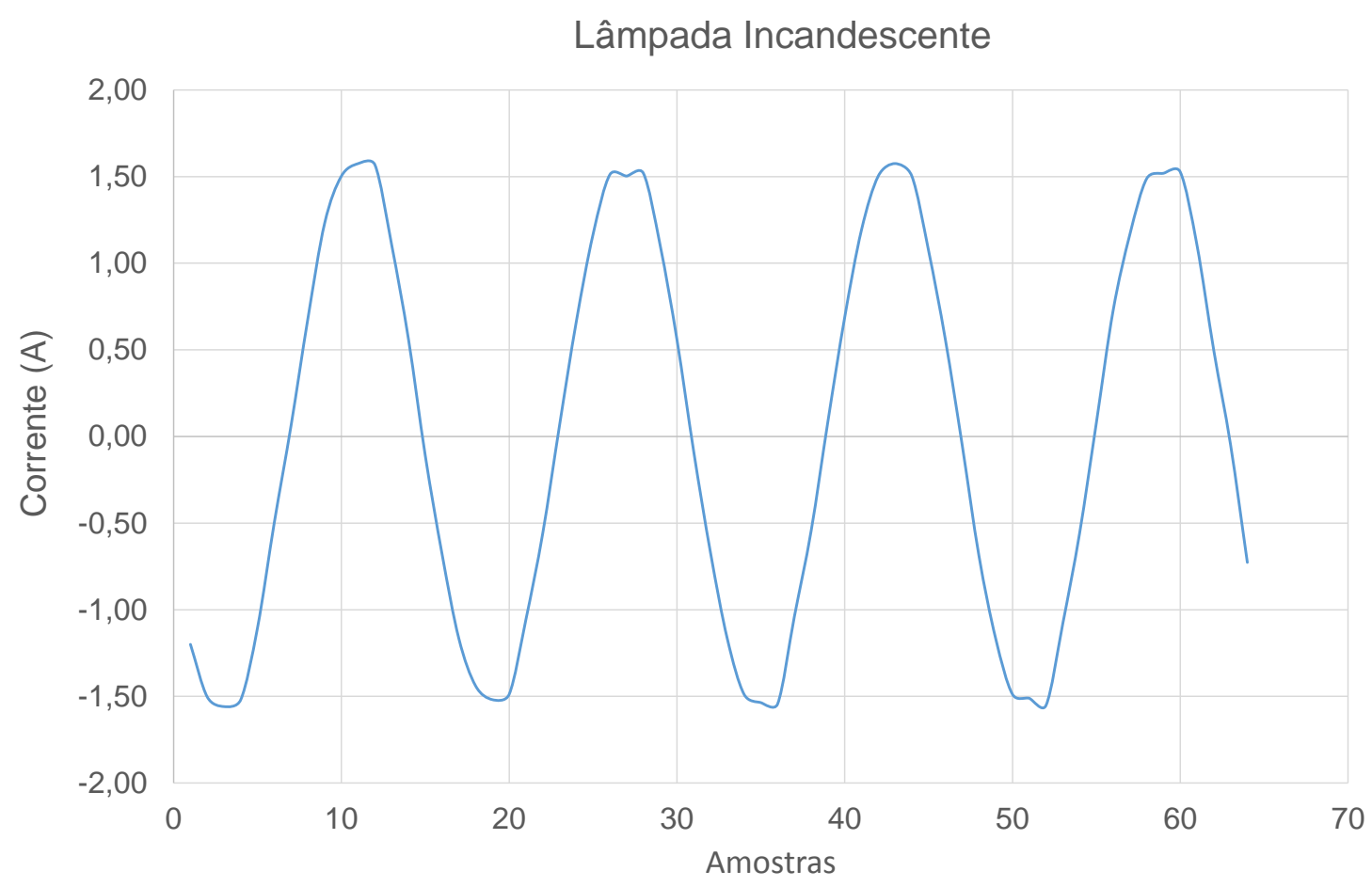

Figura 4.9 - Forma de onda da corrente de lâmpada incandescente contendo 16 pontos por ciclo.

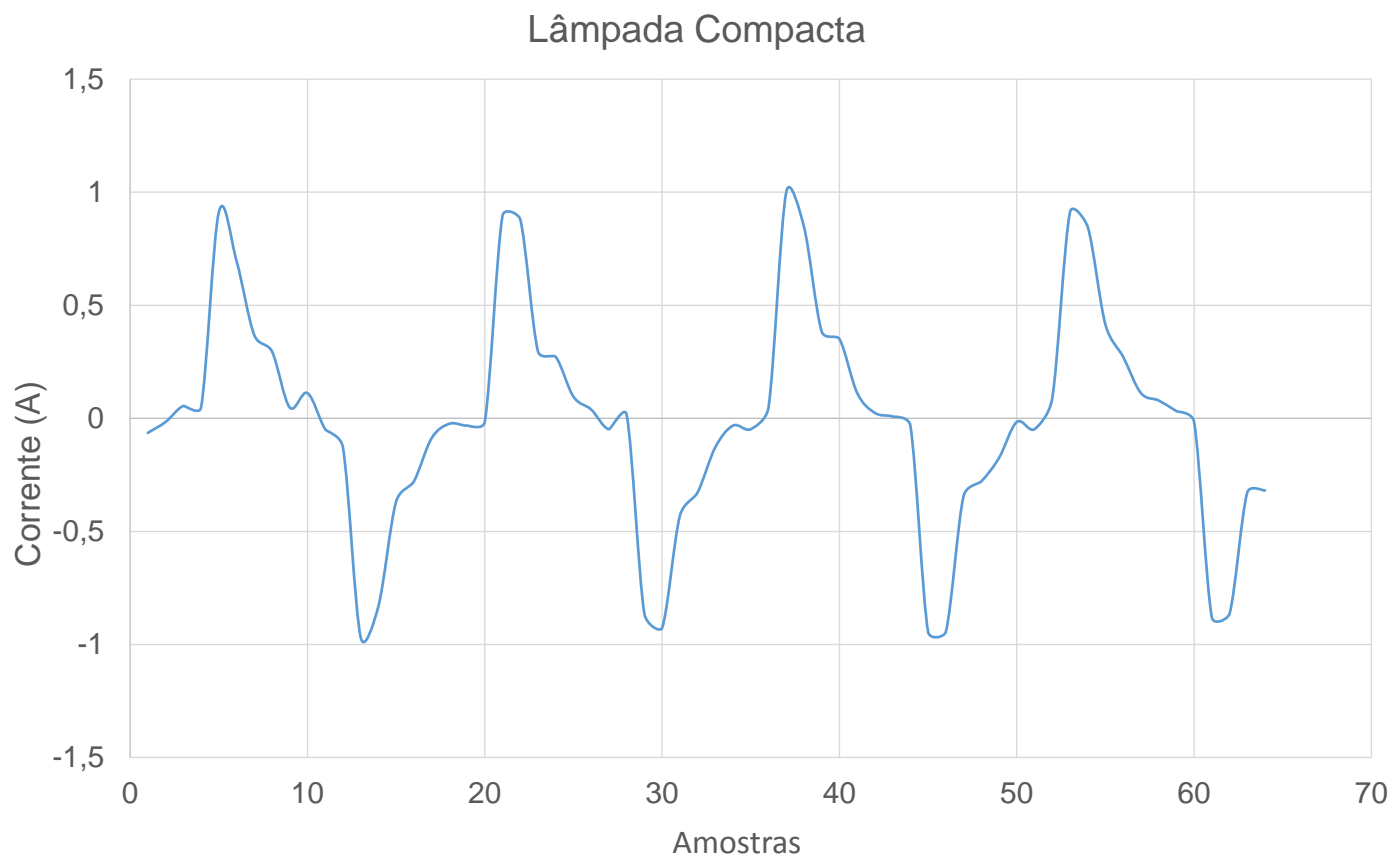

Figura 4.10 - Forma de onda da corrente de lâmpada compacta contendo 16 pontos por ciclo. 


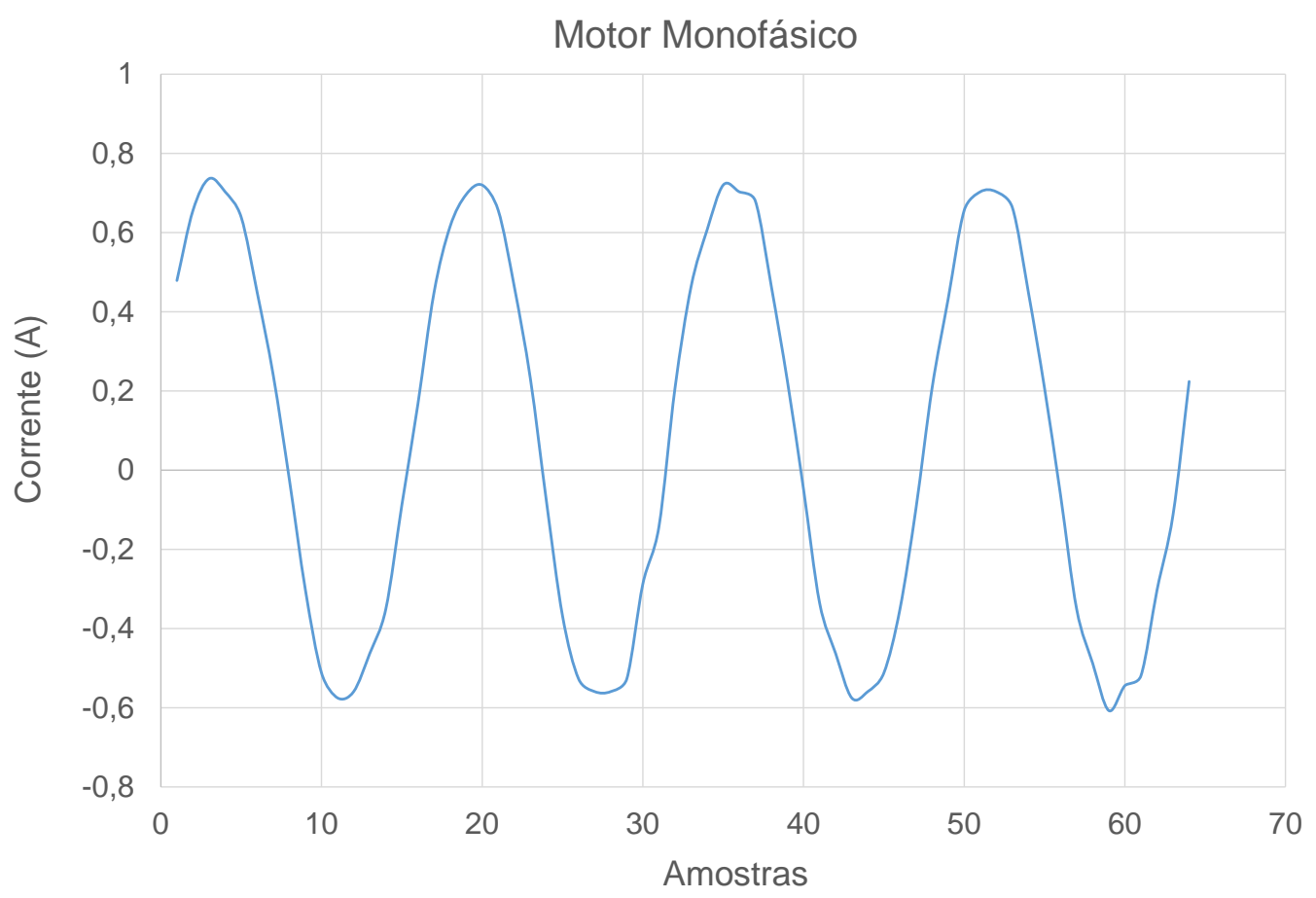

Figura 4.11 - Forma de onda da corrente de motor monofásico contendo 16 pontos por ciclo.

Seguindo a sequência dos testes, foram aquisitadas as senóides contendo 32 pontos por ciclo, e sua forma de onda é representada nas Figuras 4.12, 4.13 e 4.14 .

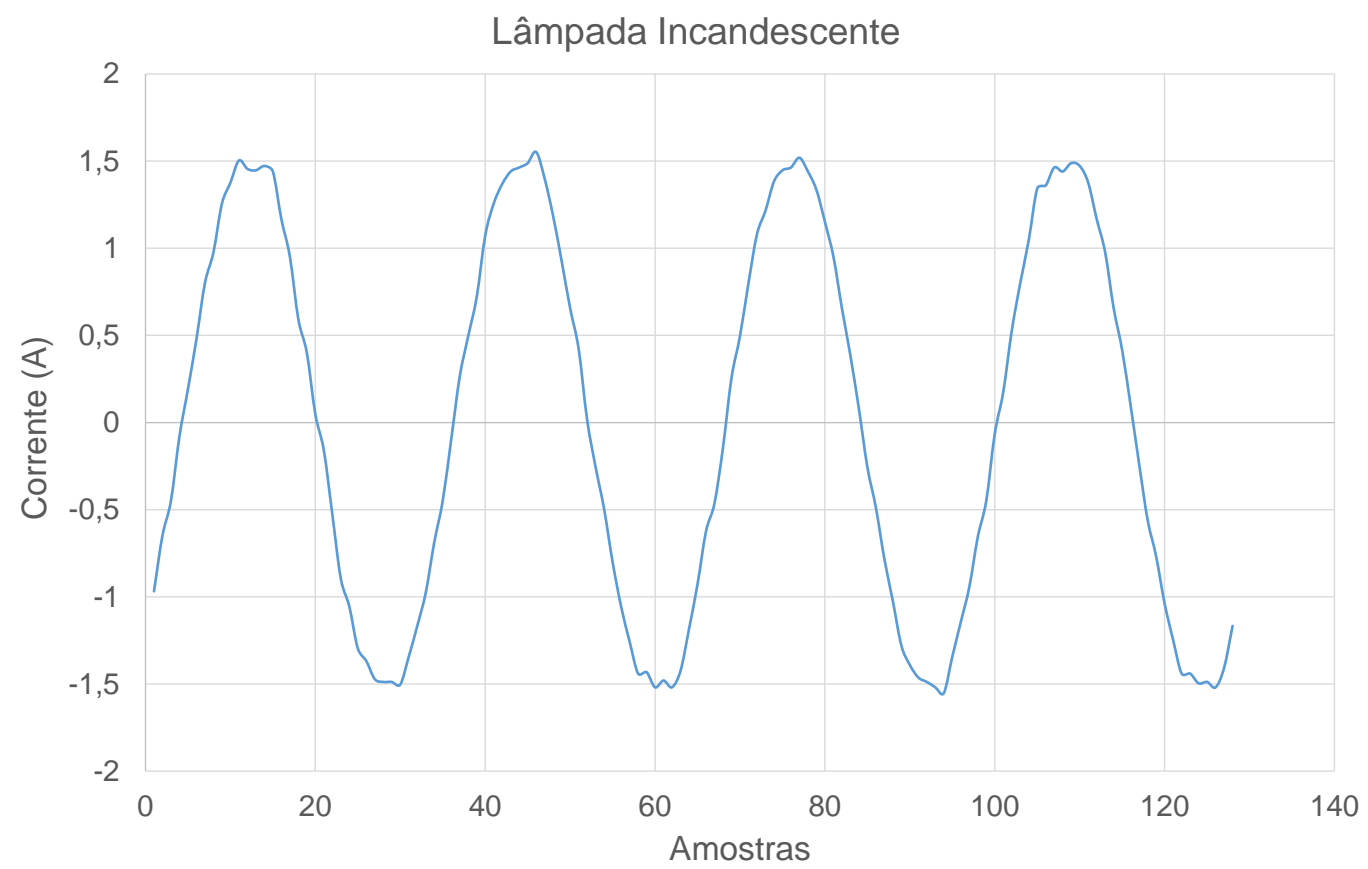

Figura 4.12 - Forma de onda da corrente de lâmpada incandescente contendo 32 pontos por ciclo. 


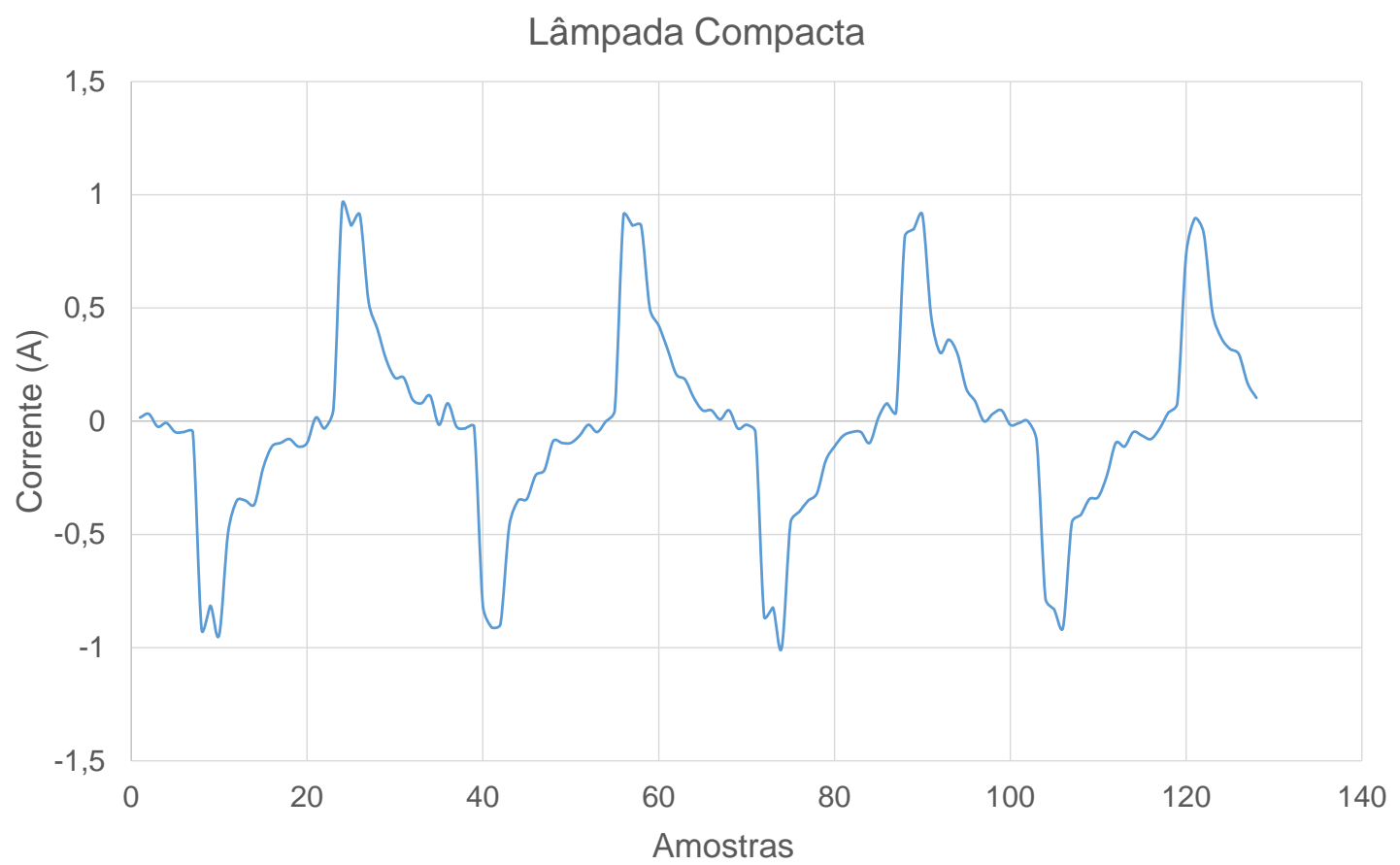

Figura 4.13 - Forma de onda da corrente de lâmpada compacta contendo 32 pontos por ciclo.

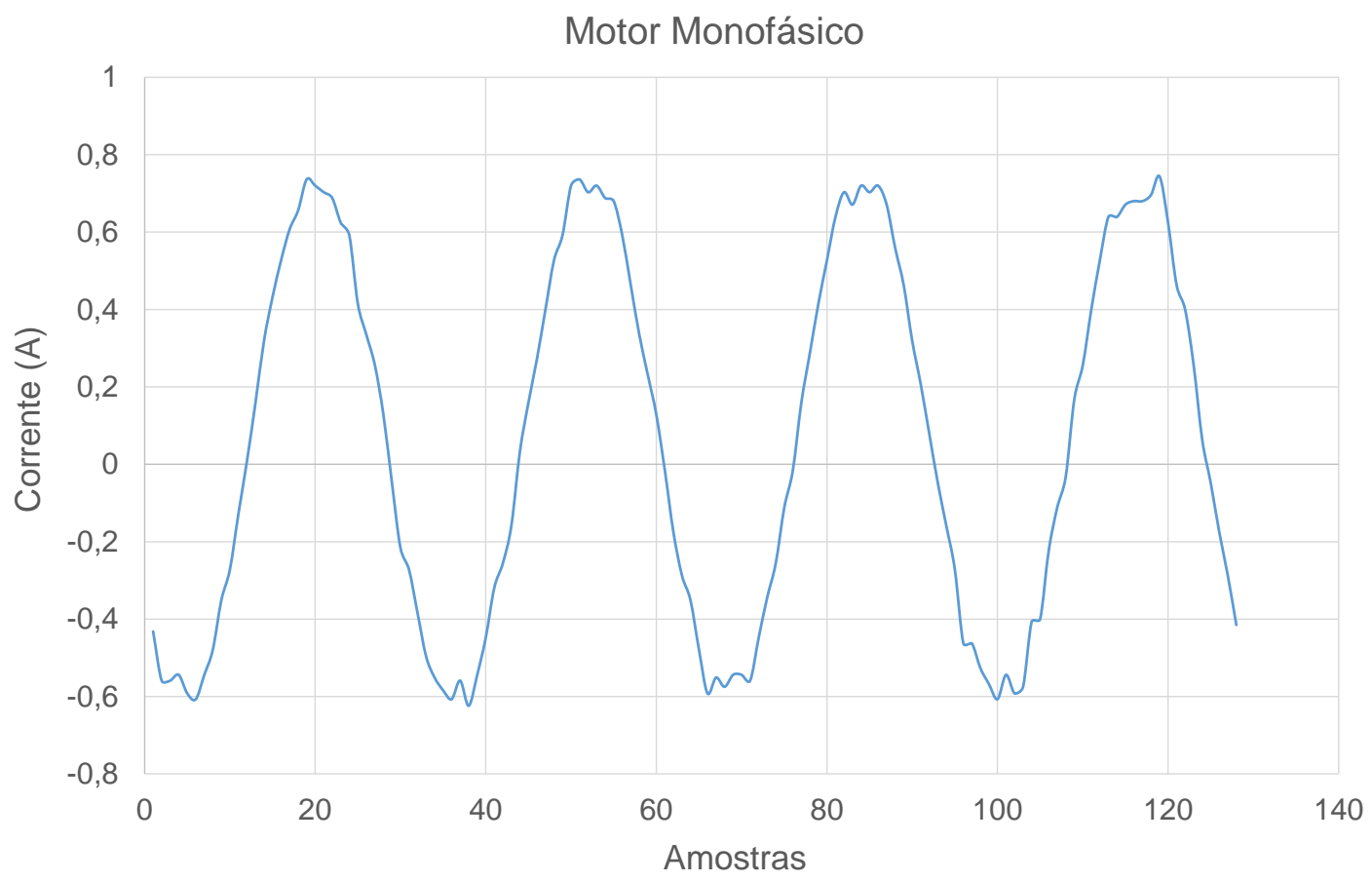

Figura 4.14 - Forma de onda da corrente de motor monofásico contendo 32 pontos por ciclo. 
Após serem feitas as aquisições para 32 pontos, foram aquisitadas as senóides contendo 64 pontos por ciclo. As Figuras 4.15, 4.16 e 4.17 ilustram as senóides aquisitadas.

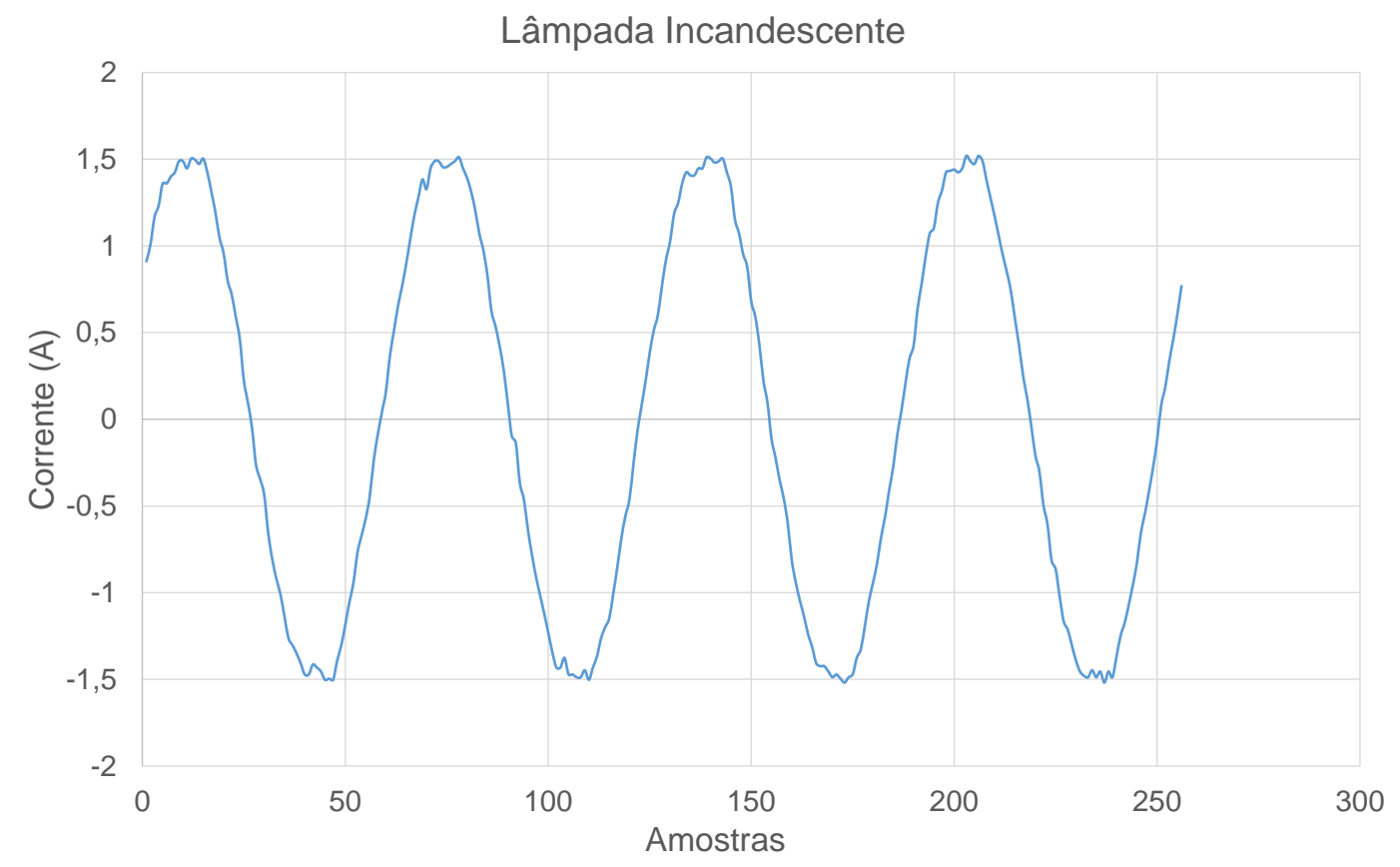

Figura 4.15 - Forma de onda da corrente de lâmpada incandescente contendo 64 pontos por ciclo.

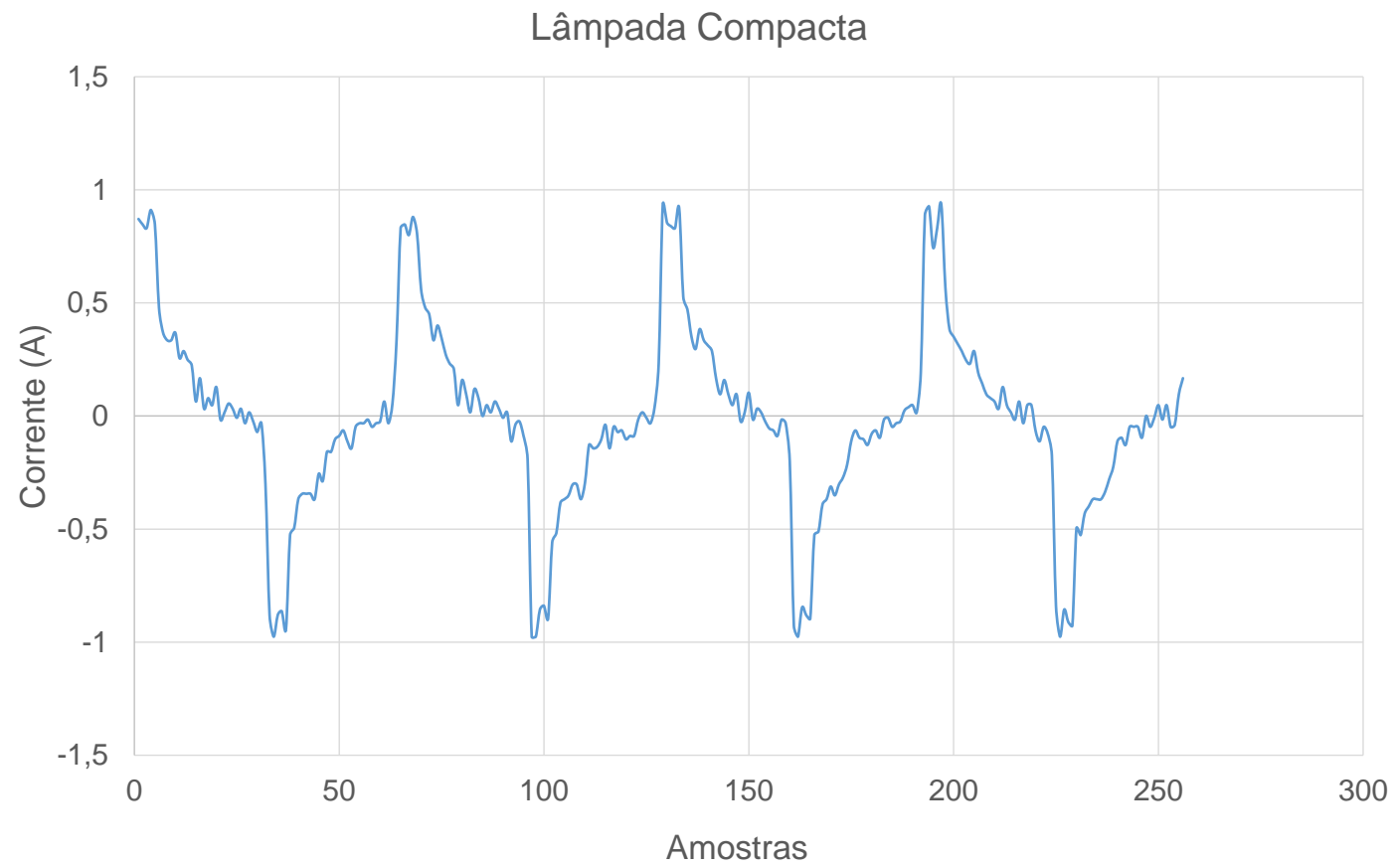

Figura 4.16 - Forma de onda da corrente de lâmpada compacta contendo 64 pontos por ciclo. 


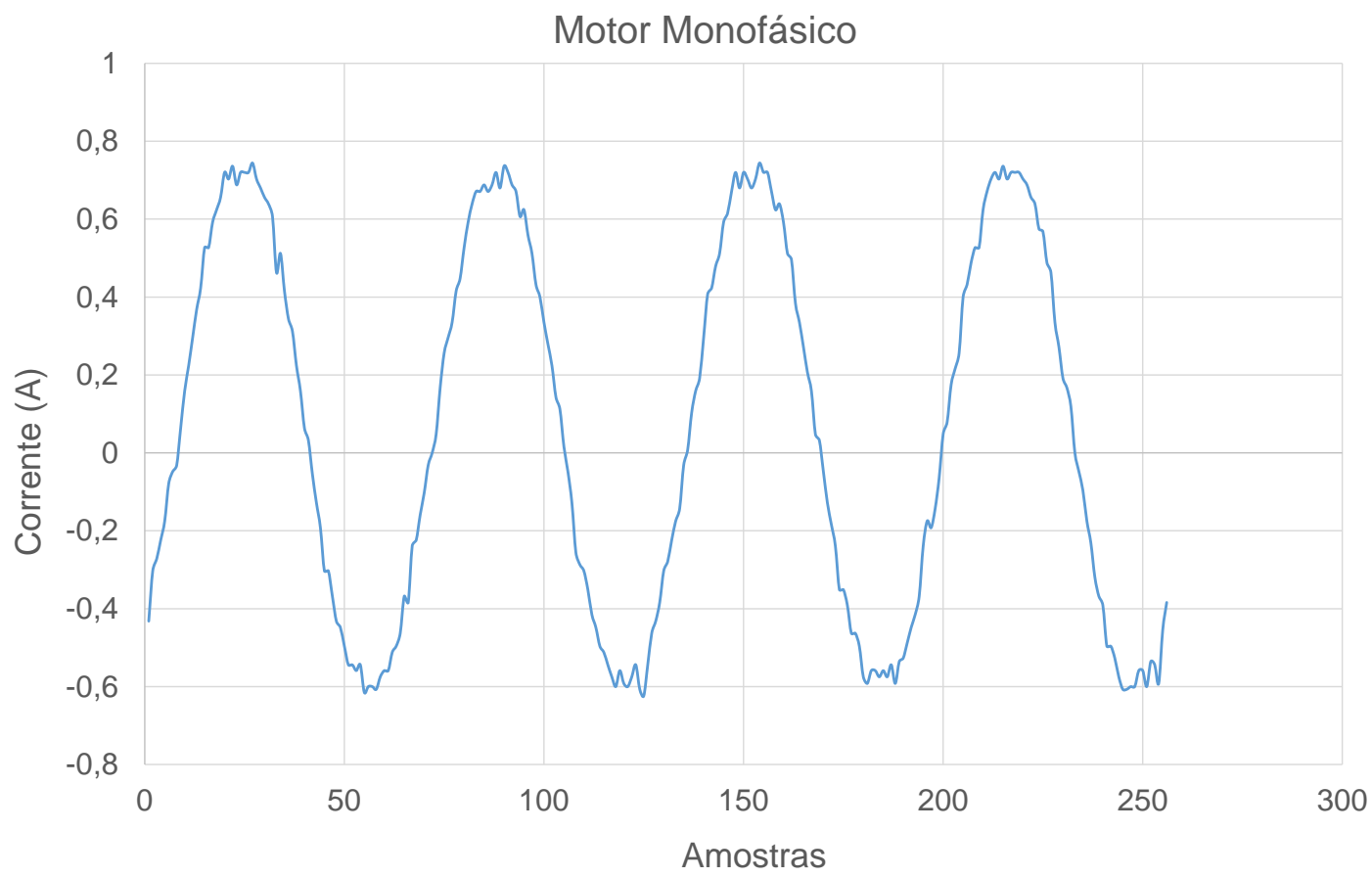

Figura 4.17 - Forma de onda da corrente de motor monofásico contendo 64 pontos por ciclo.

Na sequência foram feitas aquisições com 128 pontos por ciclo. As Figuras 4.18, 4.19 e 4.20 ilustram as aquisições.

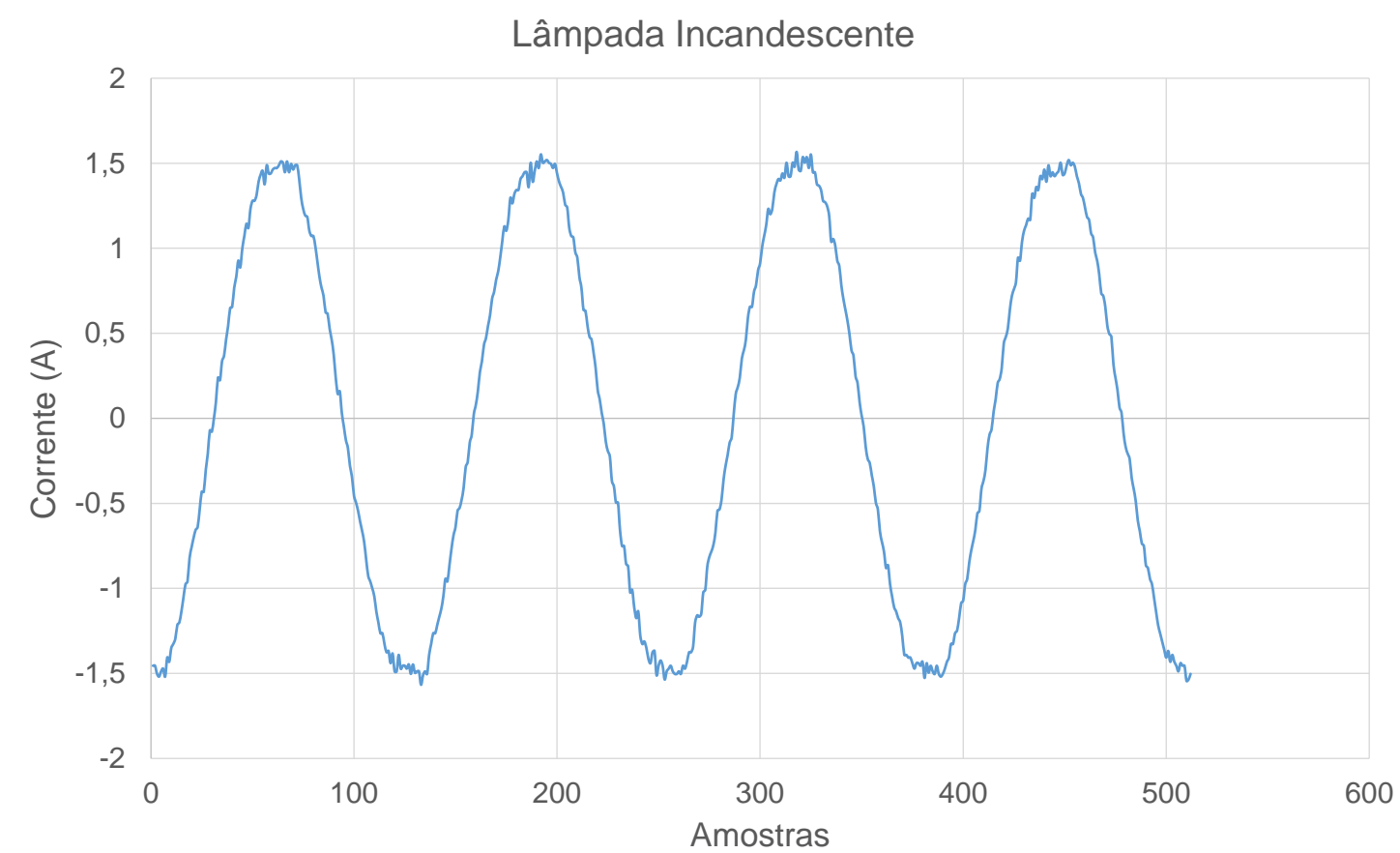

Figura 4.18 - Forma de onda da corrente de lâmpada incandescente contendo 128 pontos por ciclo. 


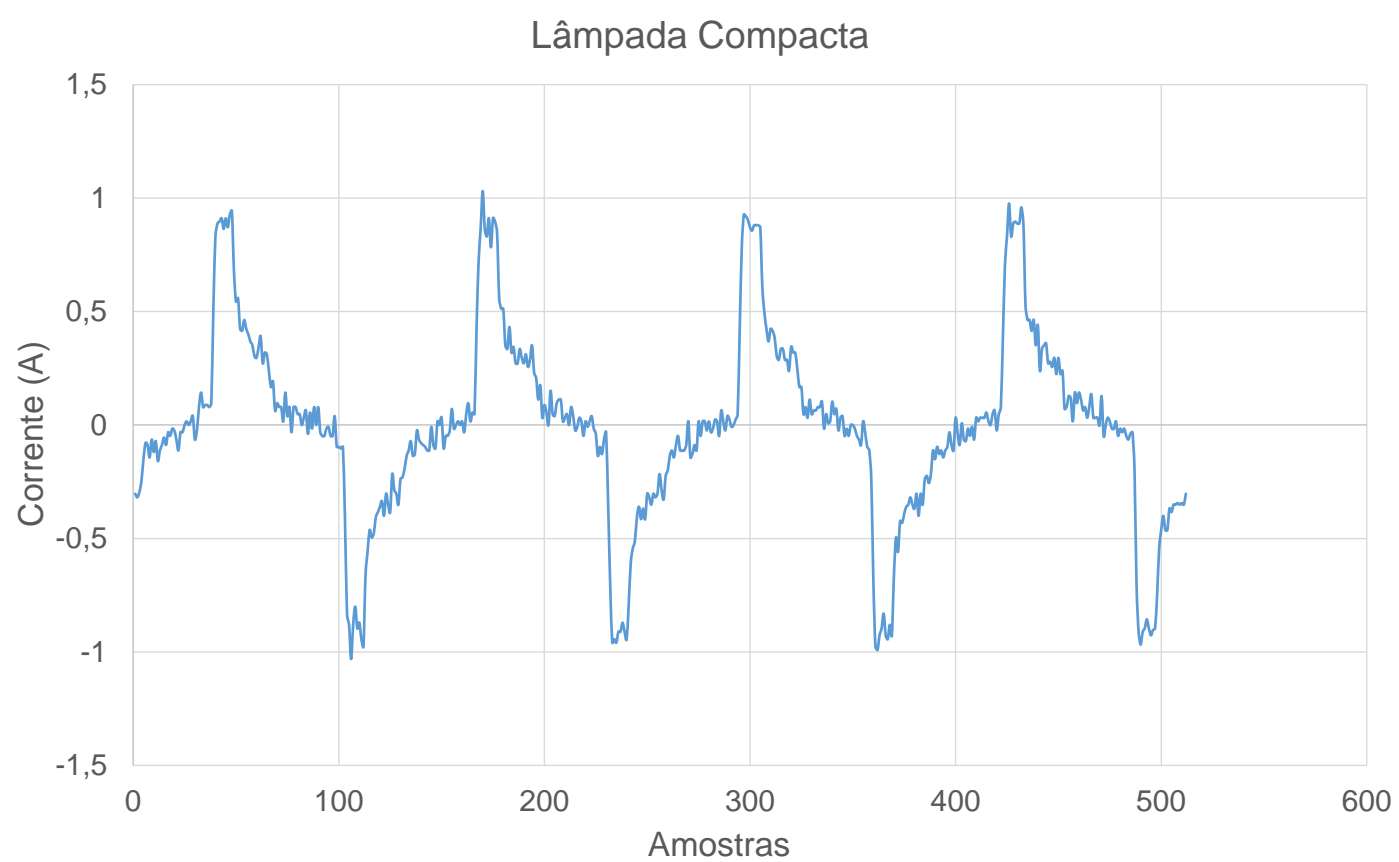

Figura 4.19 - Forma de onda da corrente de lâmpada compacta contendo 128 pontos por ciclo.

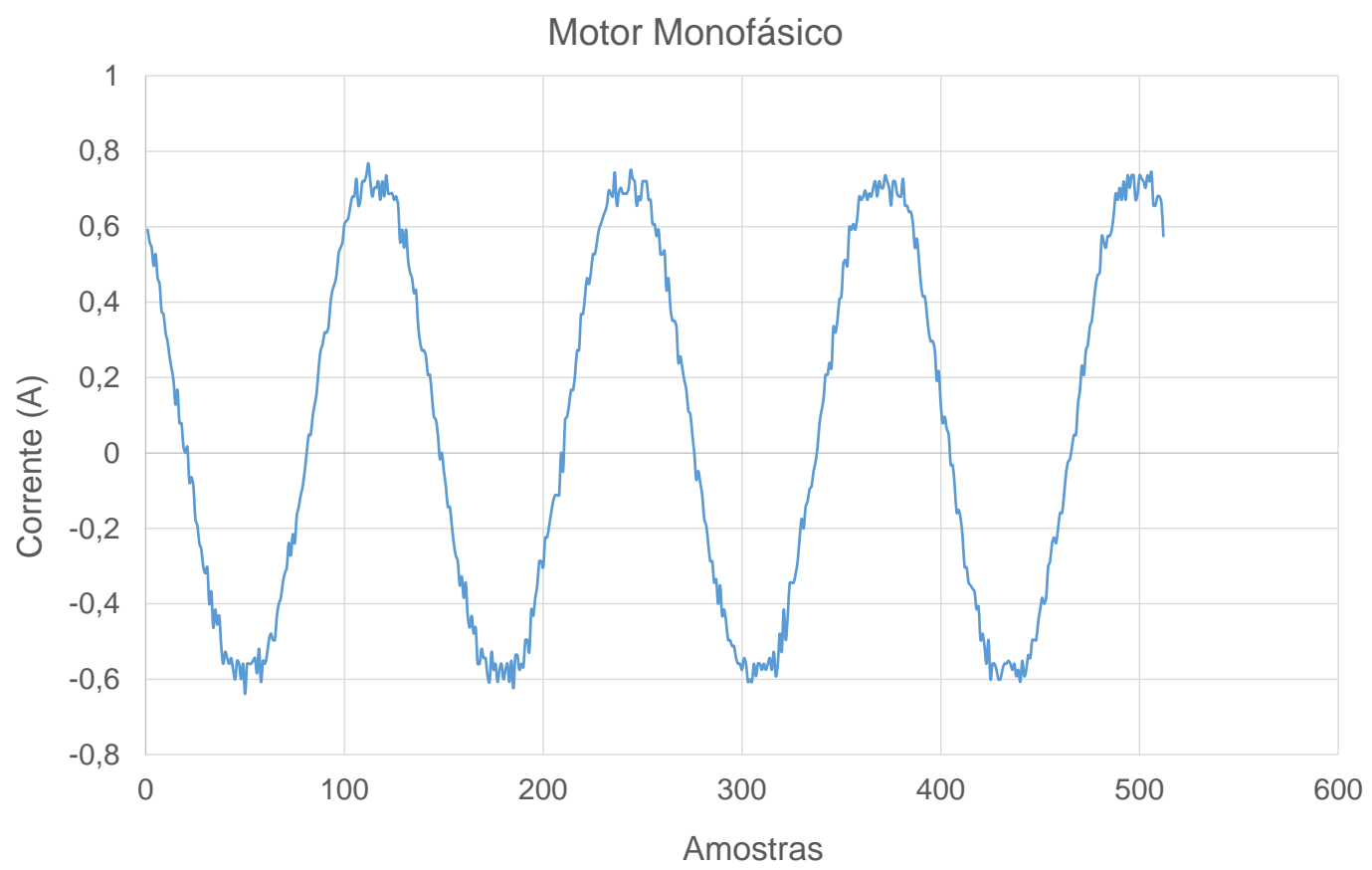

Figura 4.20 - Forma de onda da corrente de motor monofásico contendo 128 pontos por ciclo.

E, finalmente, foram feitas aquisições das senóides com 256 pontos por ciclo como mostram as Figuras 4.21, 4.22 e 4.23. 


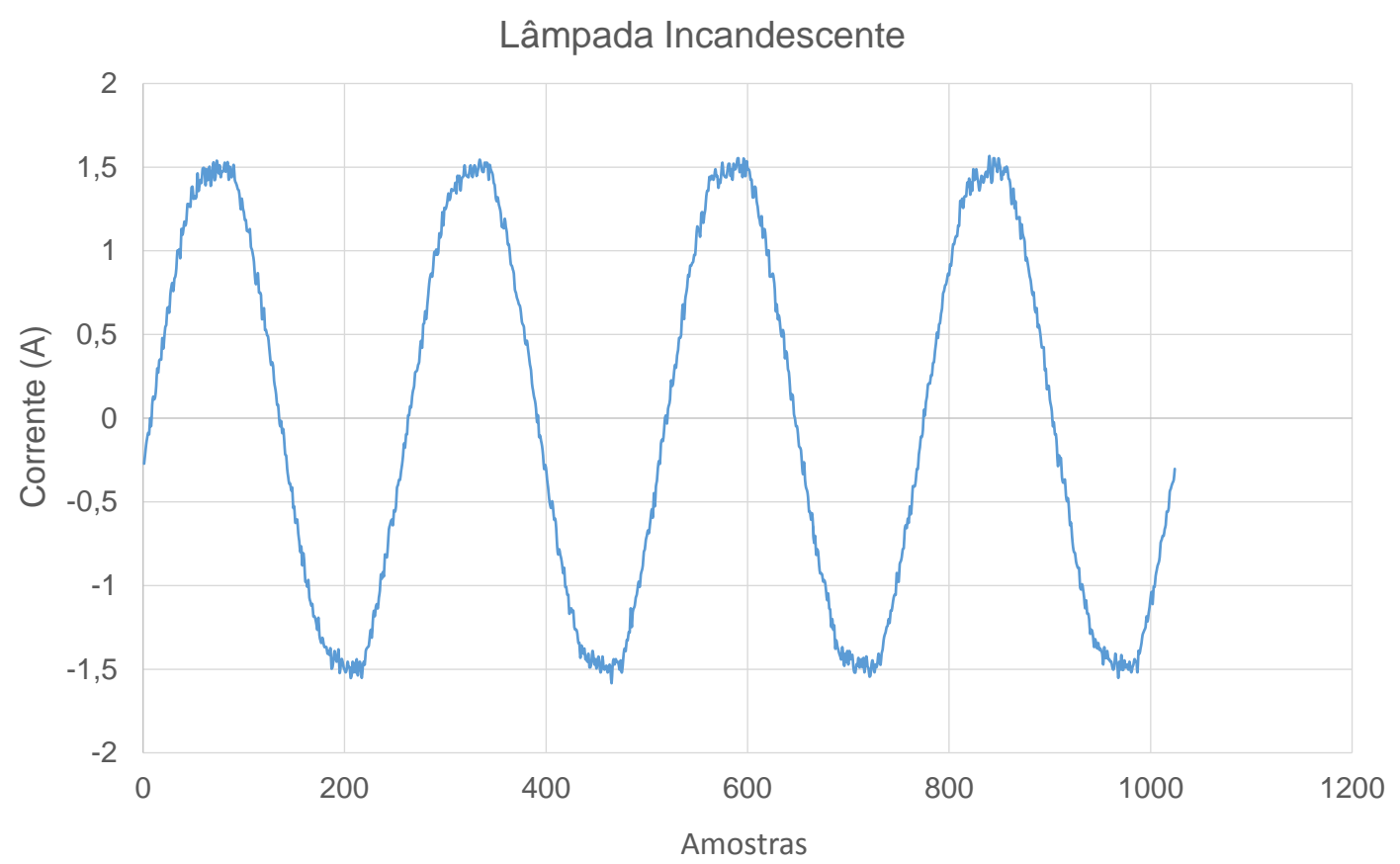

Figura 4.21 - Forma de onda da corrente de lâmpada incandescente contendo 256 pontos por ciclo.

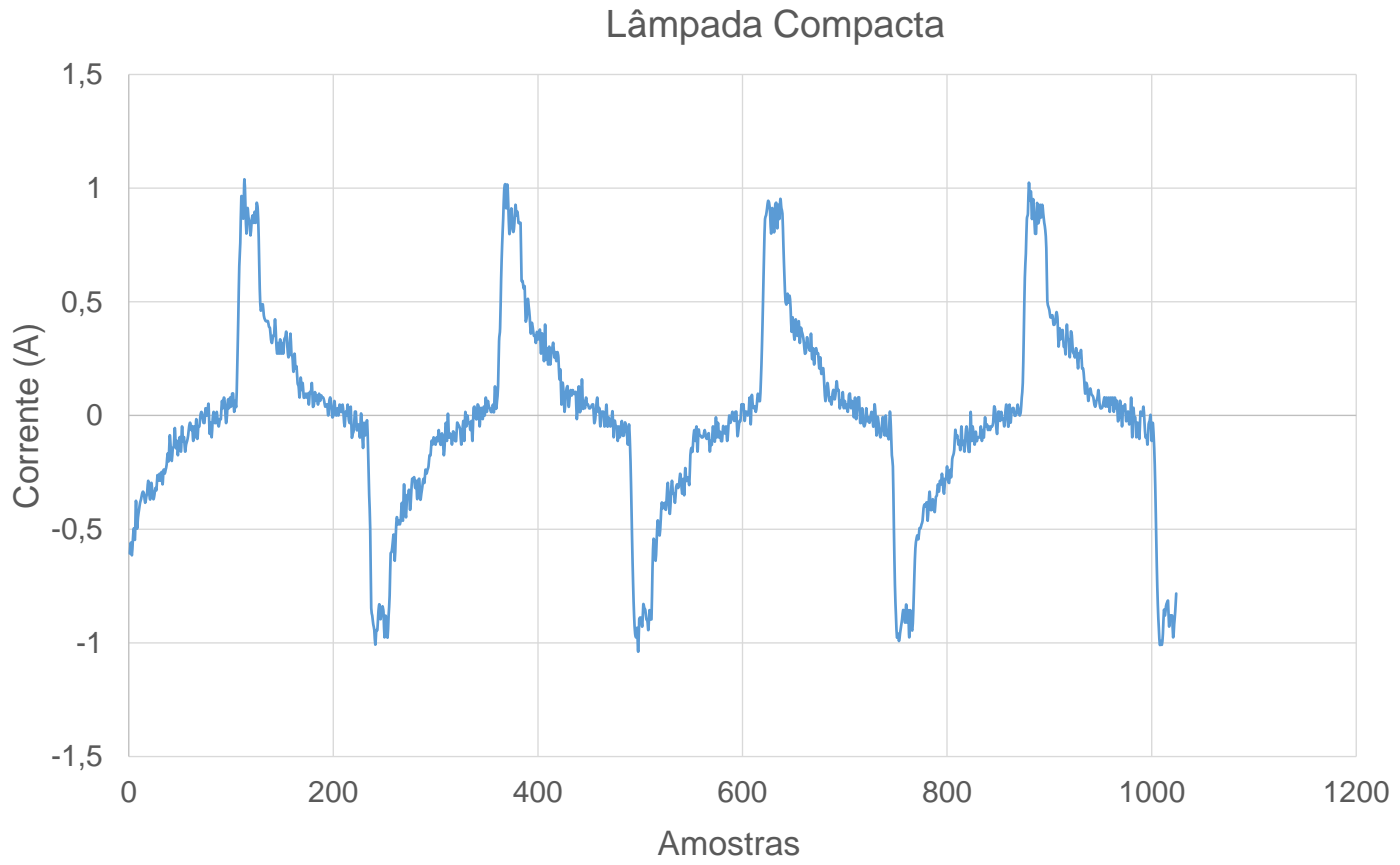

Figura 4.22 - Forma de onda da corrente de lâmpada compacta contendo 256 pontos por ciclo. 


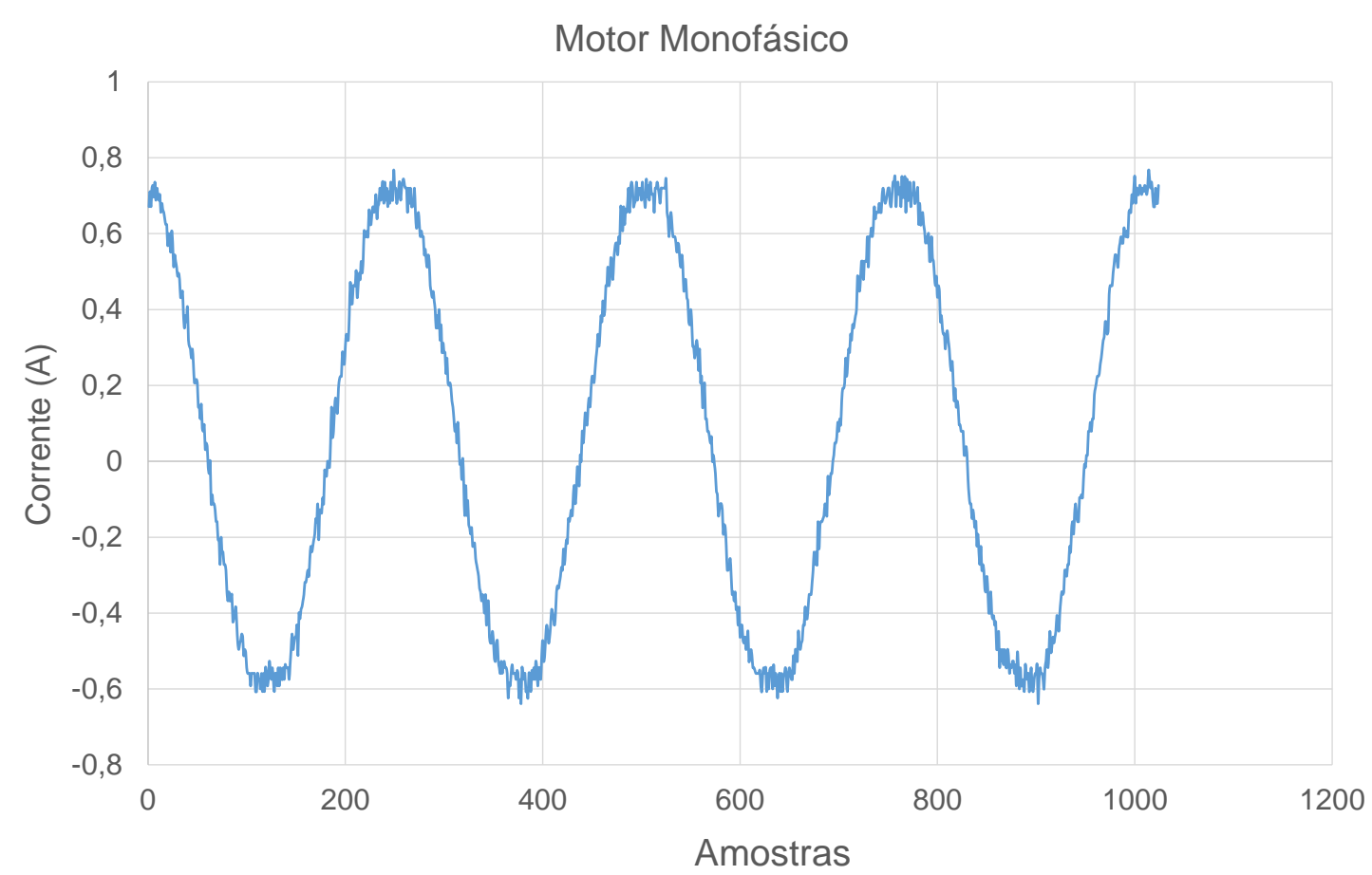

Figura 4.23 - Forma de onda da corrente de motor monofásico contendo 256 pontos por ciclo.

Como pode ser visto nas figuras relacionadas aos sinais aquisitados com 0 analisador da Fluke e o oscilógrafo da Yokogawa, os mesmos possuem uma definição um pouco melhor devido à quantidade de pontos que estes equipamentos trabalham, conforme comentado anteriormente.

Após serem feitas as aquisições das senóides referente às correntes geradas pelas cargas incandescentes e compactas, com os equipamentos mencionados anteriormente, foram aplicadas as transformadas de Fourier para os próximos testes de identificação de cargas. Porém, antes de aplicar o sistema de identificação de cargas, é necessário verificar se o medidor proposto nesta tese está realizando de forma correta a transformada de Fourier. Sendo assim, utilizou-se novamente o analisador da Fluke para realizar as comparações com o medidor proposto. 
Com o analisador de qualidade de energia da Fluke, foram coletadas as componentes harmônicas das correntes geradas pelas lâmpadas compactas e incandescentes. Este analisador é capaz de calcular até a $56^{\mathrm{a}}$ componente harmônica, entretanto, no caso do medidor proposto, optou-se por realizar os cálculos até a $25^{\text {a }}$ harmônica como regulamenta o modulo 8 do PRODIST. Estas componentes harmônicas que estão ilustradas nas Figuras 4.24 e 4.25 foram extraídas do analisador de qualidade de energia da Fluke por meio do software de comunicação com o computador que o fabricante oferece juntamente com 0 equipamento.

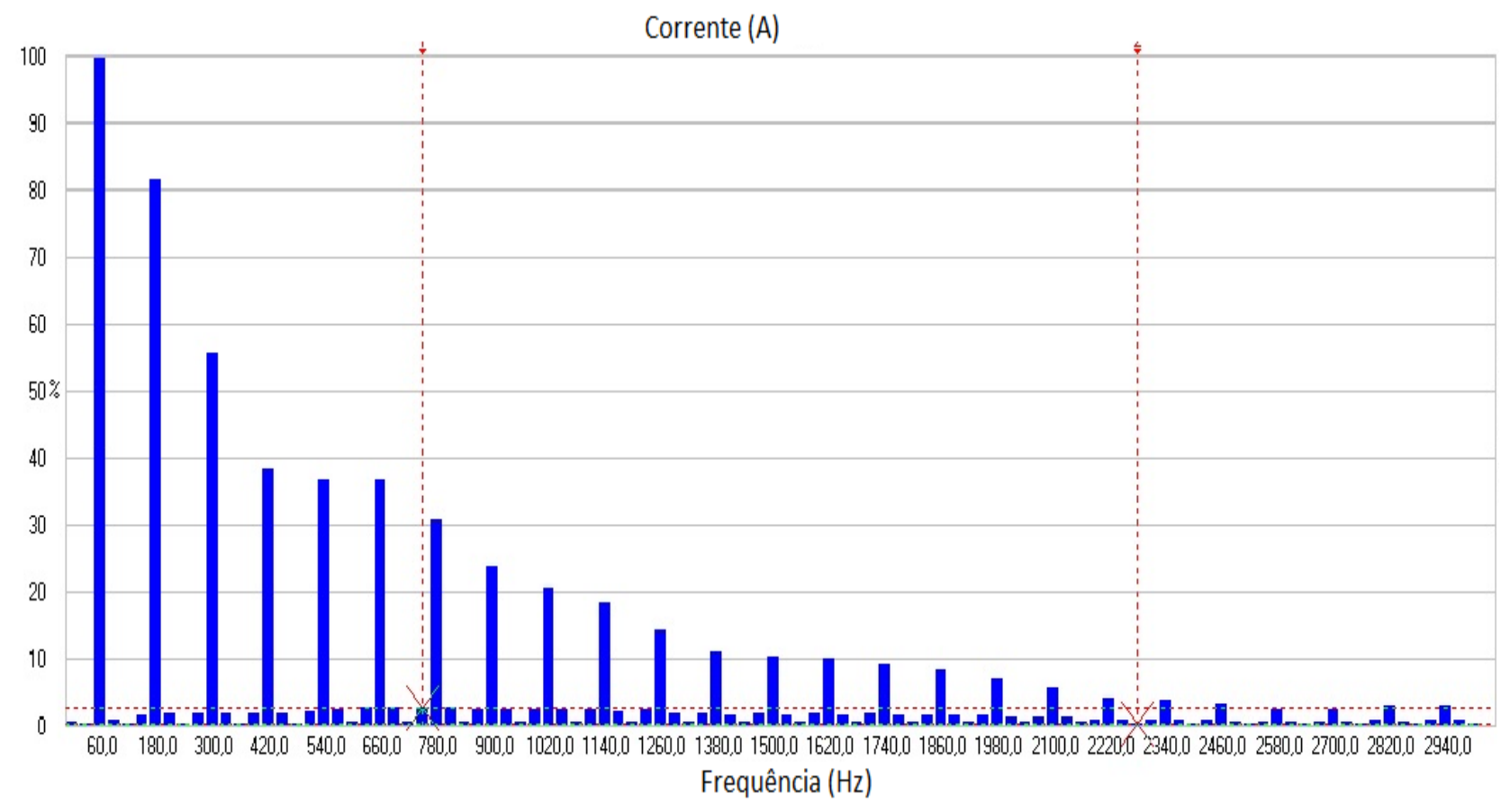

Figura 4.24 - Componentes harmônicas de lâmpada compacta. 


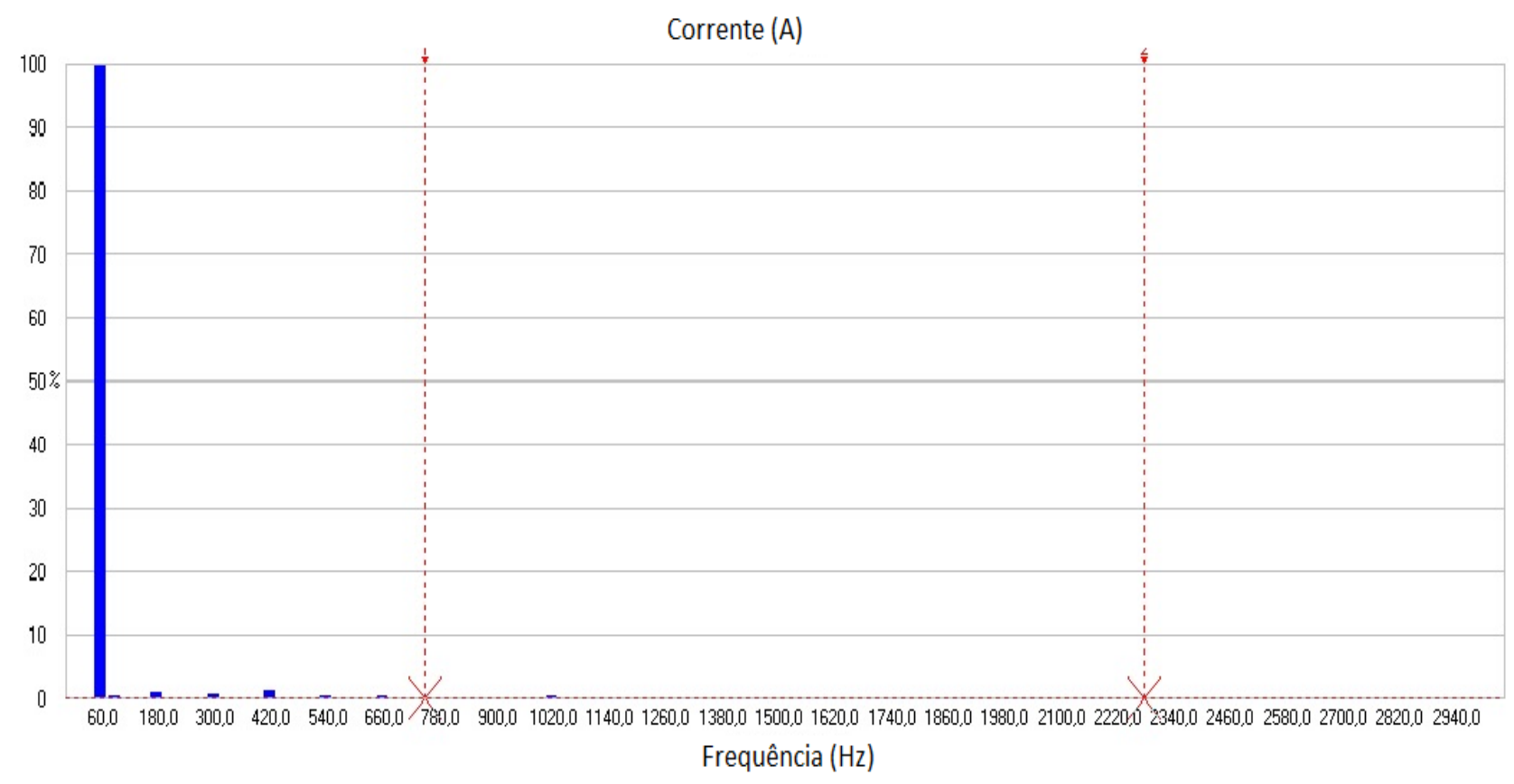

Figura 4.25 - Componentes harmônicas de lâmpada incandescente.

De acordo com as figuras anteriores, a quantidade de componentes harmônicas de uma lâmpada incandescente é muito pequena em comparação com uma lâmpada compacta, devido ao fato de ser uma carga do tipo linear resistiva.

Em seguida, foram aquisitados os sinais de corrente das cargas e calculadas as transformada de Fourier com o medidor proposto. Como dito anteriormente, para o caso do medidor proposto, optou-se apenas por realizar cálculos para obtenção de até a $25^{\mathrm{a}}$ componente harmônica; dessa forma, foi aplicada a transformada de Fourier para 64, 128 e 256 pontos por ciclo. A Figura 4.26, 4.27 e 4.28 ilustram a transformada de Fourier para 64 pontos por ciclo. 


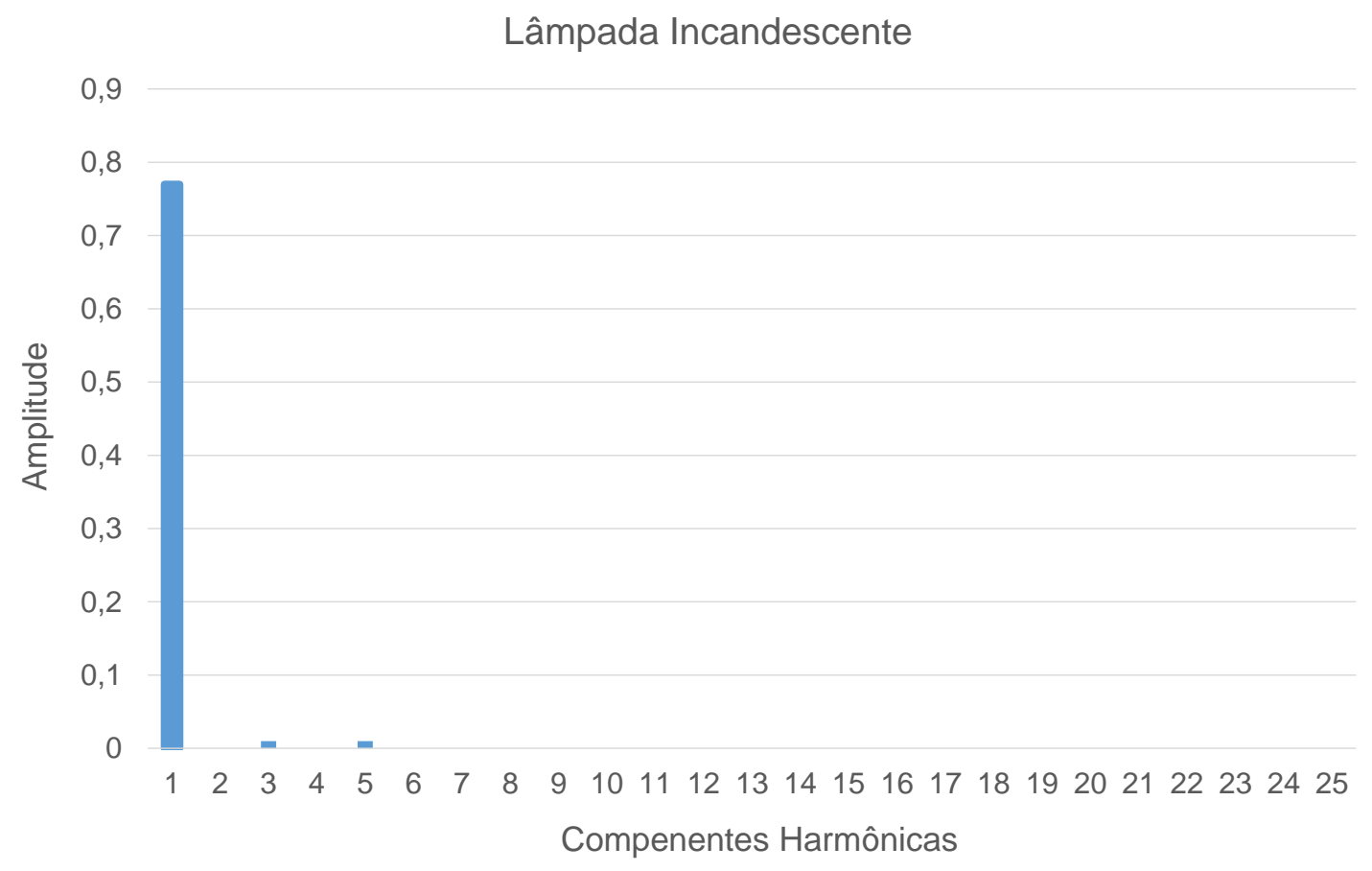

Figura 4.26 - Componentes harmônicas de lâmpada incandescente aquisitadas com 64 pontos por ciclo.

Lâmpada Compacta

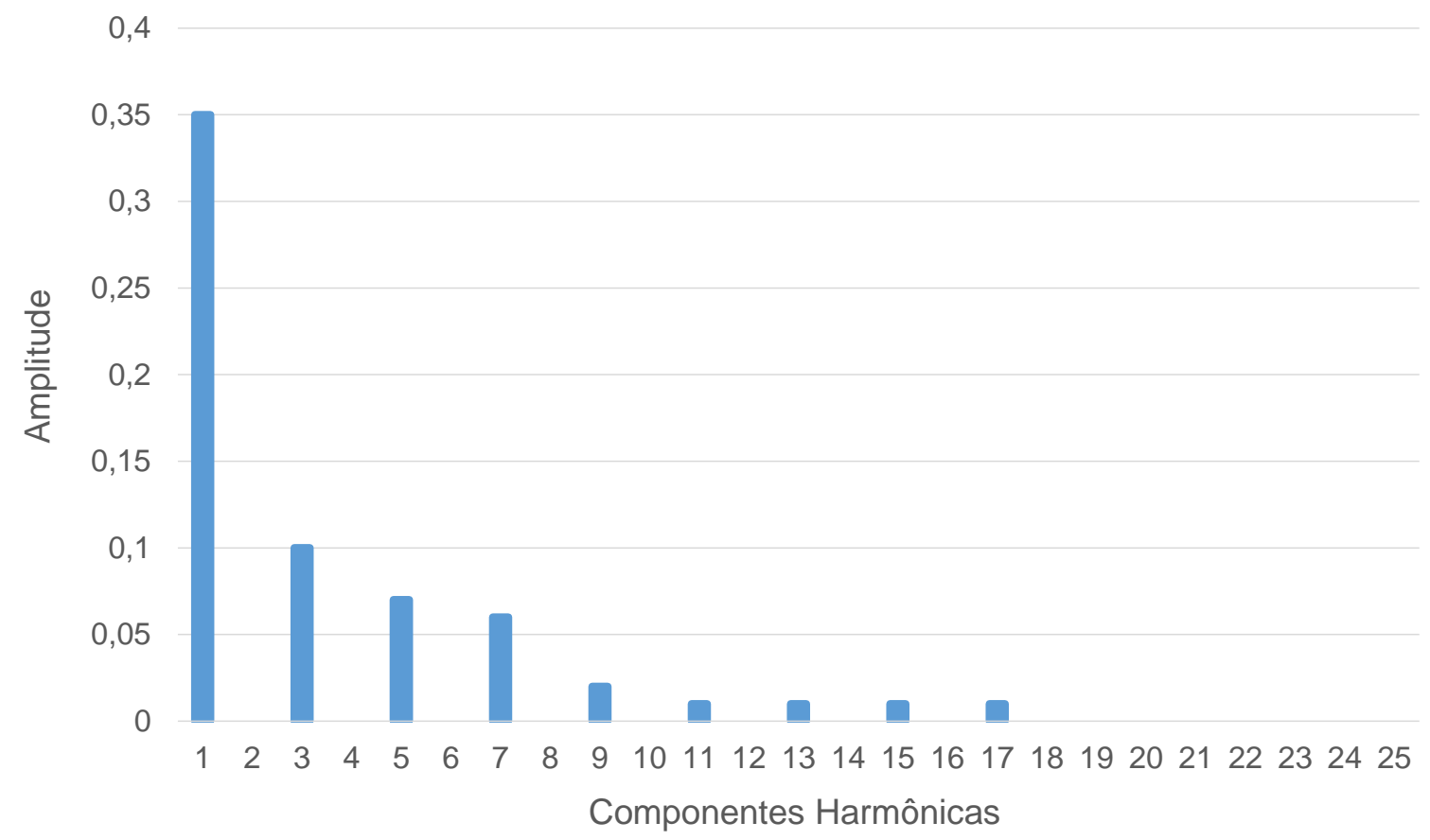

Figura 4.27- Componentes harmônicas de lâmpada compacta aquisitadas com 64 pontos por ciclo. 
Motor Monofásico

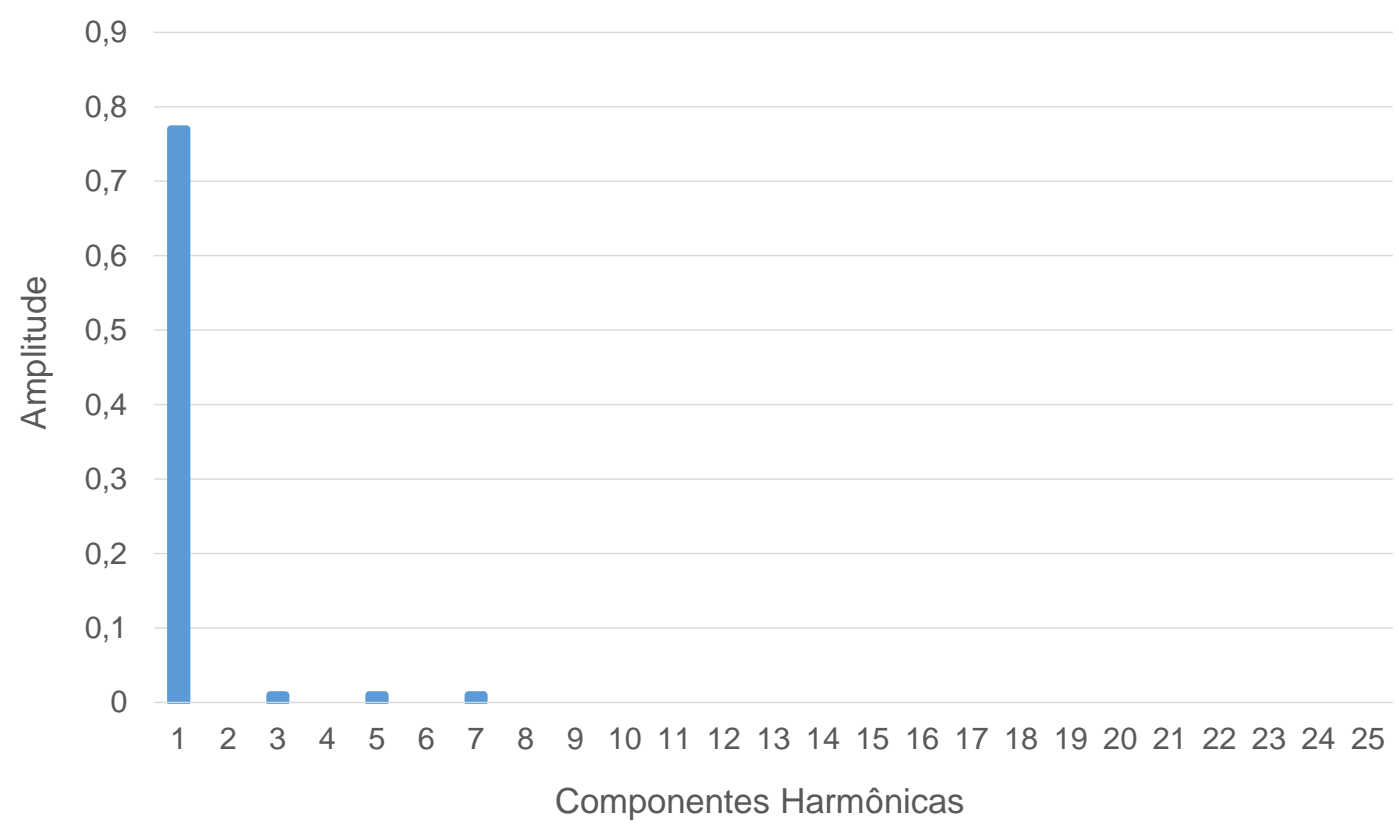

Figura 4.28 - Componentes harmônicas de motor monofásico aquisitadas com 64 pontos por ciclo.

Em seguida, foi feito o cálculo da transformada de Fourier para os sinais de corrente contendo 128 pontos por ciclo. As componentes harmônicas das lâmpadas incandescentes e compactas podem ser vistas nas Figuras 4.29, 4.30 e 4.31.

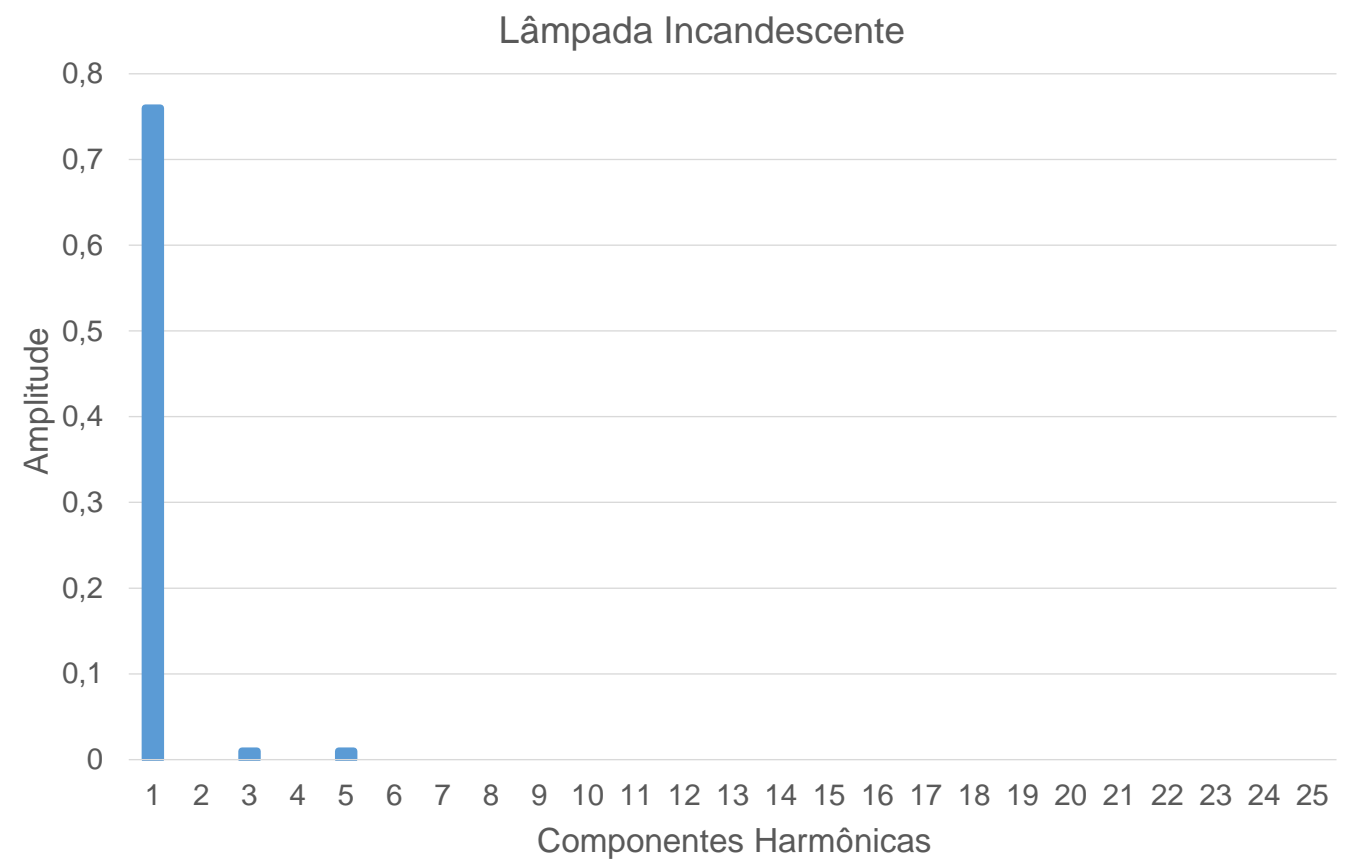

Figura 4.29 - Componentes harmônicas de lâmpada incandescente aquisitadas com 128 pontos por ciclo. 


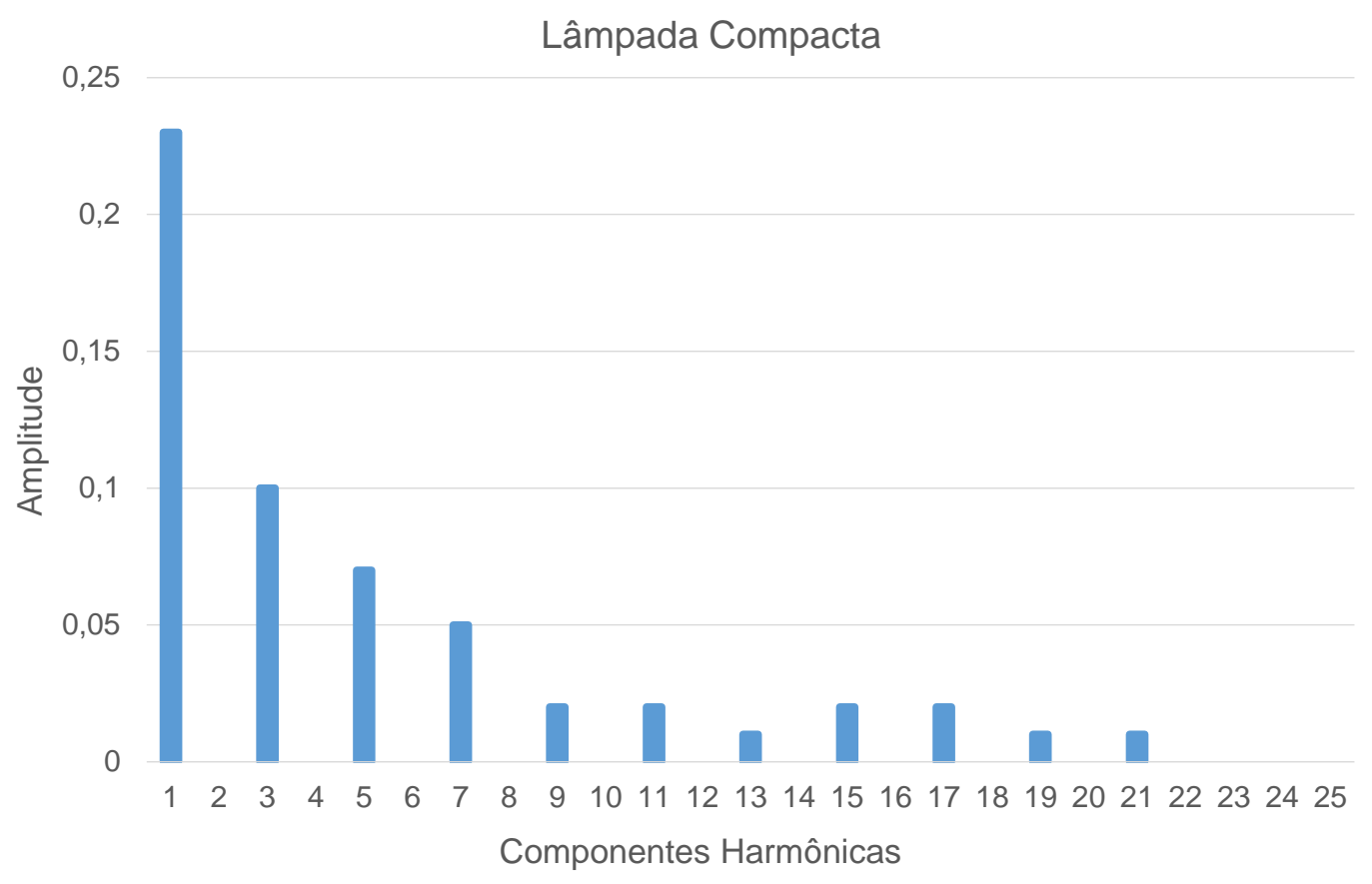

Figura 4.30 - Componentes harmônicas de lâmpada compacta aquisitadas com 128 pontos por ciclo.

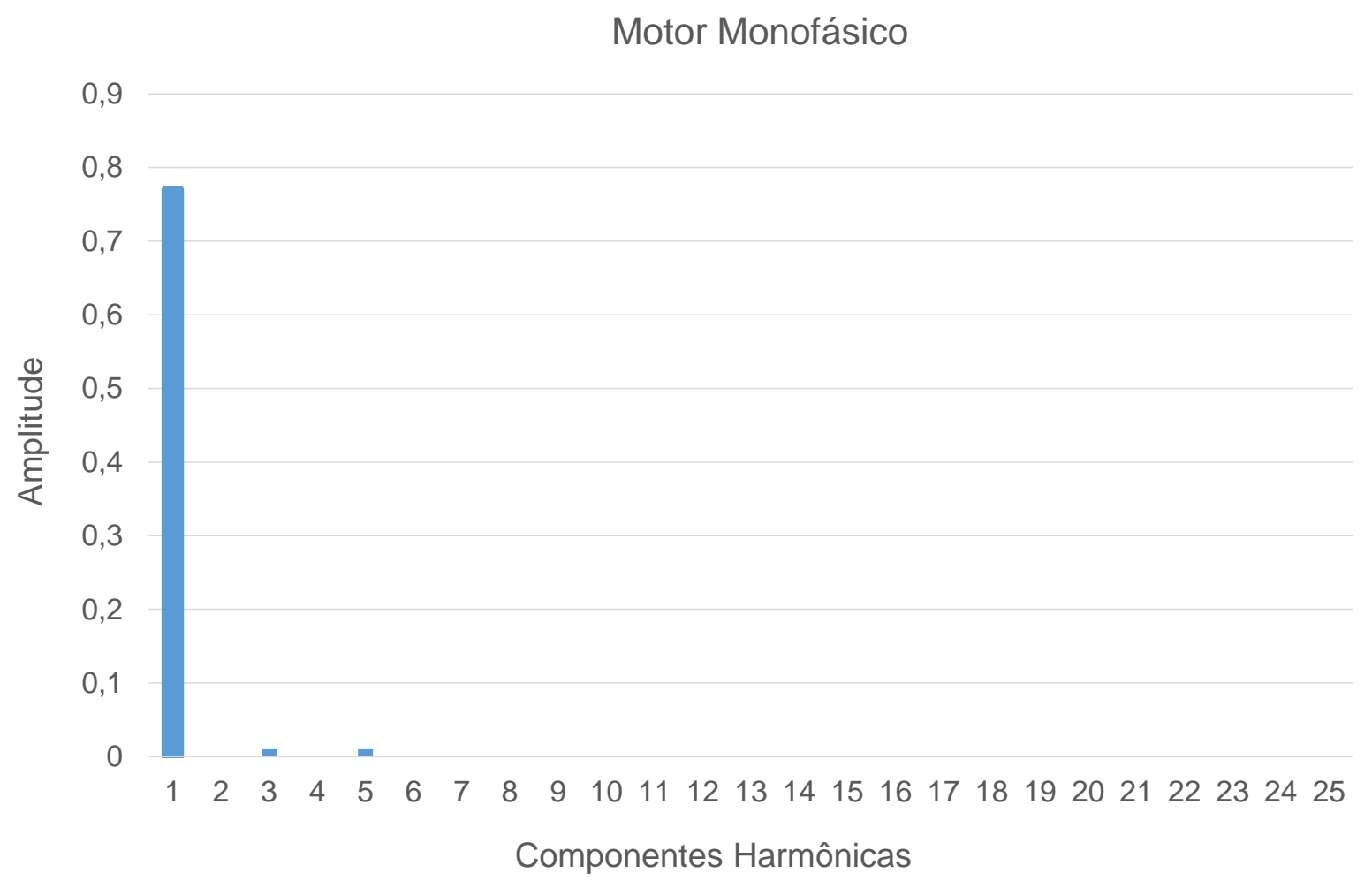

Figura 4.31 - Componentes harmônicas de motor monofásico aquisitadas com 128 pontos por ciclo. 
E, por fim, foi feito o cálculo da transformada de Fourier para os sinais de corrente contendo 256 pontos por ciclo. As componentes harmônicas das lâmpadas incandescentes e compactas podem ser vistas nas Figuras 4.32, 4.33 e 4.34 respectivamente.

\section{Lâmpada Incandescente}

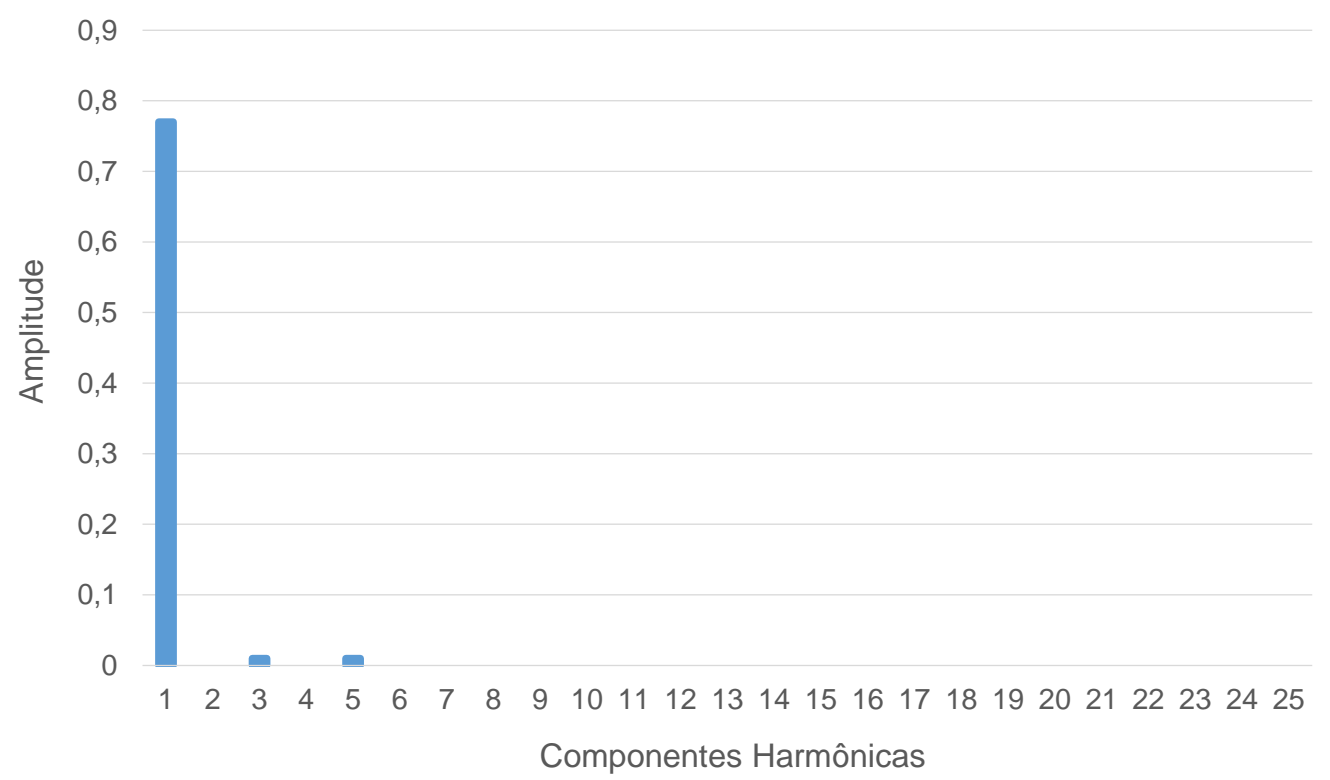

Figura 4.32 - Componentes harmônicas de lâmpada incandescente aquisitadas com 256 pontos por ciclo.

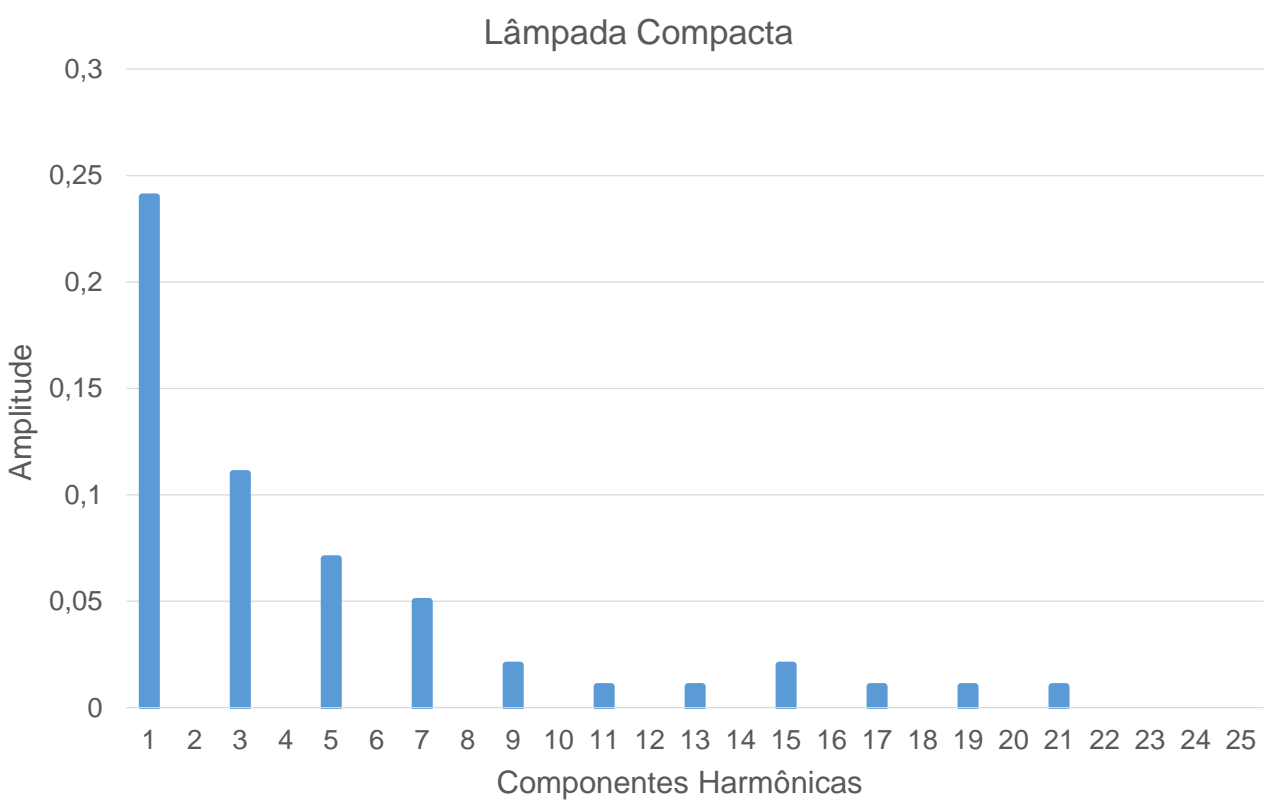

Figura 4.33 - Componentes harmônicas de lâmpada compacta aquisitadas com 256 pontos por ciclo. 


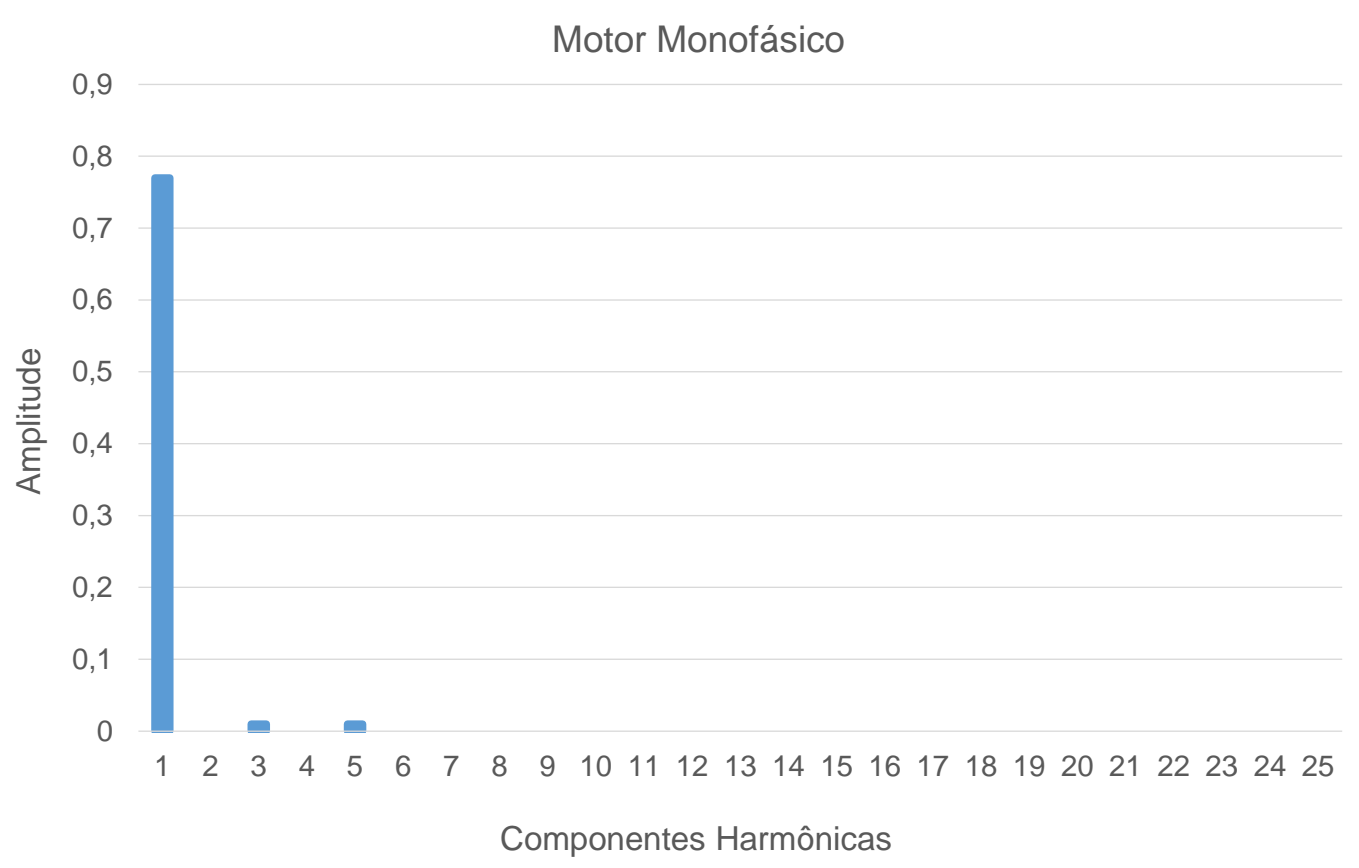

Figura 4.34 - Componentes harmônicas de motor monofásico aquisitadas com 256 pontos por ciclo.

Vale ressaltar que a quantidade de componentes harmônicas aquisitadas pelo equipamento analisador da Fluke é maior do que a quantidade do medidor proposto, devido ao analisador aquisitar até a $54^{\mathrm{a}}$ componente harmônica, ao passo que o medidor proposto faz aquisição até a $25^{\mathrm{a}}$ componente harmônica como mencionado anteriormente.

Outro ponto a ser comentado é a comparação dos valores das componentes harmônicas realizadas pelo medidor proposto e os valores coletados em Fernandes (2008), em que se utilizou uma fonte da California Instruments para alimentação das cargas e extração das componentes harmônicas, sendo estes valores bem parecidos, contendo um erro de aproximadamente $3 \%$ nas amplitudes, o que poderia causar uma diferença no reconhecimento de carga. 
Após adquirir as componentes harmônicas das cargas em análise, as mesmas são direcionadas para uma rede neural artificial, que fará a identificação das cargas.

A rede neural utilizada foi a mesma adotada por Fernandes (2008), em que se utilizou uma rede neural para cada carga, contendo 26 neurônios na $1^{\underline{a}}$ camada intermediária, 12 neurônios na $2^{a}$ camada intermediária e 2 neurônios na camada de saída. Quanto às entradas da rede, foram utilizadas 6, que consistem nas componentes harmônicas de $1^{a}, 3^{a}, 5^{a}, 7^{a}, 8^{a}$ e $9^{a}$ ordens. As funções de ativação empregadas foram do tipo tangente hiperbólica para as camadas escondidas e para a camada de saída foi utilizada a função do tipo linear com limites em 1 e -1, a fim de representar o estado atual da carga (ligada ou desligada).

Para o treinamento da rede neural foi utilizado a toolbox do software Matlab 2013 e o tipo de treinamento utilizado foi o Levenberg-Marquardt. Após serem feitos os treinamentos, foi necessária a extração das matrizes de pesos de cada camada bem como o bias e a discretização das funções de ativação, a fim de poder embarcar a rede neural no microcontrolador.

Para embarcar a rede neural no microcontrolador, utiliza-se a equação (4.6) :

$$
y=f^{3}\left(W 3 \cdot f^{2}\left(W 2 \cdot f^{1}(W 1 \cdot x+b 1)+b 2\right)+b 3\right)
$$

onde: $W 1, W 2$ e $W 3$ são as matrizes de pesos das camadas da rede; $b 1, b 2$ e $b 3$ são os respectivos bias; $f^{1}, f^{2}$ e $\beta^{\beta}$ são as funções de ativação; $x$ é um vetor de entrada com as seis componentes harmônicas e y é a saída da rede que poderá ser -1 (desligada) ou 1 (ligada).

Com a rede neural embarcada, realizaram-se os testes de validação do sistema proposto. 
Para a validação da rede neural foram testadas as cargas propostas, ou seja, lâmpadas incandescentes e compactas e o motor monofásico. Sendo assim, para visualização da saída da rede neural utilizou-se um software denominado Termite, que é um sistema que realiza a comunicação com o microcontrolador por RS232. Vale salientar que, para um trabalho futuro, é interessante desenvolver um software com alguma plataforma comercial para recepção dos dados. No entanto, para um protótipo, o software Termite responde bem ao propósito. A Figura 4.35 a 4.37 ilustram a saída da rede pelo Termite.

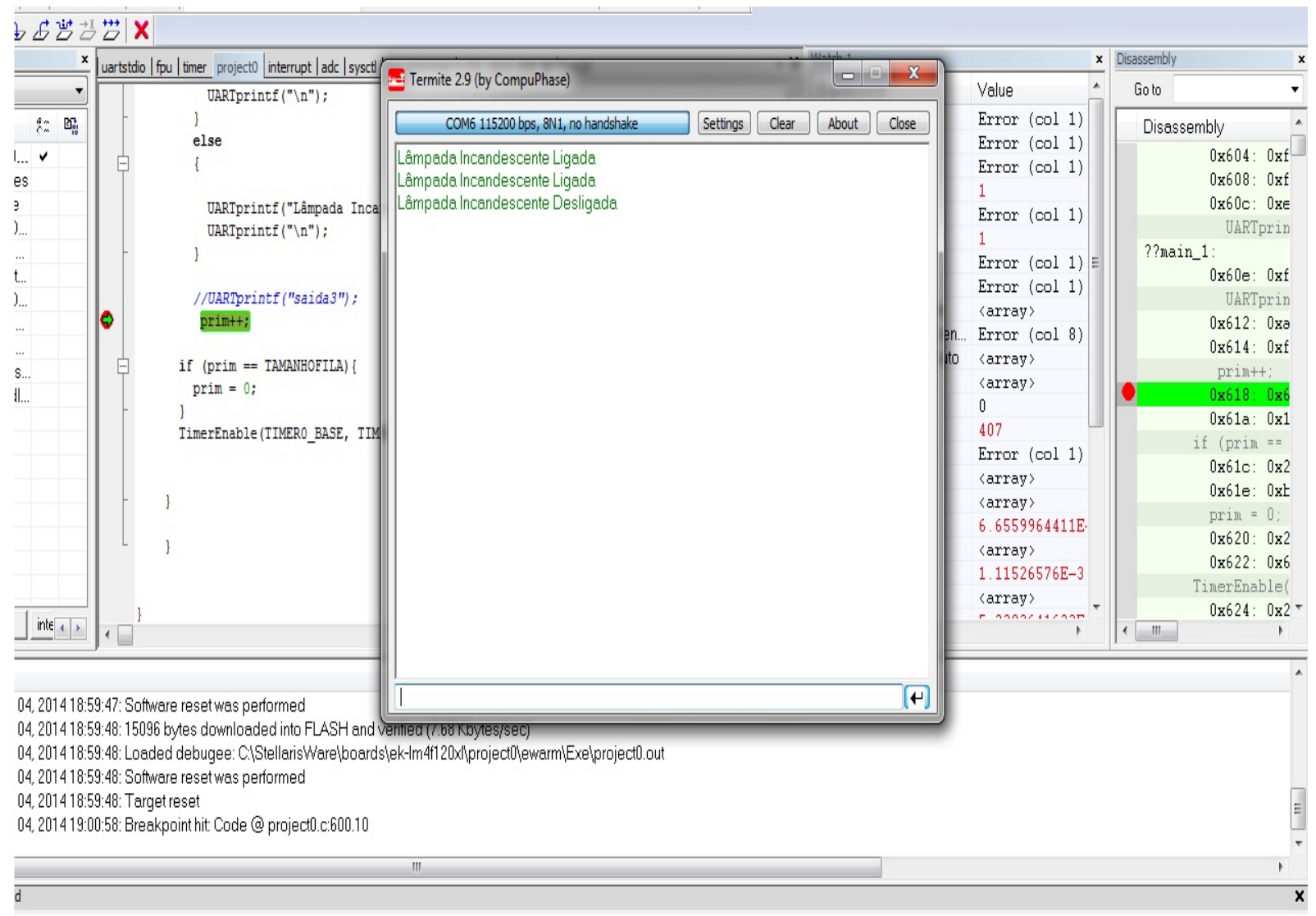

Figura 4.35 - Software Termite para recepção dos dados. 


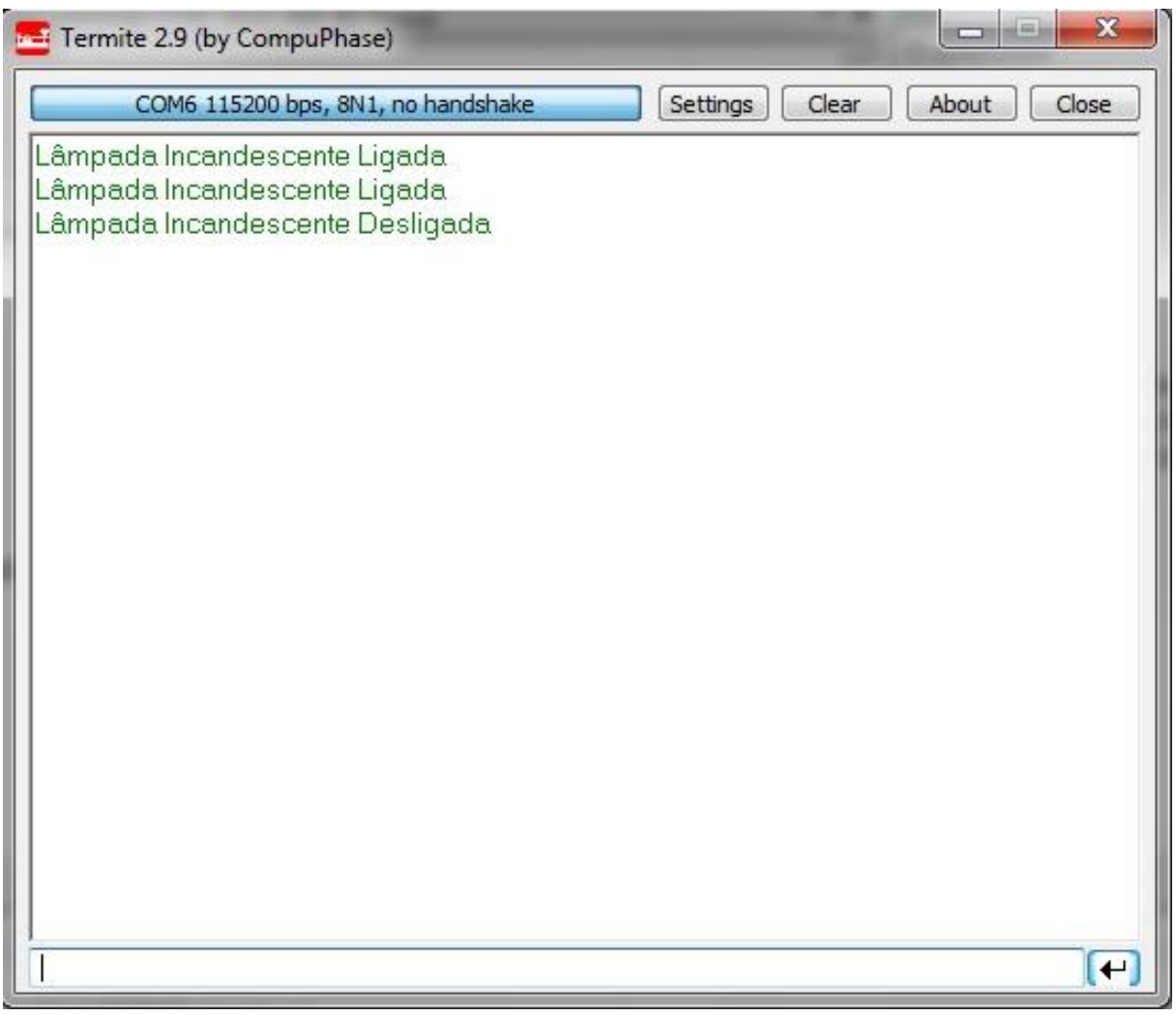

Figura 4.36 - Saída da rede neural para lâmpada incandescente.

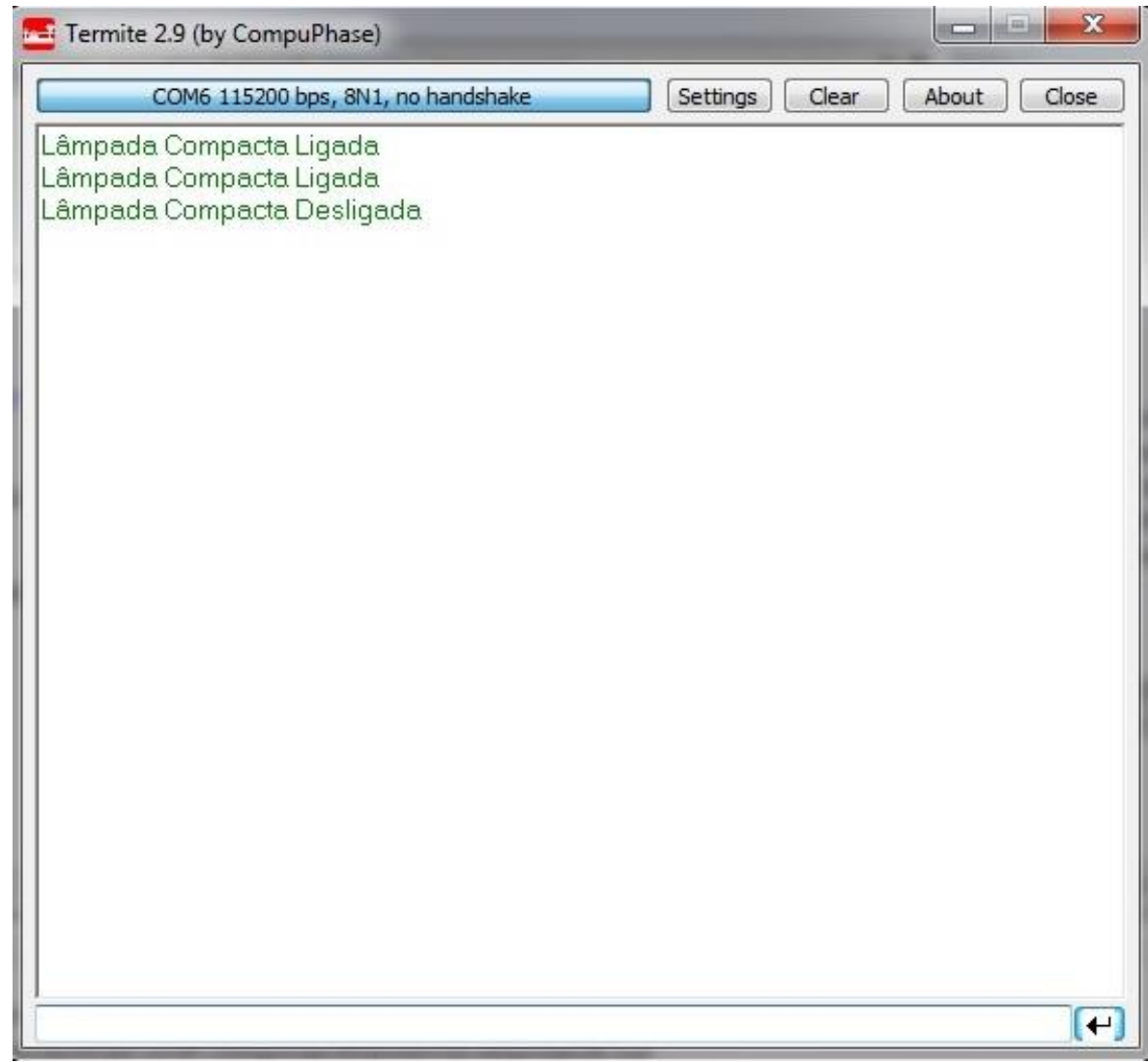

Figura 4.37 - Saída da rede neural para lâmpada compacta. 
Como ilustrado nas Figuras 4.35 a 4.37, o teste foi realizado com lâmpadas incandescentes e compactas, variando em estado ligado e desligado.

Sendo assim, a princípio, as cargas foram ligadas separadamente para verificação do comportamento da rede neural embarcada. Após serem feitos os testes de identificação das cargas separadamente, foram realizadas diversas combinações entre as cargas, para observar se a rede neural identificaria as cargas mesmo estando ligadas ao mesmo tempo e tendo a sua forma de onda modificada. A Figura 4.38 ilustra um exemplo da forma de onda contendo as três cargas ligadas ao mesmo tempo.

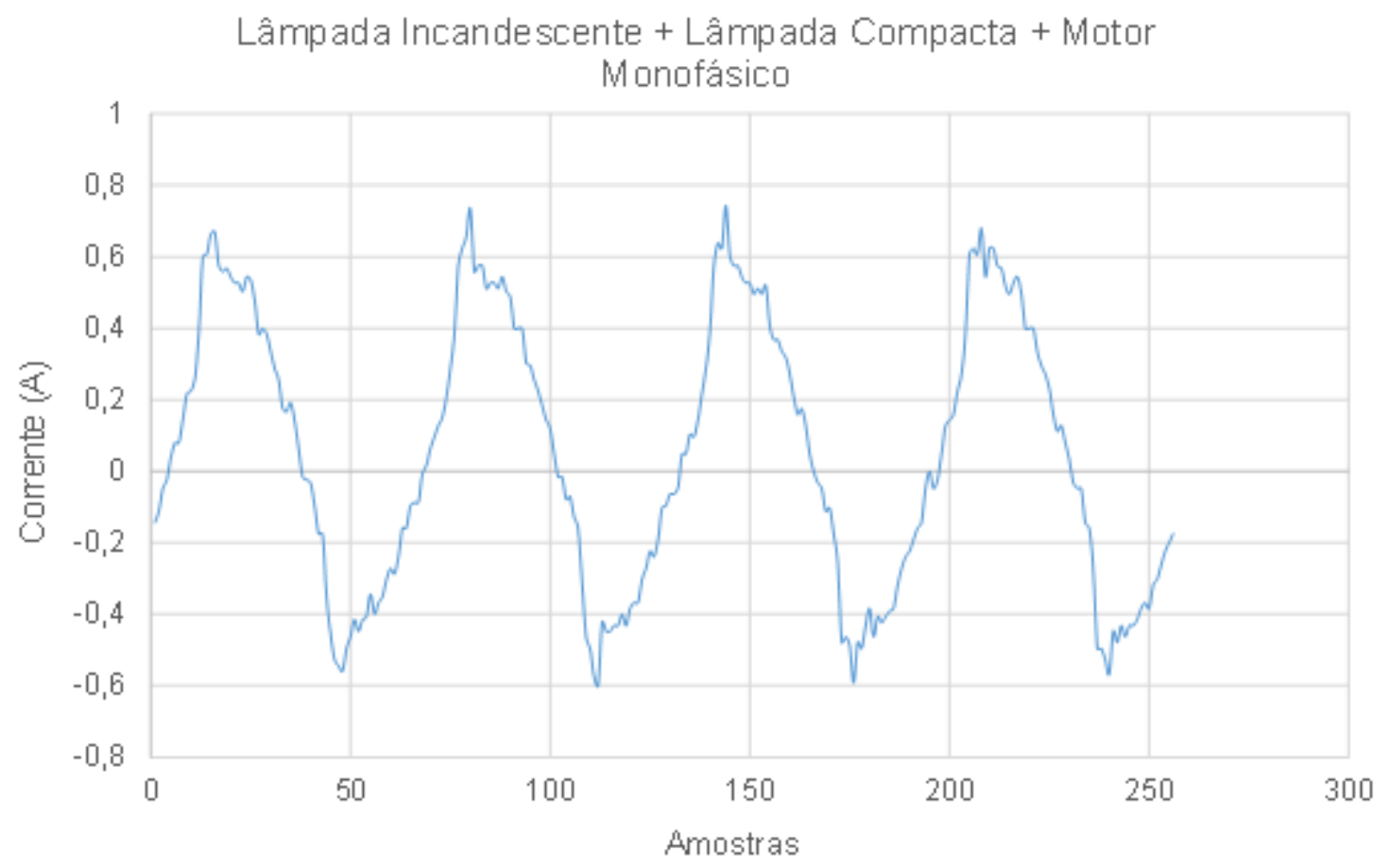

Figura 4.38 - Forma de onda das lâmpadas incandescentes e compactas e motor monofásico.

Os testes foram realizados variando a quantidade de lâmpadas incandescentes e compactas ligadas em conjunto com o motor, ou somente lâmpadas incandescentes com motor, ou lâmpadas compactas com motor, ou 
lâmpadas compactas com incandescentes. A tabela abaixo mostra as combinações realizadas para os testes.

Tabela 4.1 - Combinações de cargas realizadas para validação da rede neural.

\begin{tabular}{|c|c|c|c|c|c|c|c|c|c|c|c|c|c|}
\hline \multirow{2}{*}{ Tipo de Carga } & \multirow{2}{*}{$\begin{array}{l}\text { Tipo de Carga } \\
\text { Quantidade }\end{array}$} & \multicolumn{5}{|c|}{$\begin{array}{c}\text { Lâmpada } \\
\text { Incandescente }\end{array}$} & \multicolumn{5}{|c|}{ Lâmpada Compacta } & \multicolumn{2}{|c|}{$\begin{array}{c}\text { Motor } \\
\text { Monofásico }\end{array}$} \\
\hline & & 0 & 1 & 2 & 3 & 4 & 0 & 1 & 2 & 3 & 4 & 0 & 1 \\
\hline \multirow{5}{*}{$\begin{array}{c}\text { Lâmpada } \\
\text { Incandescente }\end{array}$} & 0 & & & & & & $\mathrm{x}$ & $\mathrm{x}$ & $\mathrm{x}$ & $\mathrm{x}$ & $\mathrm{x}$ & \multirow{5}{*}{$\mathrm{x}$} & \multirow{5}{*}{$\mathrm{x}$} \\
\hline & 1 & & & & & & $\mathrm{x}$ & $\mathrm{x}$ & $\mathrm{x}$ & $\mathrm{x}$ & $\mathrm{x}$ & & \\
\hline & 2 & & & & & & $\mathrm{x}$ & $\mathrm{x}$ & $\mathrm{x}$ & $\mathrm{x}$ & $\mathrm{x}$ & & \\
\hline & 3 & & & & & & $\mathrm{x}$ & $\mathrm{x}$ & $\mathrm{x}$ & $\mathrm{x}$ & $\mathrm{x}$ & & \\
\hline & 4 & & & & & & $x$ & $x$ & $x$ & $x$ & $x$ & & \\
\hline \multirow{5}{*}{$\begin{array}{l}\text { Lâmpada } \\
\text { Compacta }\end{array}$} & 0 & $\mathrm{x}$ & $\mathrm{x}$ & $\mathrm{x}$ & $\mathrm{x}$ & $\underline{x}$ & & & & & & \multirow{5}{*}{$x$} & \multirow{5}{*}{$\mathrm{x}$} \\
\hline & 1 & $\mathrm{x}$ & $\mathrm{x}$ & $\mathrm{x}$ & $\mathrm{x}$ & $\mathrm{x}$ & & & & & & & \\
\hline & 2 & $\mathrm{x}$ & $\mathrm{x}$ & $x$ & $x$ & $\mathrm{x}$ & & & & & & & \\
\hline & 3 & $\mathrm{x}$ & $\mathrm{x}$ & $\mathrm{x}$ & $\mathrm{x}$ & $\mathrm{x}$ & & & & & & & \\
\hline & 4 & $\mathrm{x}$ & $\mathrm{x}$ & $\mathrm{x}$ & $x$ & $\mathrm{x}$ & & & & & & & \\
\hline
\end{tabular}

Como pode ser visto na Tabela 4.1, foram realizadas combinações variando as cargas e a quantidade utilizada. Em todas as combinações a rede identificou a carga que estava em funcionamento, não causando nenhuma interferência na identificação devido ao aumento da quantidade de cargas em funcionamento.

Toda a bancada de testes é ilustrada na Figura 4.39. 


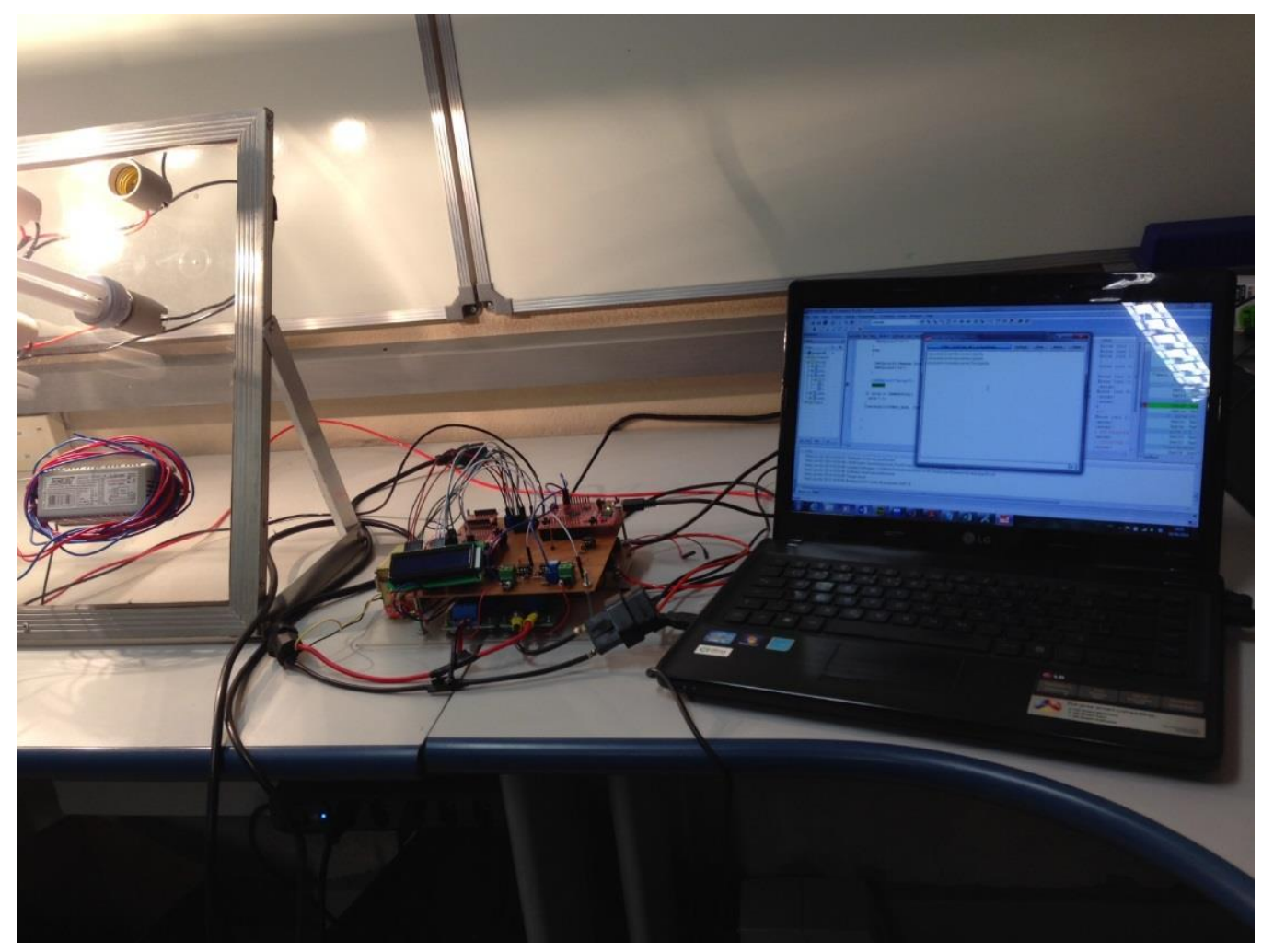

Figura 4.39- Bancada de testes.

A Figura 4.39 mostra a bancada de cargas conectada ao Smart Meter proposto, e o Smart Meter conectado ao computador via serial, para recepção dos dados de corrente, tensão, componentes harmônicas e saída da rede neural. 


\section{Conclusões Gerais}

Nesta tese foi apresentado um protótipo de um Smart Meter com características de um analisador de qualidade de energia de baixo custo, pois, equipamentos analisadores de qualidade de energia são de valores elevados. Entretanto, se somado ao Smart Meter como proposto nesta tese, o sistema se torna então mais barato para as concessionárias de energia, pois não necessita de outro equipamento para análise da rede elétrica e, como apresentado anteriormente, todo o processamento dos dados de análise da rede elétrica é executado dentro do Smart Meter, ou seja, sem a necessidade de outro equipamento de análise.

Foi apresentada toda a montagem do hardware, desde a seleção e testes dos sensores Hall para captura da corrente e tensão da rede, bem como todo o desenvolvimento do condicionador de sinal, até o projeto completo com a placa de desenvolvimento acoplada ao Smart Meter.

O Smart Meter proposto é capaz de detectar os fenômenos de VTCD, sendo eles a elevação, afundamento e interrupção de energia, pois é capaz de realizar leituras do sinal de tensão da rede elétrica; entretanto, foi dado mais atenção às análises de distorções harmônicas.

Outro ponto apresentado nesta tese é a implementação da transformada de Fourier para extração das componentes harmônicas para análises de identificação de cargas por meio de redes neuras artificiais. Este método foi apresentado em Fenandes (2008) e replicado da mesma forma para esta tese. Mas, para tanto, foram 
utilizadas apenas três cargas para identificação, devido à disponibilidade de cargas no laboratório e também ao processamento do microcontrolador.

Os resultados experimentais mostraram que o Smart Meter proposto nesta tese obteve um bom desempenho na detecção de cargas e medição do consumo de energia. Além disso, o Smart Meter proposto provou ser capaz de fazer análises de VTCD, já que este Smart Meter faz leituras da senóide da tensão. 


\section{Apêndice A}

\section{Redes Neurais Artificiais}

Redes neurais artificiais são modelos matemáticos computacionais que simulam o comportamento do cérebro humano. Uma RNA é um processador paralelamente distribuído que possuem uma capacidade natural de armazenar e utilizar conhecimento. (HAYKIN, 1999).

As principais características das redes neurais são: adaptação dos pesos sinápticos por meio de exemplos relacionados ao sistema, capacidade de aprendizado e armazenamento do comportamento do processo por intermédio de treinamento, generalização do conhecimento adquirido, organização dos dados, tolerância a falhas e facilidade de implementação em hardware e software.

As redes neurais artificiais são muito utilizadas nas áreas da Física, Matemática, Computação, Engenharias e etc.

\section{Resumo histórico}

O primeiro modelo matemático que representava o neurônio biológico foi proposto por Warren McCulloch e Walter Pitts em 1943. Entretanto, este modelo não possuía técnicas de aprendizagem.

Somente em 1949, Donald Hebb apresentou uma técnica de aprendizado utilizando uma variação dos pesos de entrada. 
Já em 1958, Frank Rosenblatt apresentou o perceptron de camada simples utilizando os conceitos apresentados por McCulloch e Pitts e Hebb.

Em 1960, Widrow e Hoff desenvolveram uma rede neural utilizando uma regra de aprendizado conhecida como regra delta, com finalidade de minimizar o erro na saída da RNA.

Entretanto, as limitações do perceptron de camada simples demonstradas por Minsky e Papert em 1969, fizeram com que autores perdessem o interesse pelo estudo das RNAs. Esses estudos foram retomados somente em 1982 por John Hopfield.

Com o intuito de solucionar as limitações do perceptron apresentadas por Minsky e Papert, em 1986, Rumelhart et al. (1986) apresentou o algoritmo de treinamento chamado backpropagation, possibilitando o treinamento das redes perceptrons de múltiplas camadas.

A partir da década de 80 , outros estudos foram surgindo e outras técnicas de treinamento foram criadas e apresentadas com 0 intuito de melhorar 0 comportamento das redes neurais.

\section{Arquiteturas de Redes Neurais Artificiais}

A arquitetura de uma rede neural está relacionada à quantidade de neurônios, quantidade de camadas e ao tipo de aprendizado utilizado para o treinamento da rede. Essa arquitetura varia para cada problema a ser solucionado.

Em conjunto com a arquitetura das redes neurais é utilizada a função de ativação de cada neurônio. Sua função é limitar a saída do neurônio dentro de um intervalo de valores. Cada função de ativação possui um cálculo e um gráfico 
característico. As principais funções de ativação são ilustradas nas Figuras A.1 a A.5:

a) Função degrau

$$
g(u)=\left\{\begin{array}{l}
1, \text { se } u \geq 0 \\
0, \text { se } u<0
\end{array}\right.
$$

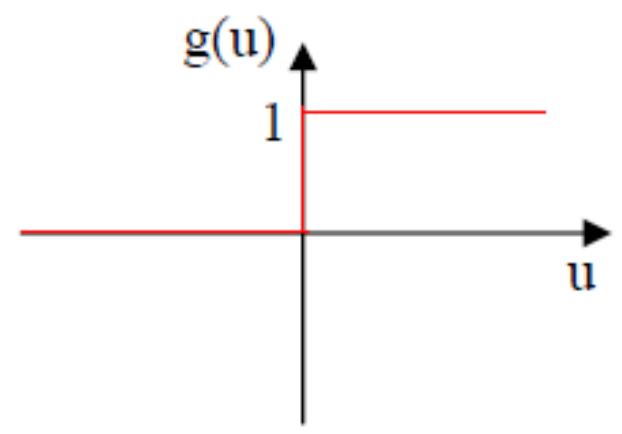

Figura A.1 - Função degrau.

b) Função degrau bipolar

$$
g(u)=\left\{\begin{array}{c}
1, \text { se } u>0 \\
0, \text { se } u=0 \\
-1, \text { se } u<0
\end{array}\right.
$$

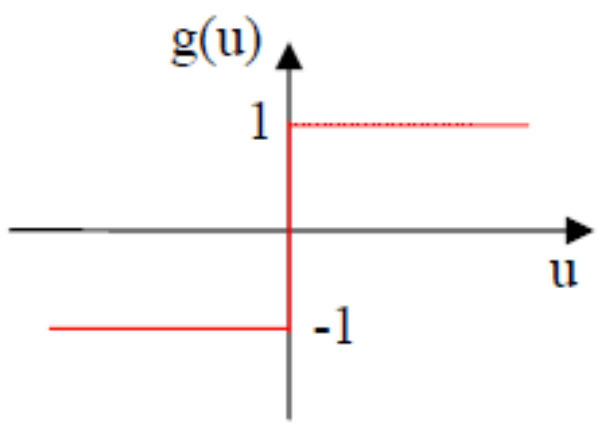

Figura A.2 - Função degrau bipolar. 
c) Tangente hiperbólica

$$
g(u)=\frac{1-e^{-\beta u}}{1+e^{-\beta u}}
$$

onde $\beta$ é o parâmetro de excentricidade.

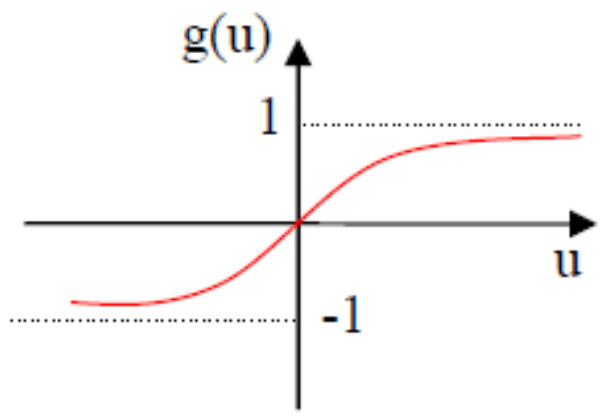

Figura A.3 - Função tangente hiperbólica.

d) Função rampa

$$
g(u)=\left\{\begin{array}{c}
1, \text { se } u>1 \\
u, \quad \text { se }-1 \leq u \leq 1 \\
-1, \text { se } u<0
\end{array}\right.
$$

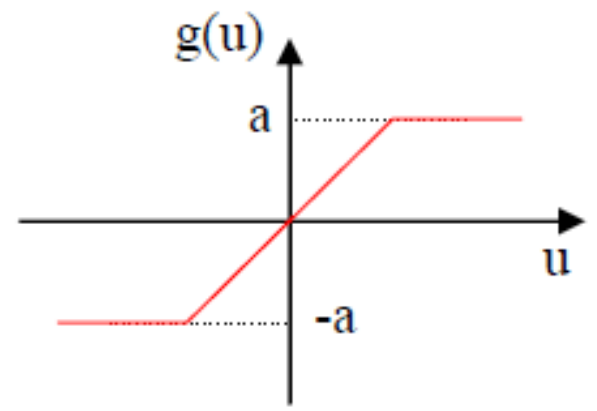

Figura A.4 - Função rampa.

e) Função logística

$$
g(u)=\frac{1}{1+e^{-\beta u}}
$$




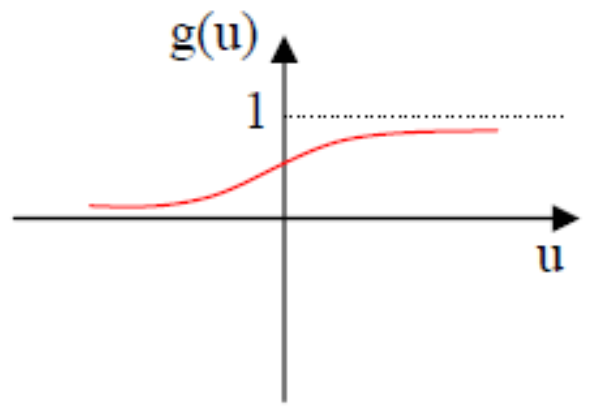

Figura A.5 - Função logística.

\section{Perceptron de Múltiplas Camadas}

Segundo Haykin (1999), as redes MLP consiste de uma camada de entrada, uma ou mais camadas ocultas e uma camada de saída. O sinal de entrada se propaga para frente da rede camada por camada.

A Figura A.6 ilustra um modelo de perceptron de múltiplas camadas.

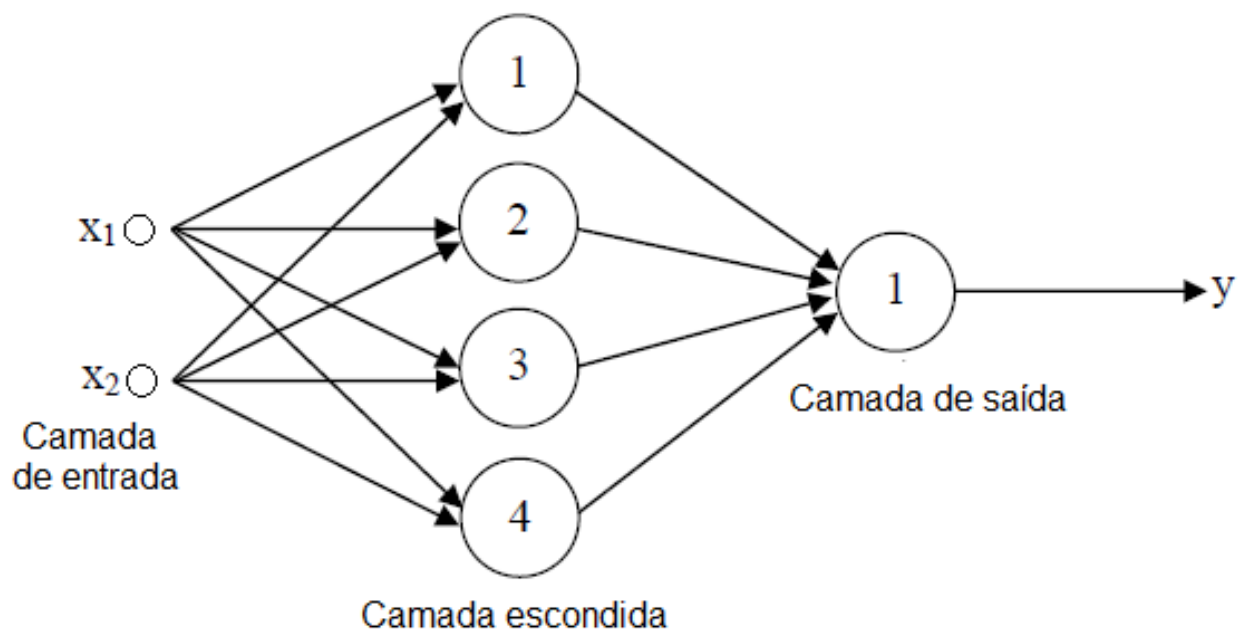

Figura A.6 - Modelo de perceptron de múltiplas camadas.

Os tipos de treinamentos mais utilizados para o perceptron de múltiplas camadas são os seguintes: o backpropagation, conhecido também como regra delta generalizada, em que se utiliza a direção oposta ao gradiente para encontrar uma solução considerada ótima dentro do problema e o Levenberg-Marquardt em que se 
utiliza o método dos mínimos quadrados. O Levenberg-Marquardt possui um treinamento mais rápido em relação ao backpropagation. 


\section{Apêndice B}

\section{Código fonte da rede neural embarcada}

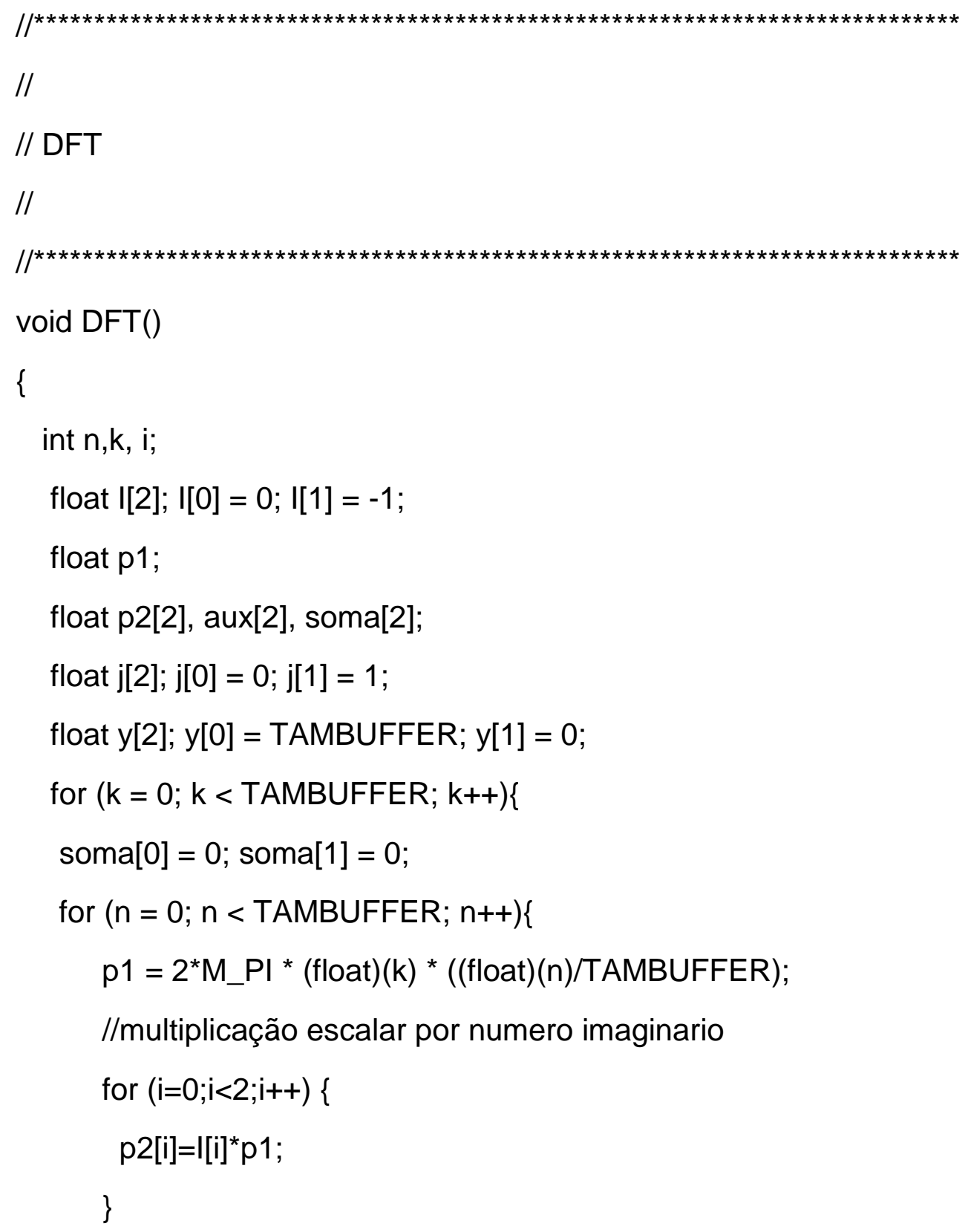


//exponencial imaginario

for $(\mathrm{i}=0 ; \mathrm{i}<2 ; \mathrm{i}++)\{$

$\operatorname{aux}[\mathrm{i}]=\mathrm{j}[\mathrm{i}]^{*} \sin (\mathrm{p} 2[1])$;

\}

$\operatorname{aux}[0]=\cos (p 2[1]) ;$

for $(i=0 ; i<2 ; i++)\{$

$\operatorname{aux}[i]=\operatorname{aux}[i]^{*} \exp (p 2[0])$;

\}

$\mathrm{p} 2[0]=\mathrm{aux}[0]$;

$\mathrm{p} 2[1]=\operatorname{aux}[1]$;

//escalar

for $(\mathrm{i}=0 ; \mathrm{i}<2 ; \mathrm{i}++)\{$

p2 $[i]=p 2[i]^{*}$ (buffer[prim].corrente[n]);

\}

//soma

for $(i=0 ; i<2 ; i++)\{$

soma $[i]=$ soma[i]+p2[i];

\}

// divisao

bufferFFT.saida[k][0]= $\left.\left.\left(\left((\text { soma[0] }]^{*} \mathrm{y}[0]\right)+(\text { soma[1] }]^{*} \mathrm{y}[1]\right)\right) /\left(\mathrm{y}[0]^{*} \mathrm{y}[0]+\mathrm{y}[1]^{\star} \mathrm{y}[1]\right)\right)$;

bufferFFT.saida[k][1] $=\left(\left(-\left(\right.\right.\right.$ soma[0] $\left.\left.\left.\left.{ }^{*} y[1]\right)+(\text { soma[1] }]^{*} y[0]\right)\right) /\left(y[0]^{*} y[0]+y[1]^{*} y[1]\right)\right)$;

bufferFFT.absoluto[k] = sqrt((bufferFFT.saida[k][0] * bufferFFT.saida[k][0]) + (bufferFFT.saida[k][1] * bufferFFT.saida[k][1]));

\}

\} 


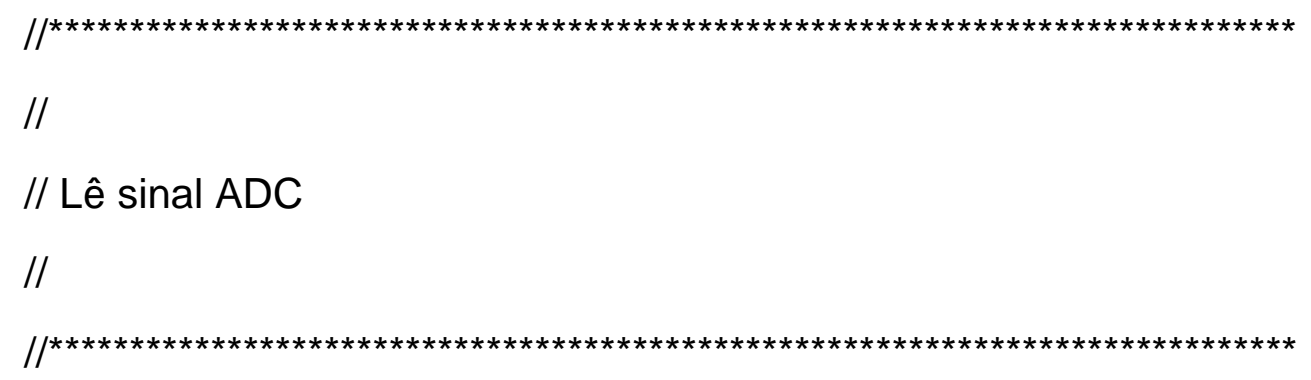

void le_sinal()

\{

ADCProcessorTrigger(ADC0_BASE, 0);

while(!ADCIntStatus(ADC0_BASE, 0, false))

\{

\}

ADCIntClear(ADC0_BASE, 0);

ADCSequenceDataGet(ADC0_BASE, 0, ulADC0_Value);

float $\mathrm{c}=0.0$;

$c=((4.0 *$ ulADC0_Value[0])/500.0) - 2.0;

buffer[fim].corrente[contador] $=\mathrm{c}$;

contador++;

ulADC0_Value[0] = 0x00;

\}

while(1)

\{

if(prim != fim) \{

TimerDisable(TIMER0_BASE, TIMER_A);

DFT();

entrada[0][0] = bufferFFT.absoluto[4];

entrada[1][0] = bufferFFT.absoluto[12];

entrada[2][0] = bufferFFT.absoluto[20]; 
entrada[3][0] = bufferFFT.absoluto[28];
entrada[4][0] = bufferFFT.absoluto[32];
entrada[5][0] = bufferFFT.absoluto[36];

int i, j, v;

${ }^{*}$ multiplica entrada pelos pesos *

for $(i=0 ; i<26 ; i++)\{$

for $(j=0 ; j<1 ; j++)\{$

saida1 $[i][j]=0$;

for $(v=0 ; v<6 ; v++)\{$

saida1 $[i][j]=$ saida1 $[i][j]+$ pesos1 Camada[i][v] * entrada[v][j];

\}

\}

\}

/* adiciona Bias $1 * /$

for $(i=0 ; i<26 ; i++)\{$

for $(j=0 ; j<1 ; j++)\{$

saida1 $[i][j]$ = saida1 $[i][j]+$ bias $1[i][j] ;$

\}

\}

/* saida função*/

for $(i=0 ; i<26 ; i++)\{$

for $(j=0 ; j<1 ; j++)\{$

saida1[i][j] = tansigDiscretizada(saida1[i][i]);

\}

\}

/* multiplica saída camada1 pelos pesos camada2 */ 


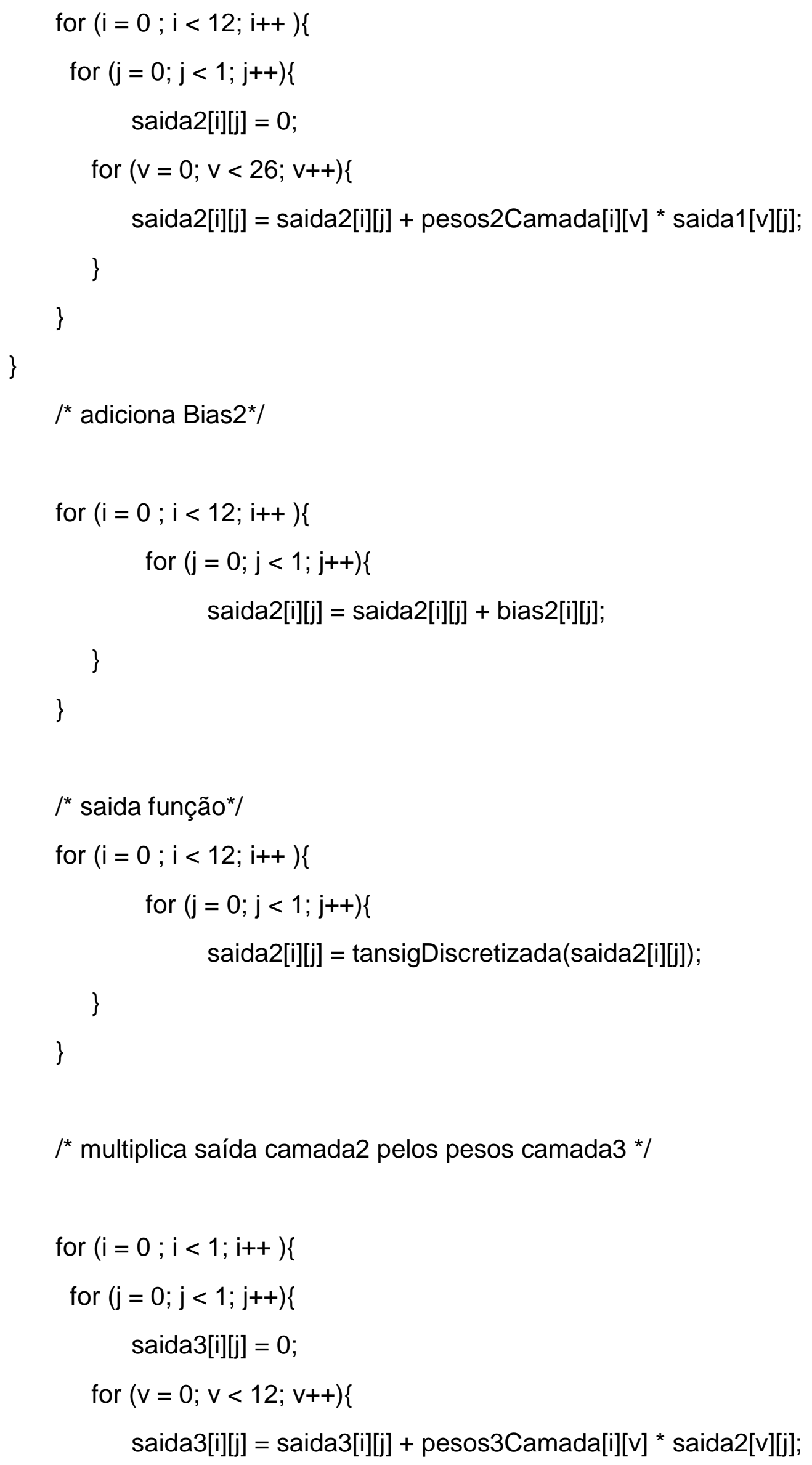




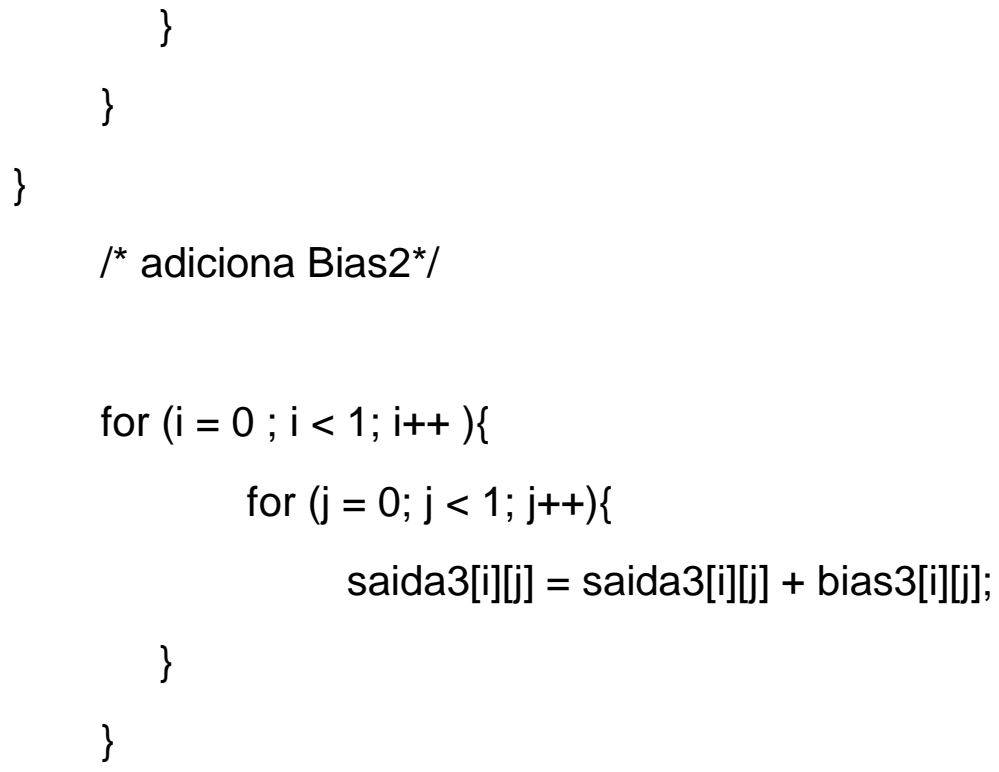




\section{Anexo 1}

\section{Fonte de Alimentação (Webench)}

\section{if TEXAS INSTRUMENTS \\ WEBENCH ${ }^{\circledR}$ Power Architect}

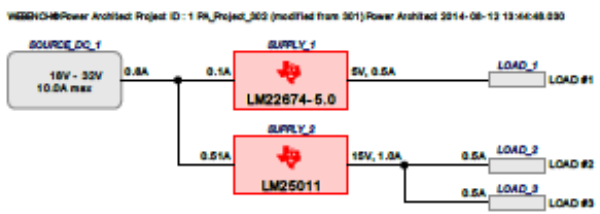

\section{Project Report}

Project : 3685159/1 : PA_Project_302 (modified from 301)

Created : 2014-08-12 13:44:48.030

Optimize project optFactor=3

Project Summary

1. Total System Efficiency

2. Total System BOM Coun

3. Total System Footprint

$90.556 \%$

20.0

4. Total System BOM Cost

$414.0 \mathrm{~mm} 2$

5. Total System Power Dissipation

$\$ 3.62$

$\rightarrow$ Launch WEBENCH Power Architect.

Power Supplies

\begin{tabular}{|c|c|c|c|c|c|c|c|c|c|c|}
\hline \# & Name & NSID & Description & Vout & lout & Efficiency & $\begin{array}{l}\text { Foot- } \\
\text { print }\end{array}$ & Cost & Design & Page \\
\hline 1 & SUPPLY_1 & LM22674-5.0 & Switcher: Low Part Count & $5 \mathrm{~V}$ & $0.5 \mathrm{~A}$ & $79.4 \%$ & 212 & $\$ 1.83$ & 1 & $\overline{4}$ \\
\hline 2 & SUPPLY_2 & LM25011 & $\begin{array}{l}\text { Switcher: COT BUCK regulator } \\
\text { with adjustable current limit }\end{array}$ & $15 \mathrm{~V}$ & $1.0 \mathrm{~A}$ & $92.7 \%$ & 202 & $\$ 1.79$ & 2 & 9 \\
\hline
\end{tabular}

Power Loads

\begin{tabular}{|c|c|c|c|c|}
\hline \# & Name & VLoad & ILoad & Description \\
\hline 1. & LOAD \#1 & $5 \mathrm{~V}$ & $0.5 \mathrm{~A}$ & VoutRipple $=10 \%$ \\
\hline 2. & LOAD \#2 & $15 \mathrm{~V}$ & $0.5 \mathrm{~A}$ & VoutRipple $=10^{\circ}$ \\
\hline & LOAD \#3 & $15 \mathrm{~V}$ & $0.5 \mathrm{~A}$ & VoutRipple $=10$ \\
\hline
\end{tabular}

SUPRLY1

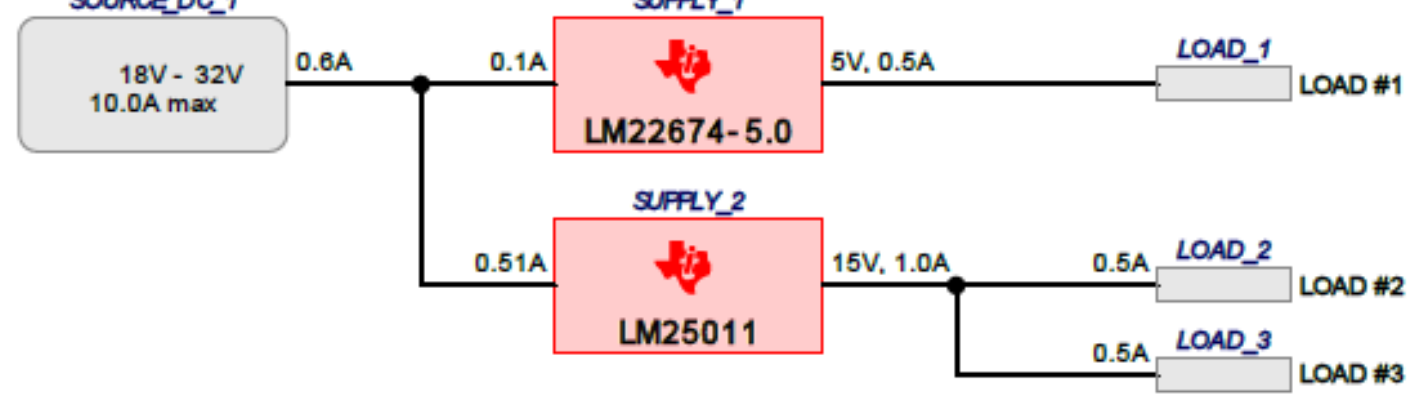


is TEXAS

INSTRUMENTS

\section{WEBENCH ${ }^{\circledR}$ Design Report}

Design : 3685159/1 LM22674MRX-5.0/NOPB

LM22674MRX-5.0/NOPB 18.0V-32.0V to 5.0V @ 0.5A
VinMin $=18.0 \mathrm{~V}$

VinMax $=32.0 \mathrm{~V}$

Vout $=5.0 \mathrm{~V}$

lout $=0.5 \mathrm{~A}$
Device $=$ LM22674MRX-5.0/NOPB

Topology $=$ Buck

Created = 8/12/14 1:44:46 PM

BOM Cost $=\$ 1.83$

Footprint $=212.0 \mathrm{~mm} 2$

BOM Count $=7$

Total Pd $=0.65 \mathrm{~W}$

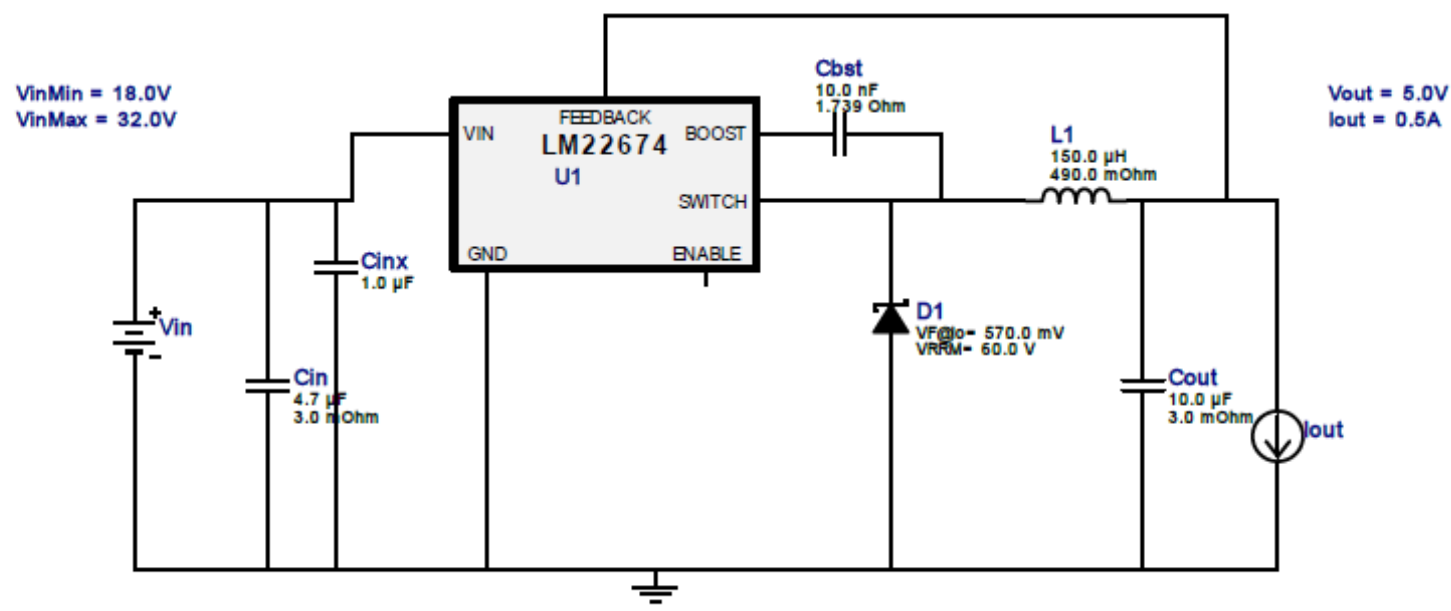

Electrical BOM

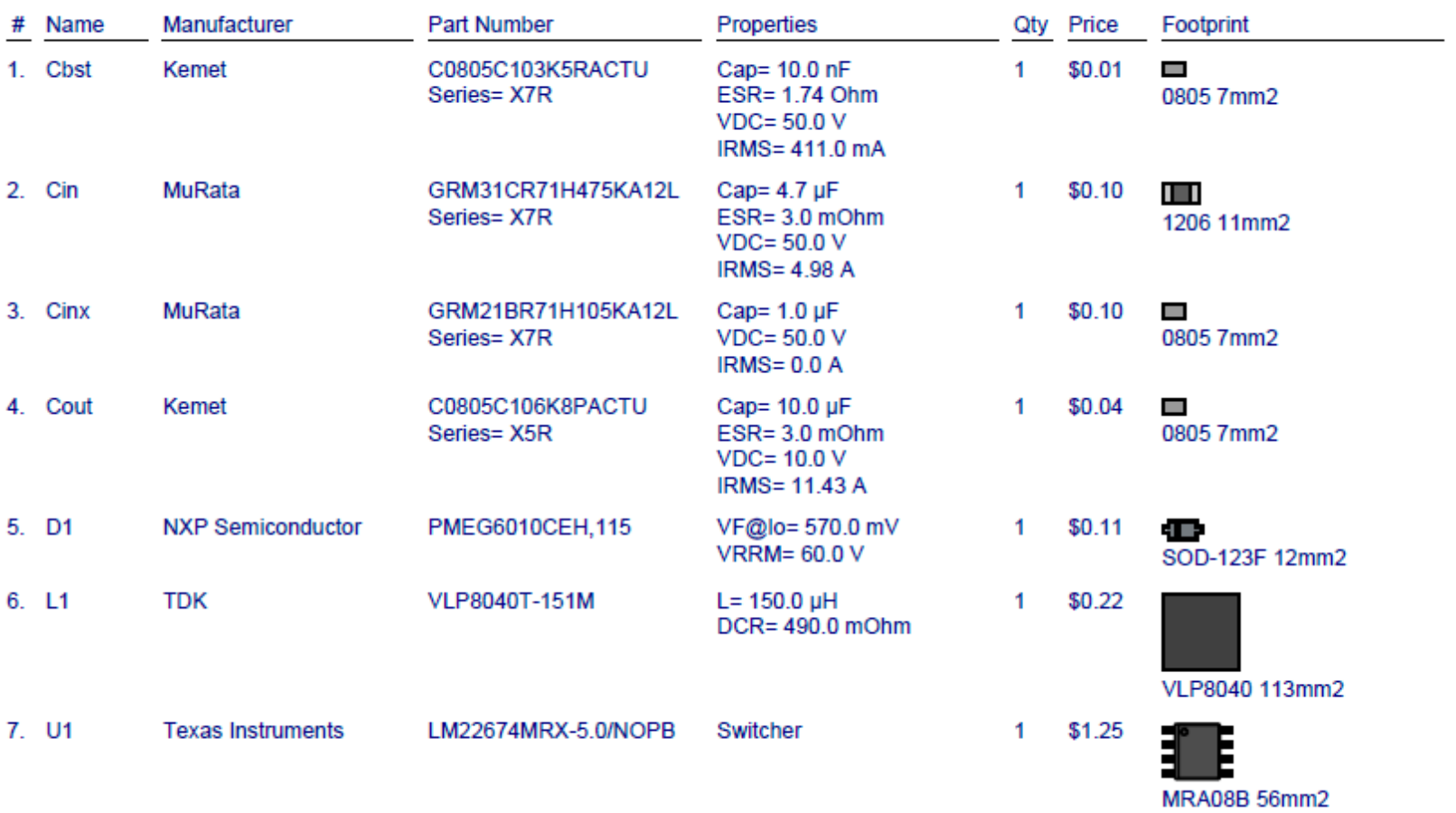


IC $\mathrm{Tj}$

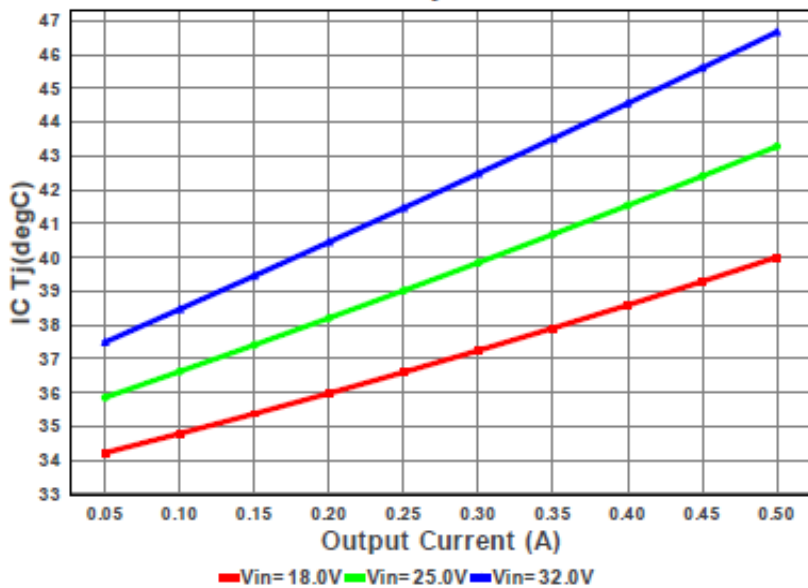

Cin IRMS

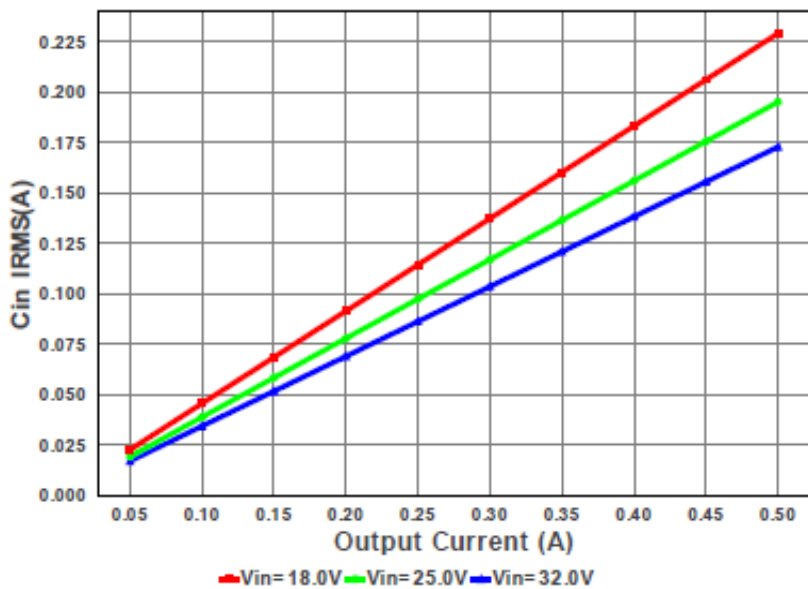

L Pd

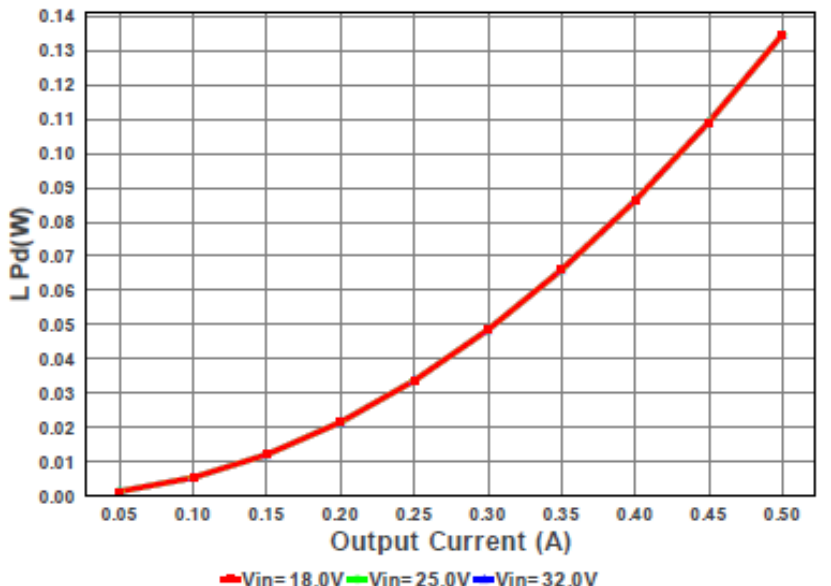

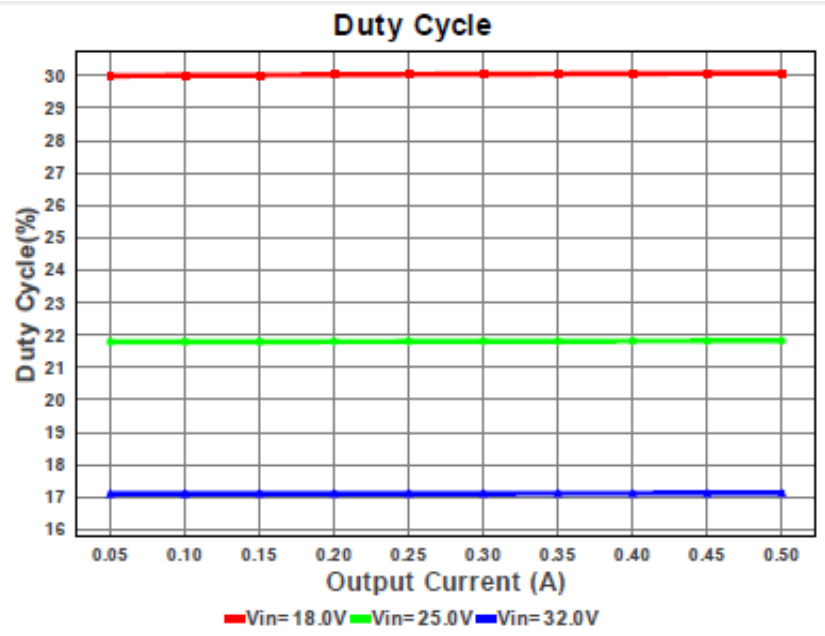

IC Ipk

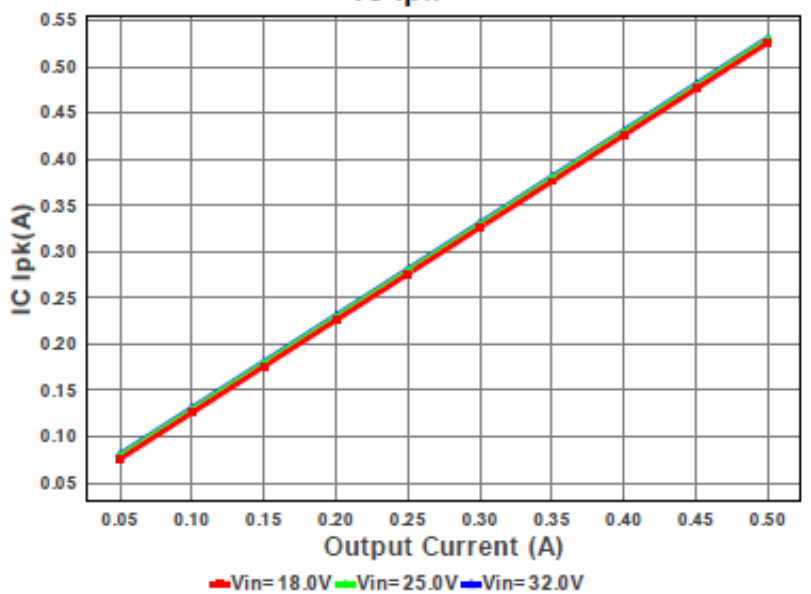

$\mathrm{D} 1 \mathrm{Tj}$

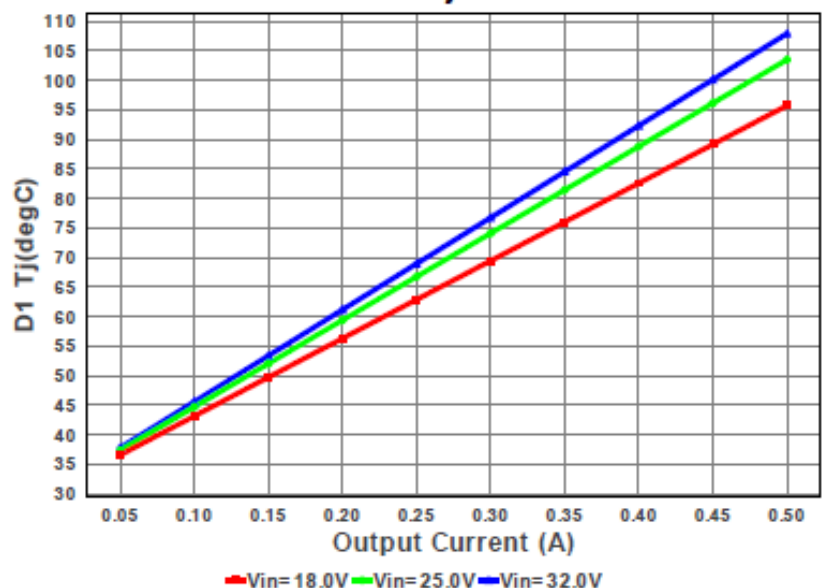




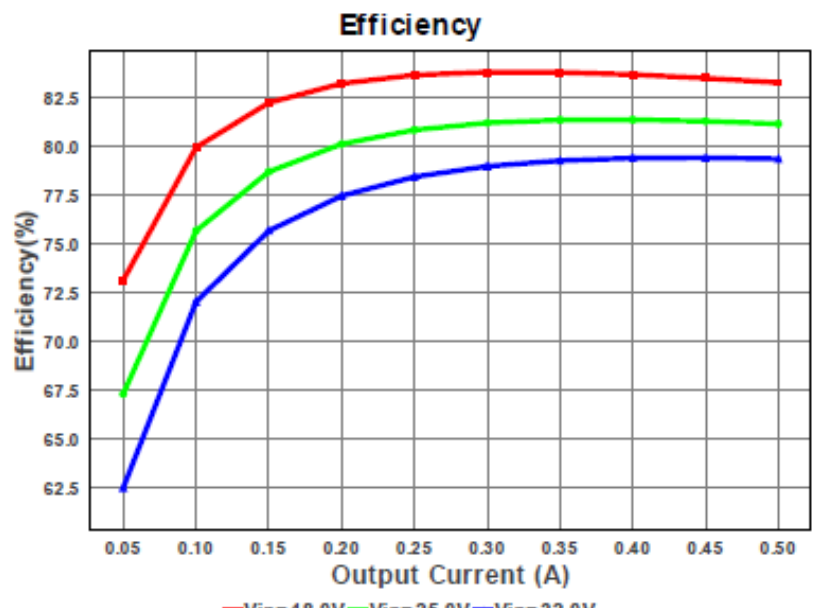

- Vin $=18.0 \mathrm{~V}=$ Vin=25.0VEVin=32.0V

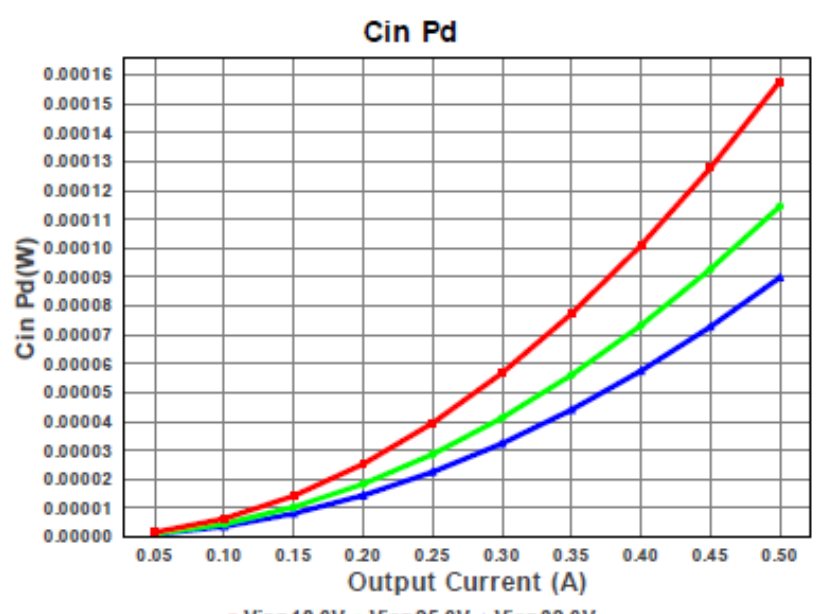

- Vin $=18.0 \mathrm{~V}=$ Vin $=25.0 \mathrm{~V}-$ Vin $=32.0 \mathrm{~V}$

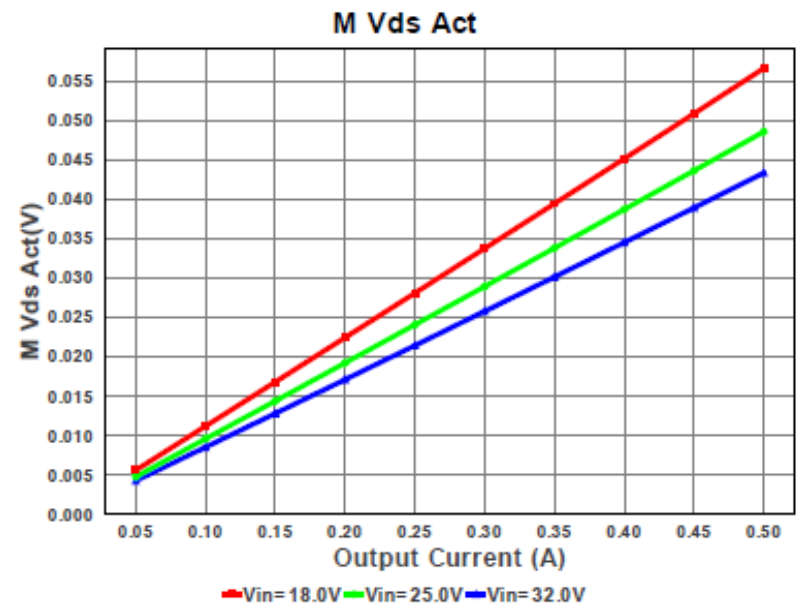

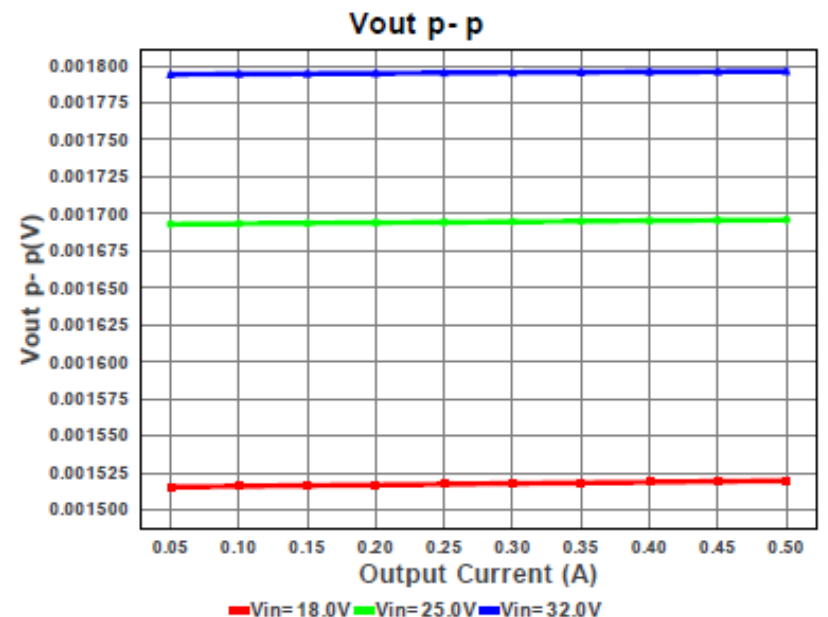
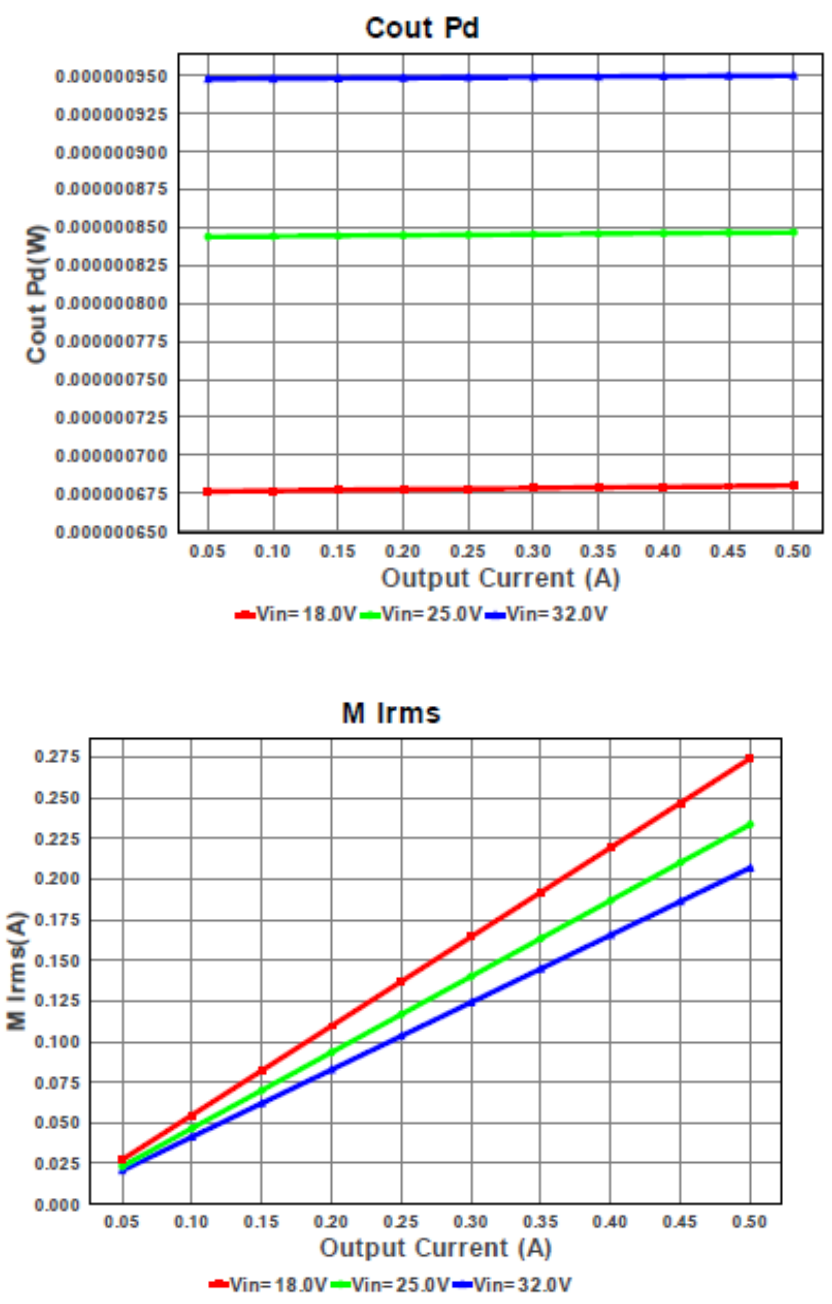

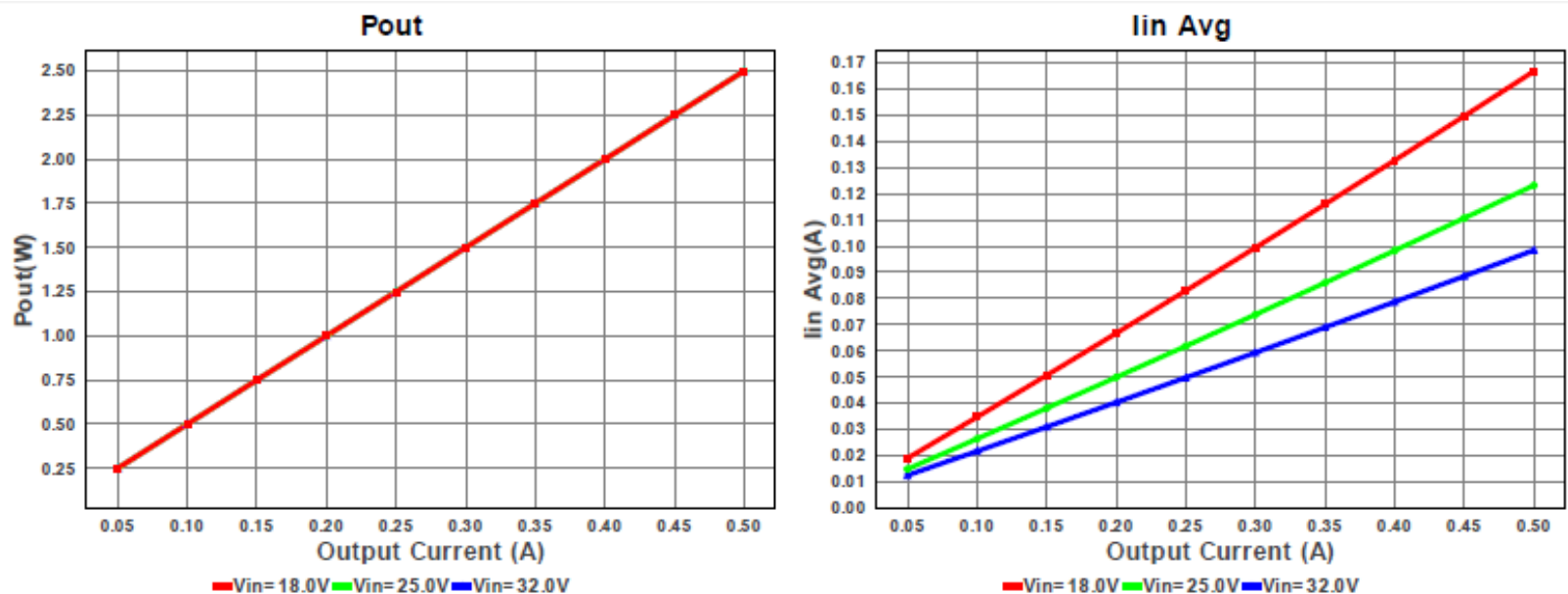

Total Po
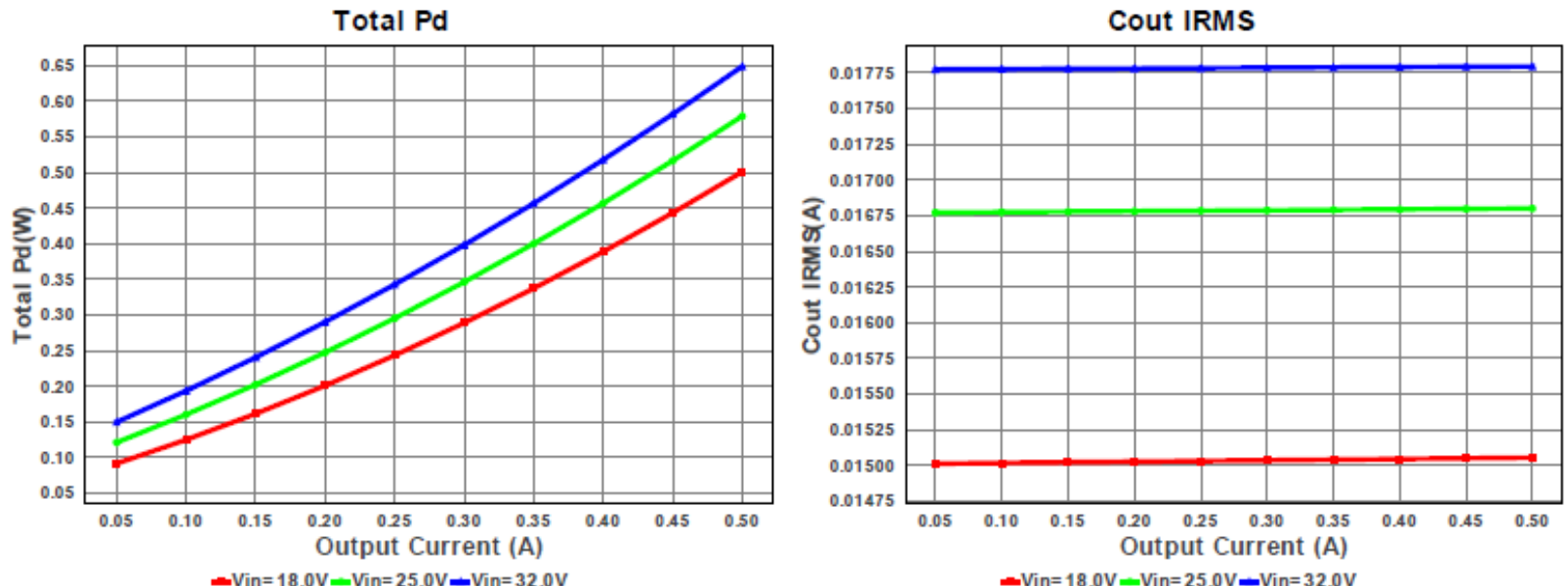

L Ipp

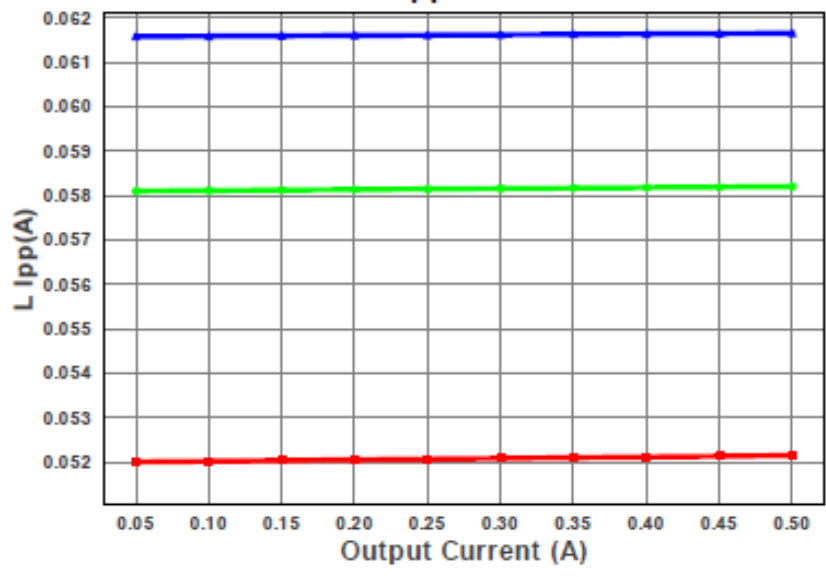

IC Pd

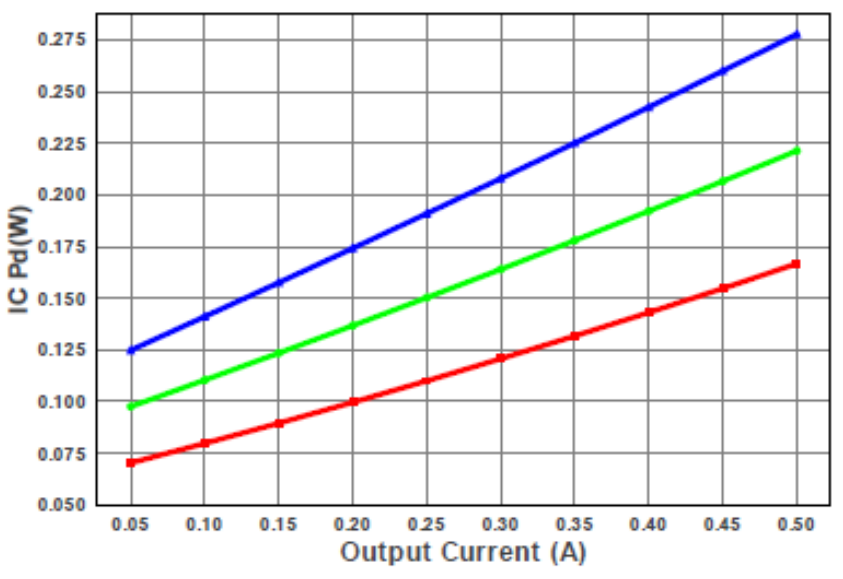

- Vin $=18.0 \mathrm{~V}-$ Vin $=25.0 \mathrm{~V}-$ Vin $=32.0 \mathrm{~V}$ 


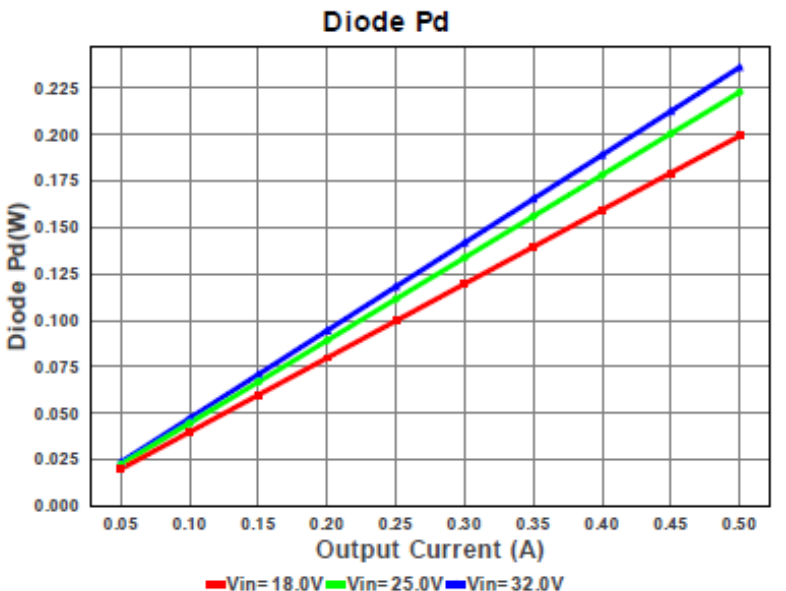

- Vin $=18.0 \mathrm{~V}=$ Vin $=25.0 \mathrm{~V}=$ Vin $=32.0 \mathrm{~V}$

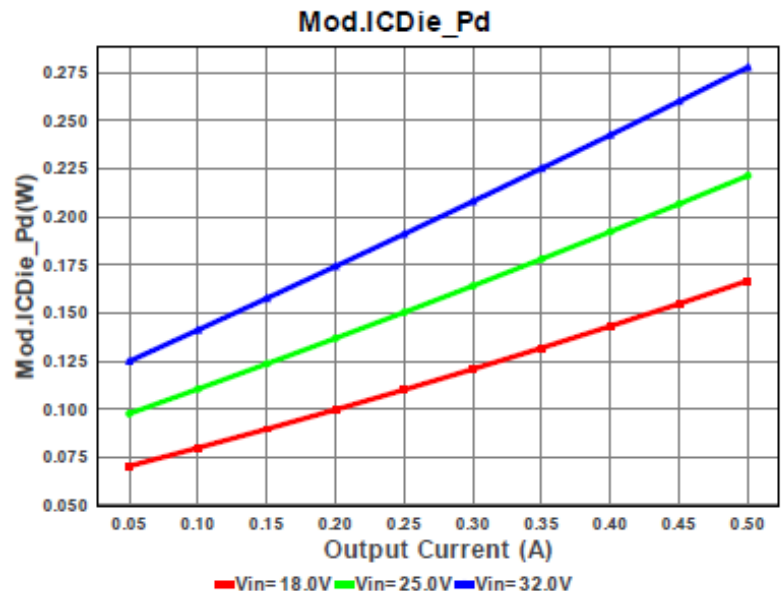

Description

Input capacitor RMS ripple current

Output capacitor RMS ripple current

Peak switch current in IC

Average input current

Peak-to-peak inductor ripple current

Q lavg

Total Design BOM count

Total Foot Print Area of BOM components

Switching frequency

IC Feedback Tolerance

Voltage drop across the MosFET

Total output power

Total BOM Cost

D1 junction temperature

Operational Output Voltage

Bode plot crossover frequency

Duty cycle

Steady state efficiency

IC junction temperature

IC junction-to-ambient thermal resistance

lout operating point

Bode Plot Phase Margin

Vin operating point

Peak-to-peak output ripple voltage

Input capacitor power dissipation

Output capacitor power dissipation

Diode power dissipation

IC power dissipation

Inductor power dissipation

Total Power Dissipation

\section{Design Inputs}

\begin{tabular}{clll}
$\#$ & Value & Description \\
\hline 1. & lout & $500.0 \mathrm{~mA}$ & Maximum Output Current \\
2. lout1 & $500.0 \mathrm{mAmps}$ & Output Current \#1 \\
3. VinMax & $32.0 \mathrm{~V}$ & Maximum input voltage \\
4. VinMin & $18.0 \mathrm{~V}$ & Minimum input voltage \\
5. Vout & $5.0 \mathrm{~V}$ & Output Voltage \\
6. Vout1 & $5.0 \mathrm{Volt}$ & Output Voltage \#1 \\
7. base_pn & LM22674 & Base Product Number \\
8. Source & DC & Input Source Type \\
9. Ta & $30.0 \mathrm{degC}$ & Ambient temperature
\end{tabular}

\section{Design Assistance}

1. Part Description The LM22674 is a monolithic integrated circuit that provides all of the active functions for a step-down (buck) switching regulator capable of driving up to $0.5 \mathrm{~A}$ loads with excellent line and load regulation characteristics. High efficiency ( $>90 \%$ ) is obtained through the use of a low ON-resistance N-channel MOSFET.

2. LM22674 Product Folder : http://www.ti.com/product/lm22674 : contains the data sheet and other resources. 
Tis TEXAS

INSTRUMENTS

WEBENCH ${ }^{\circledR}$ Design Report
VinMin $=18.0 \mathrm{~V}$

VinMax $=32.0 \mathrm{~V}$

Vout $=15.0 \mathrm{~V}$

lout $=1.0 \mathrm{~A}$
Device $=$ LM25011MY $/$ NOPB

Topology $=$ Buck

Created $=8 / 12 / 14$ 1:44:46 PM

BOM Cost $=\$ 1.79$

Footprint $=202.0 \mathrm{~mm} 2$

BOM Count $=13$

Total Pd $=1.18 \mathrm{~W}$

Design : 3685159/2 LM25011MY/NOPB

LM25011MY/NOPB $18.0 \mathrm{~V}-32.0 \mathrm{~V}$ to $15.0 \mathrm{~V} @ 1.0 \mathrm{~A}$

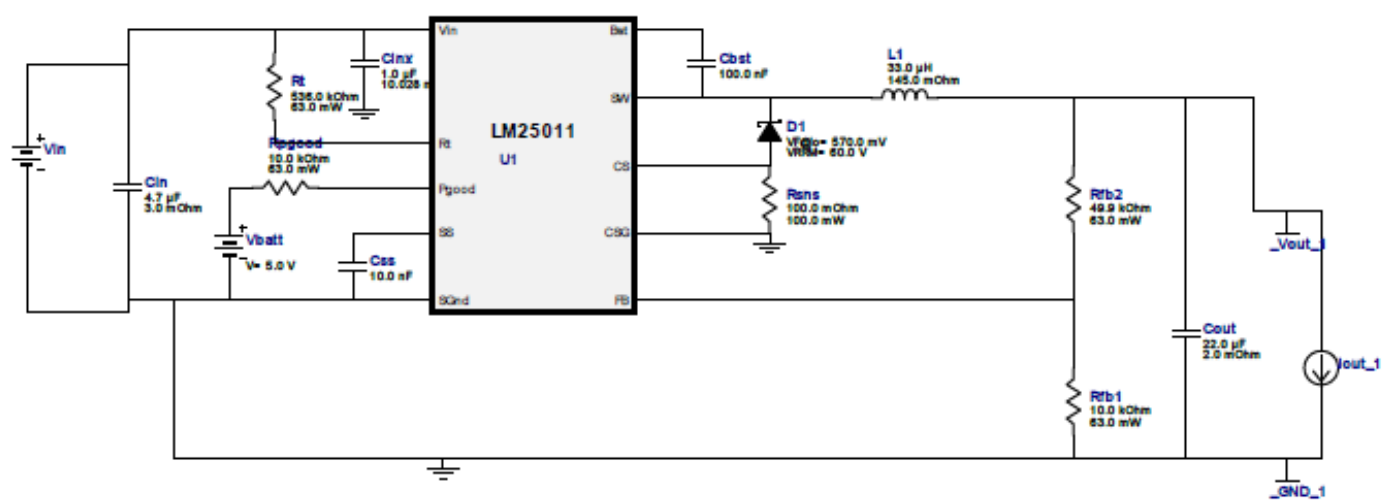<smiles>CCOCCO</smiles>

Electrical BOM

\# Name Manufacturer $\quad$ Part Numb

1. Cbst Yageo America

CC0805KRX7R9BB104 Cap $=100.0 \mathrm{nF}$

Series $=\mathrm{X} 7 \mathrm{R}$

$\mathrm{VDC}=50.0 \mathrm{~V}$

IRMS $=0.0 \mathrm{~A}$

2. Cin

GRM31CR71H475KA12L

Cap $=4.7 \mu \mathrm{F}$

$\mathrm{ESR}=3.0 \mathrm{mOhm}$

$\mathrm{VDC}=50.0 \mathrm{~V}$

IRMS $=4.98 \mathrm{~A}$

3. $\operatorname{Cin} x \quad T D K$

C3216JB1H105K

Series $=285$

$\mathrm{Cap}=1.0 \mu \mathrm{F}$

$\mathrm{ESR}=10.028 \mathrm{mOhm}$

$\mathrm{VDC}=50.0 \mathrm{~V}$

IRMS $=0.0 \mathrm{~A}$

4. Cout MuRata

GRM32ER61E226KE15L Series $=$ X5R

$\mathrm{Cap}=22.0 \mu \mathrm{F}$

$\mathrm{ESR}=2.0 \mathrm{mOhm}$

$\mathrm{VDC}=25.0 \mathrm{~V}$

IRMS $=3.67 \mathrm{~A}$

5. Css MuRata

GRM216R71H103KA01D

Series $=\mathrm{X} 7 \mathrm{R}$

$\mathrm{Cap}=10.0 \mathrm{nF}$

$\mathrm{VDC}=50.0 \mathrm{~V}$

IRMS $=0.0 \mathrm{~A}$

6. D1 NXP Semiconductor

PMEG6010CEH,115

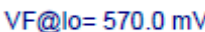

VRRM $=60.0 \mathrm{~V}$

SRN8040-330M

$\mathrm{L}=33.0 \mu \mathrm{H}$

DCR $=145.0 \mathrm{mOhm}$

Qty Price Footprint

$08057 \mathrm{~mm} 2$

Tा

$120611 \mathrm{~mm} 2$

$\$ 0.04$ पा

$120611 \mathrm{~mm} 2$

$\$ 0.28$

$121015 \mathrm{~mm} 2$

$08057 \mathrm{~mm} 2$

$1 \$ 0.11$

SOD-123F 12mm2

$1 \$ 0.22$

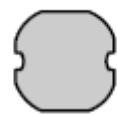

SRN8040 100mm2 


\begin{tabular}{|c|c|c|c|c|c|c|}
\hline \# Name & Manufacturer & Part Number & Properties & Qty & Price & Footprint \\
\hline 8. $\mathrm{Rfb} 1$ & Vishay-Dale & $\begin{array}{l}\text { CRCW040210KOFKED } \\
\text { Series= CRCW..e3 }\end{array}$ & $\begin{array}{l}\text { Res }=10.0 \mathrm{kOhm} \\
\text { Power }=63.0 \mathrm{~mW} \\
\text { Tolerance }=1.0 \%\end{array}$ & 1 & $\$ 0.01$ & $04023 \mathrm{~mm} 2$ \\
\hline 9. $\mathrm{Rfb} 2$ & Vishay-Dale & $\begin{array}{l}\text { CRCW040249K9FKED } \\
\text { Series= CRCW..e3 }\end{array}$ & $\begin{array}{l}\text { Res }=49.9 \mathrm{kOhm} \\
\text { Power }=63.0 \mathrm{~mW} \\
\text { Tolerance }=1.0 \%\end{array}$ & 1 & $\$ 0.01$ & $04023 \mathrm{~mm} 2$ \\
\hline 10. Rpgood & Vishay-Dale & $\begin{array}{l}\text { CRCW040210KOFKED } \\
\text { Series= CRCW..e3 }\end{array}$ & $\begin{array}{l}\text { Res }=10.0 \mathrm{kOhm} \\
\text { Power }=63.0 \mathrm{~mW} \\
\text { Tolerance }=1.0 \%\end{array}$ & 1 & $\$ 0.01$ & $04023 \mathrm{~mm} 2$ \\
\hline 11. Rsns & Panasonic & $\begin{array}{l}\text { ERJ-3RSFR10V } \\
\text { Series }=227\end{array}$ & $\begin{array}{l}\text { Res }=100.0 \mathrm{mOhm} \\
\text { Power }=100.0 \mathrm{~mW} \\
\text { Tolerance }=1.0 \%\end{array}$ & 1 & $\$ 0.03$ & $06035 \mathrm{~mm} 2$ \\
\hline 12. Rt & Vishay-Dale & $\begin{array}{l}\text { CRCW0402536KFKED } \\
\text { Series= CRCW..e3 }\end{array}$ & $\begin{array}{l}\text { Res }=536.0 \mathrm{kOhm} \\
\text { Power }=63.0 \mathrm{~mW} \\
\text { Tolerance }=1.0 \%\end{array}$ & 1 & $\$ 0.01$ & $04023 \mathrm{~mm} 2$ \\
\hline 13. U1 & Texas Instruments & LM25011MY/NOPB & Switcher & 1 & $\$ 0.95$ & \\
\hline
\end{tabular}

IC Tj

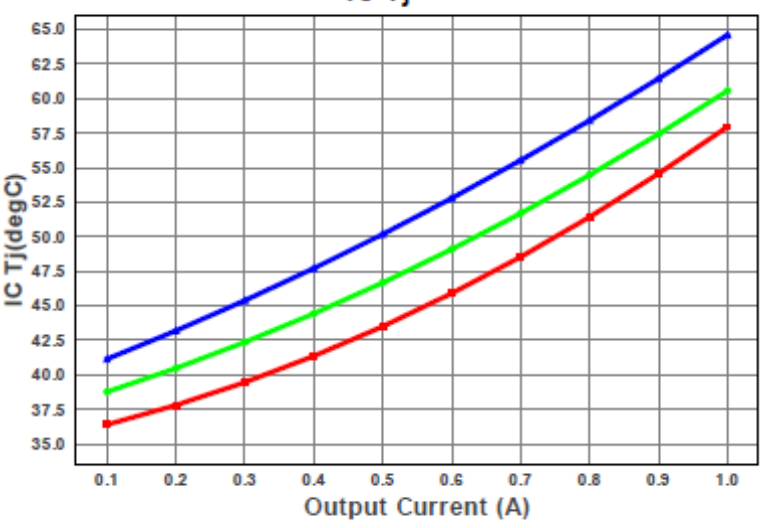

- Vin $=18.0 \mathrm{~V}=$ Vin $=25.0 \mathrm{~V}-$ Vin $=32.0 \mathrm{~V}$

Cin IRMS

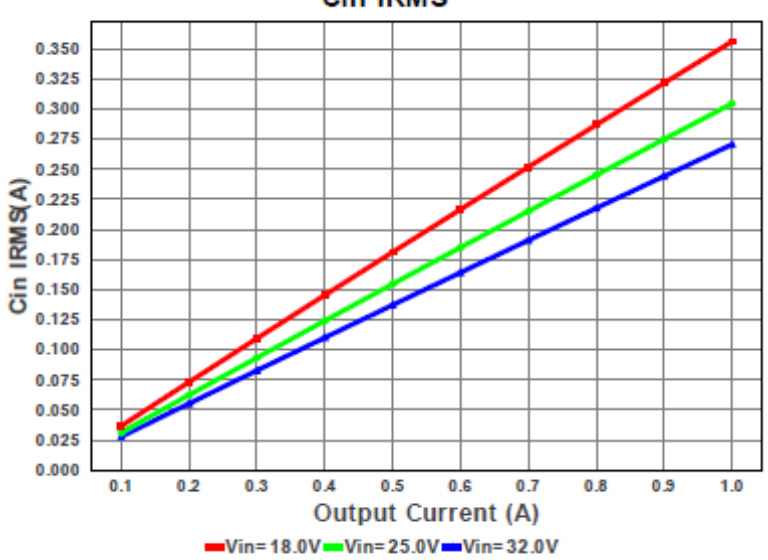

Duty Cycle

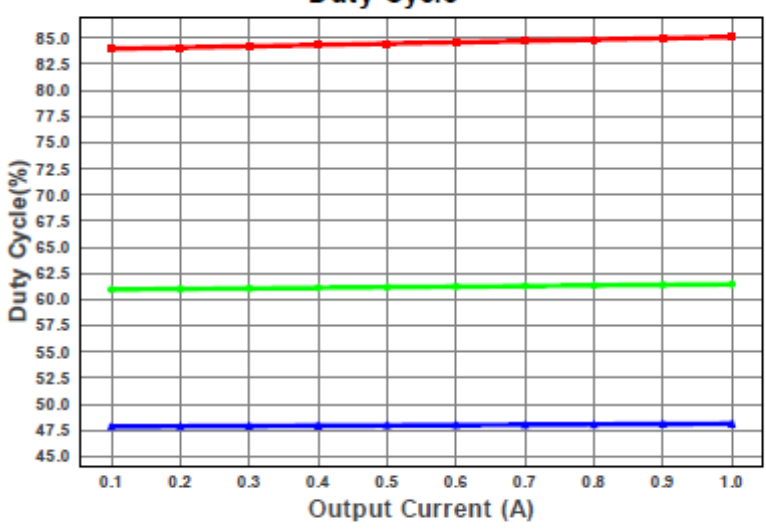

- Vin $=18.0 \mathrm{~V}-\mathrm{Vin}=25.0 \mathrm{~V}-\mathrm{Vin}=32.0 \mathrm{~V}$

IC Ipk

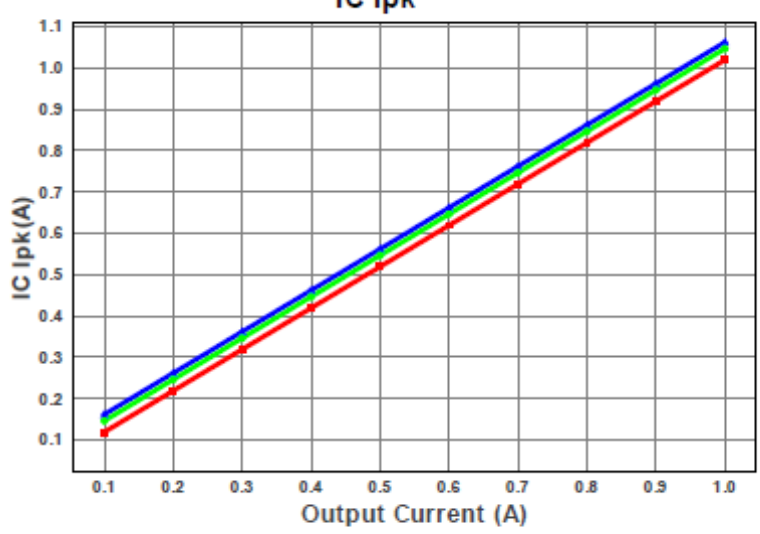

$-\mathrm{Vin}=18.0 \mathrm{~V}=\mathrm{Vin}=25.0 \mathrm{~V}=\mathrm{Vin}=32.0 \mathrm{~V}$ 
L Pd

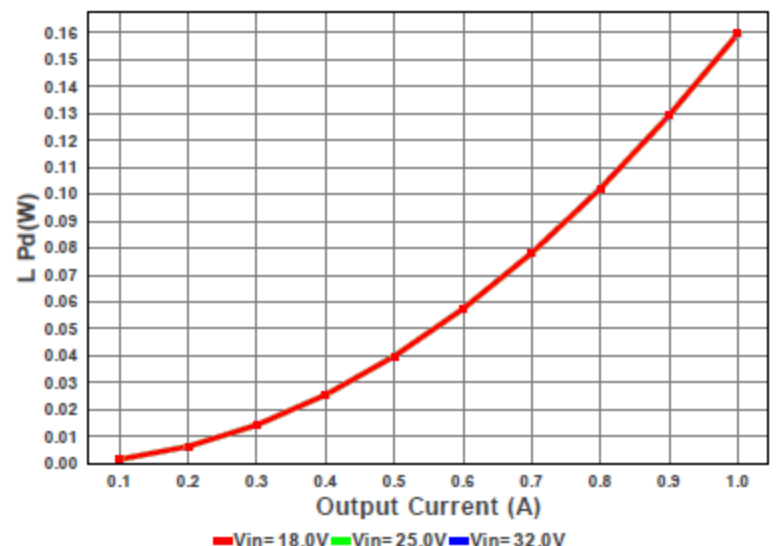

Efficiency

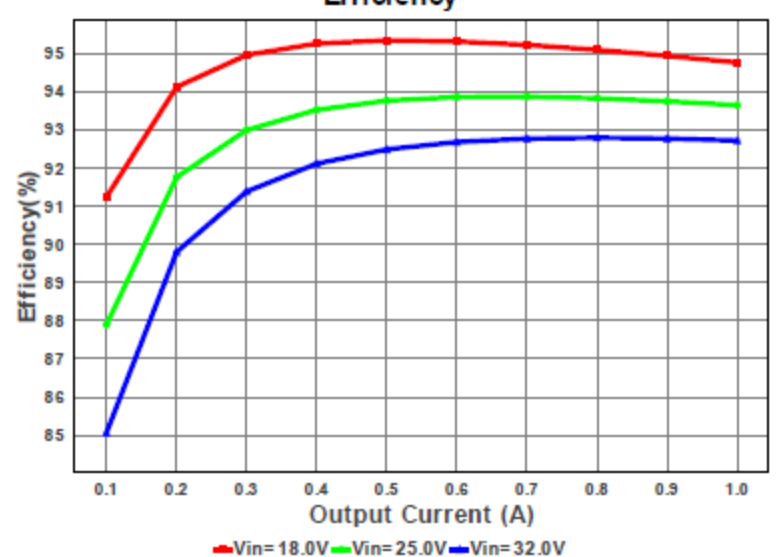

Cin Pd

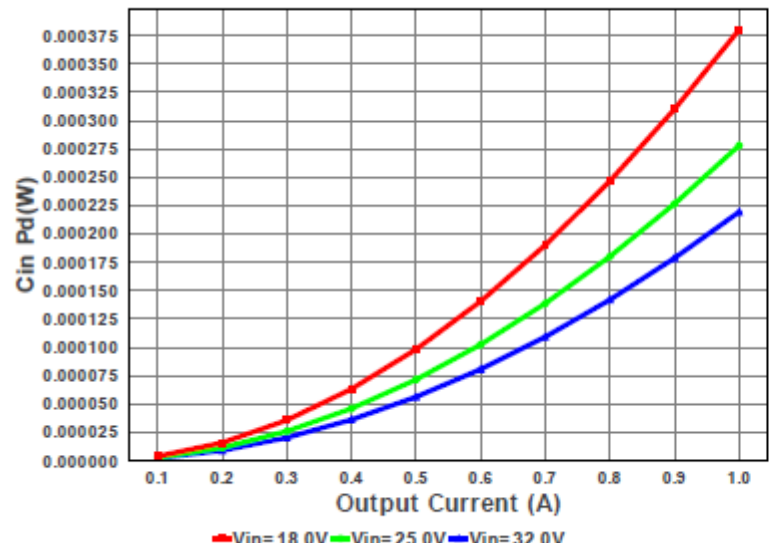

D1 Tj

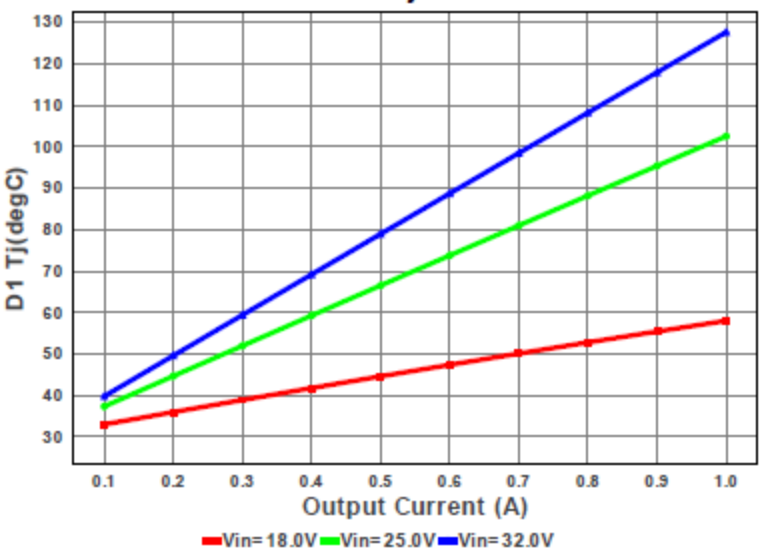

Vout $p-p$

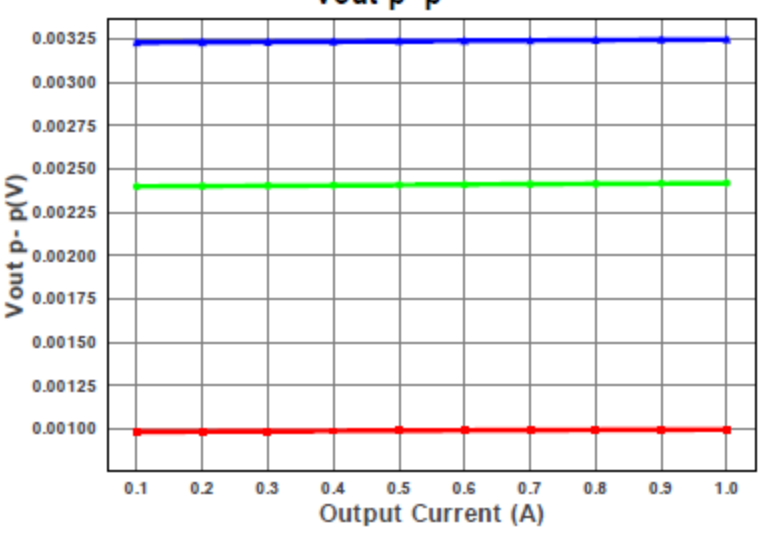

- Vin $=18.0 \mathrm{~V}-$ Vin $=25.0 \mathrm{~V}-$ Vin $=32.0 \mathrm{~V}$

Cout Pd

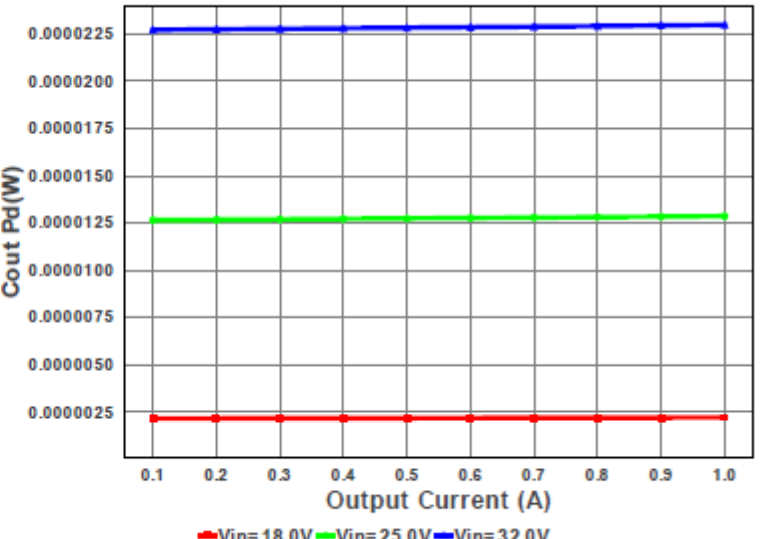



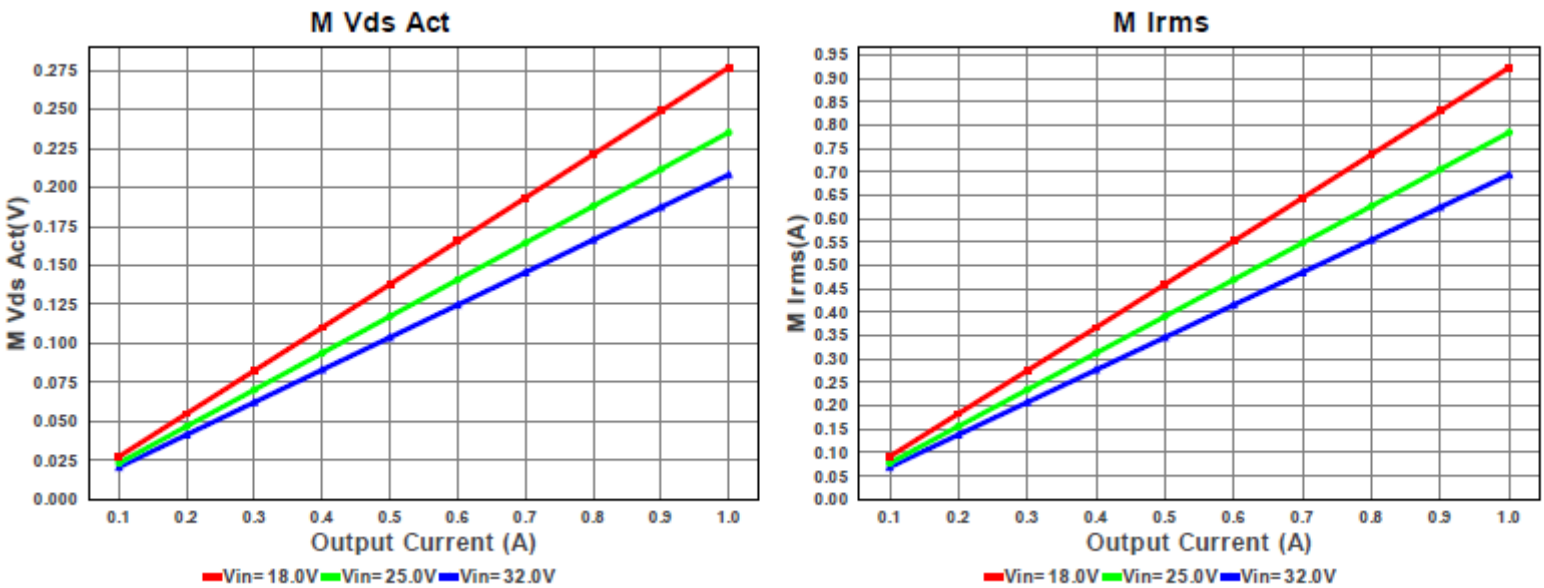

Pout
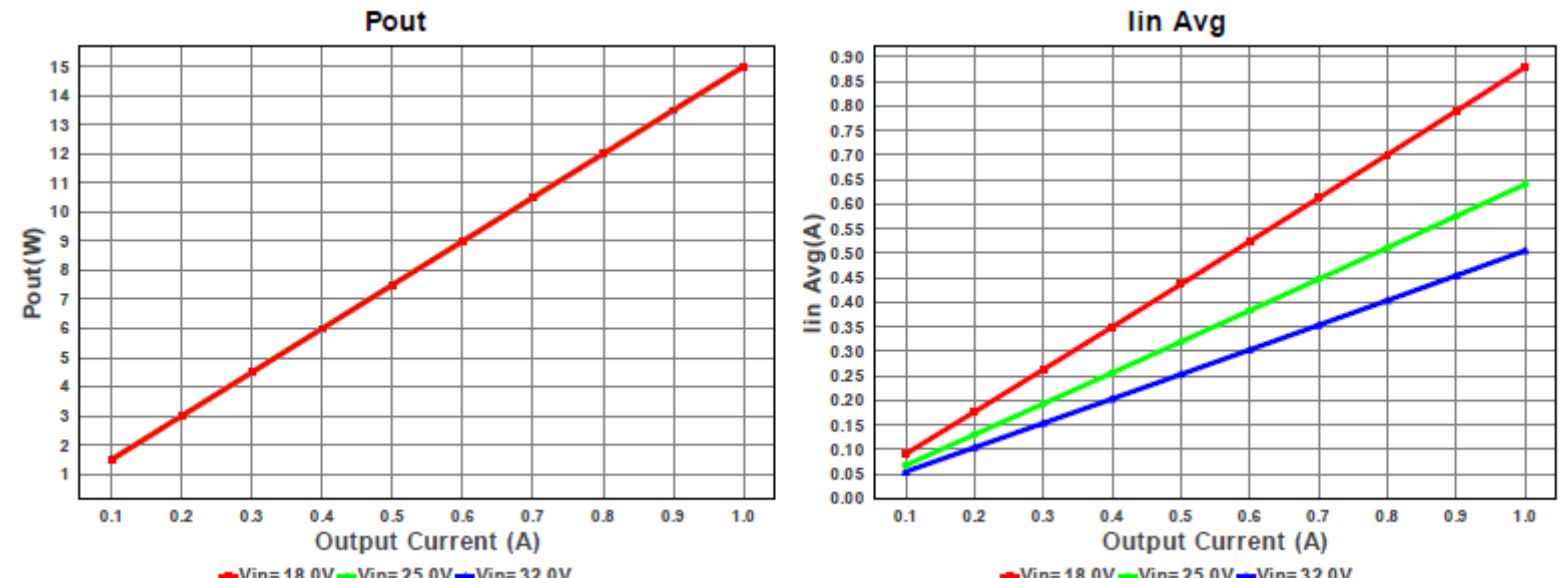

$-V_{i n}=18.0 \mathrm{~V}-V_{i n}=25.0 \mathrm{~V}-$ Vin $=32.0 \mathrm{~V}$

Total Pd
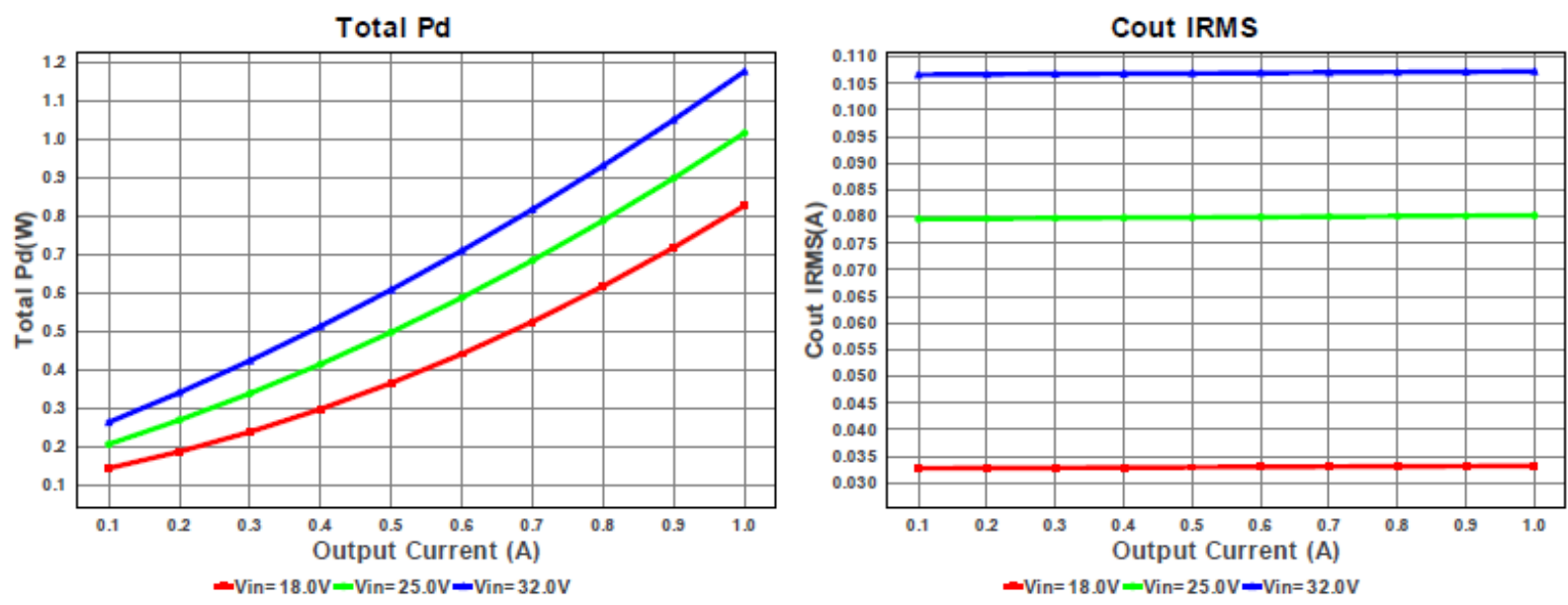
L Ipp

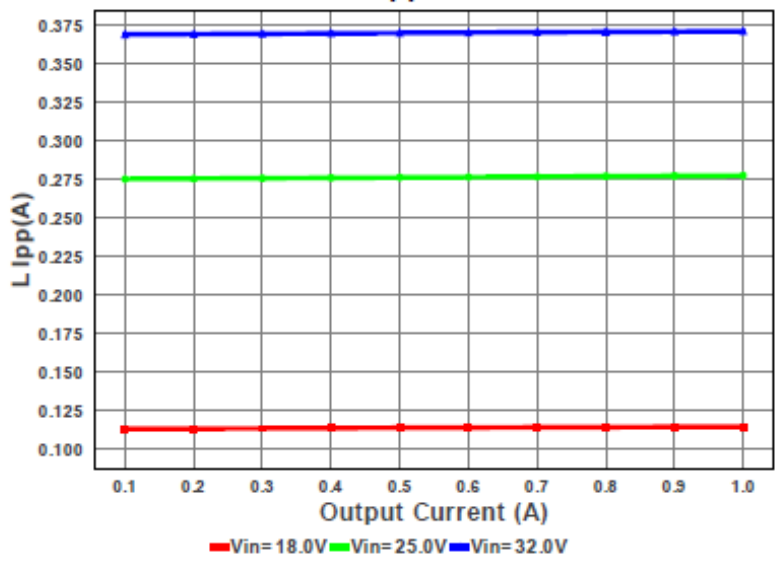

Diode Pd

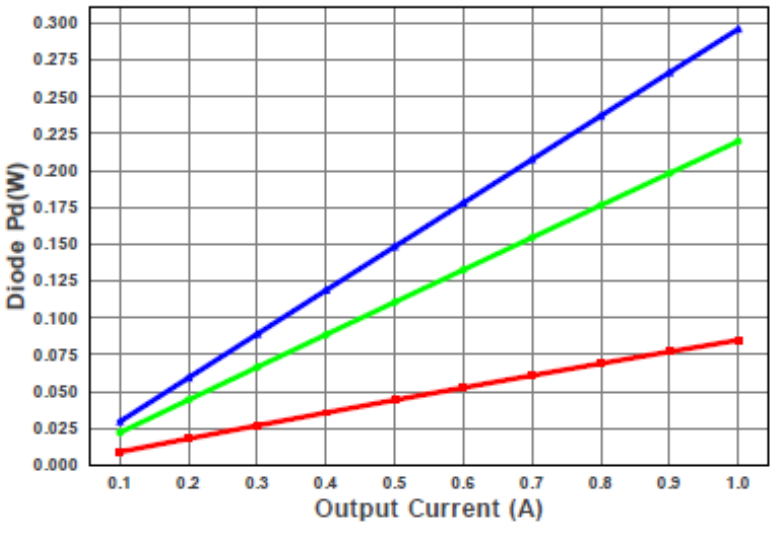

- Vin $=18.0 \mathrm{~V}-$ Vin $=25.0 \mathrm{~V}-$ Vin $=32.0 \mathrm{~V}$
IC Pd

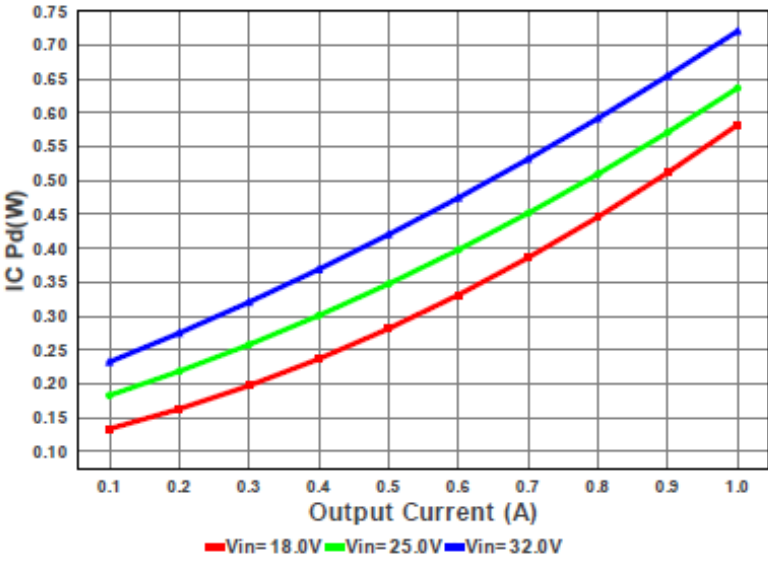

Mod.ICDie_Pd

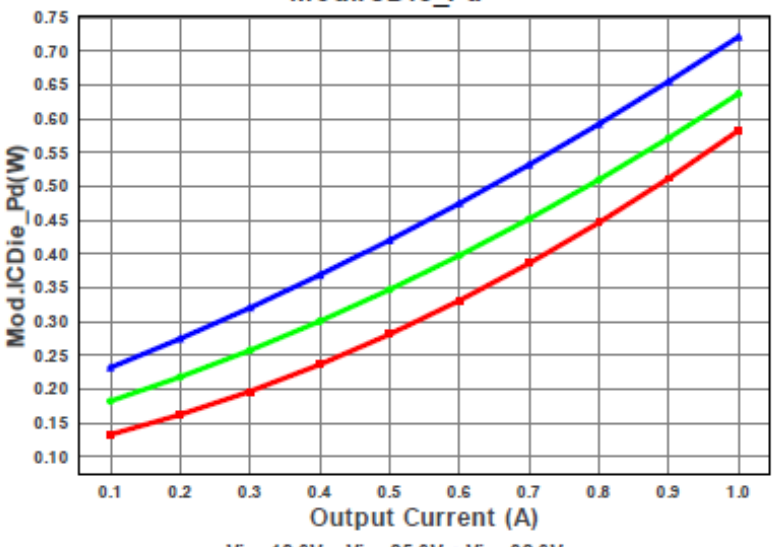

- Vin $=18.0 \mathrm{~V}-\mathrm{Vin}=25.0 \mathrm{~V}-\mathrm{Vin}=32.0 \mathrm{~V}$

\section{Operating Values}

\begin{aligned} \# & Name \\ \hline 1. & Cin IRMS \\ 2. & Cout IRMS \\ 3. & IC Ipk \\ 4. & lin Avg \\ 5. & L Ipp \\ 6. & M1 Irms \\ 7. & BOM Count \\ 8. & FootPrint \\ 9. & Frequency \\ 10. & IC Tolerance \\ 11. & M Vds Act \\ 12. & Pout \\ 13. & Total BOM \\ 14. & D1 Tj \\ 15. & Vout OP \\ 16. & Duty Cycle \\ 17. & Efficiency \\ 18. & IC Tj \\ 19. & ICThetaJA \\ 20. & IOUT_OP \\ 21. & VIN_OP \\ 22. & Vout p-p \\ 23. & Cin Pd \\ 24. & Cout Pd \\ 25. & Diode Pd \\ 26. & IC Pd \\ 27. & L Pd \\ 28. & Total Pd \\ & \end{aligned}

Value

107.21 mA Current

$1.186 \mathrm{~A}$

$505.51 \mathrm{~mA}$

$371.387 \mathrm{~mA}$

$693.629 \mathrm{~mA}$

13

$202.0 \mathrm{~mm} 2$

$667.364 \mathrm{kHz}$

$50.0 \mathrm{mV}$

$208.089 \mathrm{mV}$

$15.0 \mathrm{~W}$

$\$ 1.79$

$127.601 \mathrm{degC}$

$15.0 \mathrm{~V}$

$48.112 \%$

$92.728 \%$

$64.602 \mathrm{degC}$

$48.0 \mathrm{deg} \mathrm{C} / \mathrm{W}$

$1.0 \mathrm{~A}$

$32.0 \mathrm{~V}$

$3.248 \mathrm{mV}$

$219.462 \mu \mathrm{W}$

$22.988 \mu \mathrm{W}$

$295.761 \mathrm{~mW}$

$720.872 \mathrm{~mW}$

$159.5 \mathrm{~mW}$

$1.176 \mathrm{~W}$
Category

Current

Current

Current

Current

Current

General

General

General

General

General

General

General

Op_Point

Op_Point

Op_point

Op_point

Op_point

Op_point

Op_point

Op_point

Op_point

Power

Power

Power

Power

Power

Power
Description

Input capacitor RMS ripple current

Output capacitor RMS ripple current

Peak switch current in IC

Average input current

Peak-to-peak inductor ripple current

Q lavg

Total Design BOM count

Total Foot Print Area of BOM components

Switching frequency

IC Feedback Tolerance

Voltage drop across the MosFET

Total output power

Total BOM Cost

D1 junction temperature

Operational Output Voltage

Duty cycle

Steady state efficiency

IC junction temperature

IC junction-to-ambient thermal resistance

lout operating point

Vin operating point

Peak-to-peak output ripple voltage

Input capacitor power dissipation

Output capacitor power dissipation

Diode power dissipation

IC power dissipation

Inductor power dissipation

Total Power Dissipation 


\section{Design Inputs}

\begin{tabular}{clll}
$\#$ & Name & Value & Description \\
\hline 1. & lout & $1.0 \mathrm{~A}$ & Maximum Output Current \\
2. & lout1 & $1.0 \mathrm{Amps}$ & Output Current \#1 \\
3. VinMax & $32.0 \mathrm{~V}$ & Maximum input voltage \\
4. VinMin & $18.0 \mathrm{~V}$ & Minimum input voltage \\
5. Vout & $15.0 \mathrm{~V}$ & Output Voltage \\
6. Vout1 & $15.0 \mathrm{Volt}$ & Output Voltage \#1 \\
7. base_pn & LM25011 & Base Product Number \\
8. & source & $\mathrm{DC}$ & Input Source Type \\
9. Ta & $30.0 \mathrm{degC}$ & Ambient temperature
\end{tabular}

\section{Design Assistance}

1. LM25011 Product Folder : http://www.ti.com/product/lm25011: contains the data sheet and other resources. 


\section{Referências Bibliográficas}

ANDREY, E., MORELLI, J. (2010). Design of a smart meter techno-economic model for electric utilities in Ontario. IEEE Electric Power and Energy Conference (EPEC), 2010, pp.25-27.

ANEEL (2014). Pesquisa Legislativa. Todos os regulamentos da Aneel citados neste trabalho estão disponíveis na página eletrônica da Agência, disponível em: <http://biblioteca.aneel.gov.br/index.html>. Acesso em 05 de agosto de 2014.

ANGLANI, N., BASSI, E., BENZI, F., FROSINI, L., TRAINO, T. (2011). Energy smart meters integration in favor of the end user. IEEE International Conference on Smart Measurements for Future Grids (SMFG), 2011, pp.16-21.

ARRILAGA, J., WATSON, N. R. e CHEN, S. (2000). Power System Quality Assessment. John Wiley \& Sons.

CEMIG (2013). Projeto Cidades do Futuro. Disponivel em: <www.cemig.com.br> Acesso em 05 de Agosto de 2014.

CHO, H. S., YAMAZAKI, T., HAHN M. (2009). Determining location of appliances from multi-hop tree structures of power strip type smart meters. IEEE Transactions on Smart Grid, vol. 55, no.4, pp. 2314-2322.

DE CAPUA, C., ROMEO, E. (2007) A smart THD meter performing an original uncertainty Evaluation Procedure," IEEE Transactions on Instrumentation and Measurement, vol.56, no.4, pp.1257-1264. 
DEPURU, S.S.S.R., WANG, L., DEVABHAKTUNI, V., GUDI, N. (2011). Smart meters for power grid - Challenges, issues, advantages and status. IEEE Power Systems Conference and Exposition (PSCE), 2011, pp. 20-23.

DUGAN, R. C., McGRANAGHAN, M. F., SANTOSO, S. e BEATY, H. W. (2004). Electrical Power Systems Quality, McGraw-Hill.

ELETROPAULO (2014). AES Eletropaulo anuncia o maior projeto de Smart Grid do país. Disponível em: <www.aeseletropaulo.com.br> Acesso em 05 de agosto de 2014.

FAN, Z., KULKARNI, P., GORMUS, S. EFTHYMIOU, C., KALOGRIDIS, G., SOORIYABANDARA, M., ZHU, Z., LAMBOTHARAN, S., WOON HAU C. (2013). Smart Grid Communications: Overview of Research Challenges, Solutions, and Standardization Activities. IEEE Communications Surveys \& Tutorials, vol.15, no.1, pp.21-38.

FERNANDES, R. A. S. (2008). Identificação de fontes de correntes harmônicas por redes neurais artificiais, Dissertação de Mestrado, Universidade de São Paulo (USP), São Carlos - SP.

MICROCHIP FilterLab ${ }^{\circledR}$ Filter Design Software, version 2.0: Microchip Technology Inc.

FUGITA, S. D., FERNANDES, R. A. S., SUETAKE, M., DA SILVA, I. N. (2013) Hall sensors applied as transducers to smart meters in the context of power quality. IEEE Conference on Innovative Smart Grid Technologies Latin America (ISGT LA), pp.15-17

GROB, G. R. (2009). Future transportation with smart grids \& sustainable energy. Proc. 6th International Multi-Conference Systems Signals and Devices, pp. 1-5. 
GÜNGÖR, V. C., SAHIN, D., KOCAK, T., ERGUT, S., BUCCELLA, C., CECATI, C., HANCKE, G. P. (2011). Smart Grid Technologies: technologies communication and standards. IEEE Transactions on Industrial Informatics, vol.7, no.4, pp.529-539.

GÜNGÖR, V. C., SAHIN, D., KOCAK, T., ERGUT, S., BUCCELLA, C., CECATI, C., HANCKE, G. P. (2012). Smart Grid and Smart Homes: Key Players and Pilot Projects. IEEE Industrial Electronics Magazine, vol.6, no.4, pp.18-34.

HART, D. G. (2008). Using AMI to realize the smart grid, IEEE Power and Energy Society General Meeting, pp. 1-2.

HAYKIN, S. (1999). Neural Networks - A Comprehensive Foundation, Prentice Hall. HUANG J., WANG H., QIAN Y., WANG C. (2013). Priority-Based Traffic Scheduling and Utility Optimization for Cognitive Radio Communication Infrastructure-Based Smart Grid. IEEE Transactions on Smart Grid, vol.4, no.1, pp.78-86.

IEEE Standard 1159-2009 (Recommended Practice for Monitoring Electric Power Quality).

JIXUAN Z., GAO, D.W., LI L. (2013). Smart Meters in smart grid: An Overview. IEEE Green Technologies Conference, pp.57-64.

KHALIFA, T., NAIK, K., NAYK, A. (2011). A Survey of communication protocols for automatic meter reading applications. IEEE Communications Surveys \& Tutorials, vol.13, no.2, pp.168-182.

KHATTAK, AR., MAHMUD S.A., KHAN G.M. (2012). The Power to Deliver: Trends in Smart Grid Solutions. IEEE Power and Energy Magazine, vol.10, no.4, pp.56-64. KAPETANOVIC, T. e BOTTING, D. (2008). Smart Grids: strategic deployment document for europe's eletricity networks of the future: set. 2008. Disponível em: <http://www.smartgrids.eu>. Acesso em: 04 de Setembro 2009. 
KIM, S. K. (2006). Automatic meter reading system and method using telephone line, in United States Patent 7102533.

KOAY, B. S., CHEAH, S. S., SNG, Y. H., CHONG, P. H. J., SHUM, P., TONG, Y. C., WANG, X. Y., ZUO, Y. X., KUEK, H. W. (2003). Design and implementation of Bluetooth energy meter, information, communications and signal processing. Proc. of Joint Conference on Multimedia. vol.3, pp. 1474- 1477.

LAMIM, H. (2013). Análise de impacto regulatório da implantação de redes inteligentes no Brasil, Tese de Doutorado, Universidade de Brasília, Brasilia - DF.

LEW, M. (2009). Duke Energy Reaches Agreement with Key Groups on Modernizing Indiana Electric Grid. Disponível em: <http://www.dukeenergy.com/news/rss.asp>. Acesso em: 7 out. 2009.

LI, Q. e ZHOU, M. (2011). The Future-Oriented Grid-Smart Grid. Journal of Computers. vol 6, no. 1, p.98.

LIRA, J. G. A., OLIVEIRA J., Adeilton C. F., Raimundo C. S., LUCIANO, B. Antonio. (2005). SWART, Jacobus Willibrordus. Dynamic characterization of thermoresistive micro-sensor. IEEE Transaction on Instrumentation and Measurements, vol. 3, pp.1647-1651.

LIU, Q., ZHAO, B., WANG, Y. e HU, J. (2009). Experience of AMR systems based on BPL in China. IEEE International Symposium Power Line Communications and Its Applications, pp.280-284.

LIU, Y. (1996). Calibrating an industrial microwave six-port instrument using artificial neural network technique. IEEE Transactions on Instrumentation and Measurement, vol. 45, no. 2, pp. 651-656. 
LUAN, S., TENG, J., CHAN, S., HWANG, L. (2009). Development of a smart power meter for AMI based on ZigBee communication. International Conference on Power Electronics and Drive Systems, pp. 661-665.

MME - Ministério de Minas e Energia (2010). Relatório - Smart Grid - Grupo de Trabalho de Redes Elétricas Inteligentes. Relatório resultante do Grupo de Trabalho instaurado pela Portaria MME no 440/2010. Brasília, Brasil.

MORGAN, M. G., J. APT, LAVE, L. B., ILIC, M. D., SIRBU, M. e PEHA, J. M. (2009). The many meanings of smart grid. Carnegie Mellon University.

NING L., PENGWEI D., XINXIN G., GREITZER, F. L. (2012). Smart meter data analysis. IEEE Transmission and Distribution Conference and Exposition (T\&D), pp.1-6.

OWEN, G, e WARD, J. (2006). Smart Meters: Commercial, Policy and Regulatory Drivers, Technical Report, Sustainability First.

PERTENCE, A. J. (2007). Amplificadores Operacionais e Filtros Ativos, Bookman.

POTTER, C. W., ARCHANMBAULT, A. e WESTRICK, K. (2009). Building a smarter smart grid through better renewable energy information. IEEE Power Systems Conference and Exposition, pp.1-5.

RUMELHART, D. E. e MCCLELLAND, J. L. (1986). Parallel distributed processing, MIT Press.

SILVA, J. M. e WHITNEY, B. (2002). Evaluation of the potencial for power line carrier (PLC) to interfere with use of the nationwide differential GPS network. IEEE Transactions on Power Delivery, vol. 17, no. 2, pp. 348-352.

SIMOES, M.G., ROCHE, R., KYRIAKIDES, E., SURYANARAYANAN, S., BLUNIER, B., MCBEE, K.D., NGUYEN, P.H., RIBEIRO, P.F., MIRAOUI, A. (2012) A 
Comparison of Smart Grid Technologies and Progresses in Europe and the U.S. IEEE Transactions on Industry Applications, vol.48, no.4, pp.1154-1162.

TOMOSADA, M., SINOHARA, Y. (2011) Virtual energy demand data: Estimating energy load and protecting consumers' privacy. IEEE Innovative Smart Grid Technologies (ISGT), pp.17-19.

TULCIDÁS, G. (2010). Contador de Energia Eléctrica Inteligente, Dissertação de Mestrado, Instituto Superior Técnico, Universidade Técnica de Lisboa, Lisboa 2010.

WEI, X., YU-HUI, Z. e JIE-LIN, Z. (2009). Energy-efficient distribution in smart grid. IEEE International Conference on Sustainable Power Generation and Supply, pp.1-6.

WEISS, M., HELFENSTEIN, A., MATTERN, F., StAAKE, T. (2012). Leveraging smart meter data to recognize home appliances. IEEE International Conference on Pervasive Computing and Communications, pp.190-197.

YAN, Y., QIAN, Y., SHARIF, H., TIPPER, D. (2013). A Survey on Smart Grid Communication Infrastructures: Motivations, Requirements and Challenges. IEEE Communications Surveys \& Tutorials, vol.15, no.1, pp. 5-20.

XI, F., SATYAJAYANT, M., GUOLIANG, X., DEJUN, Y. (2012) Smart Grid - The New and Improved Power Grid: A Survey. IEEE Communications Surveys \& Tutorials, vol.14, no.4, pp. 944-980. 